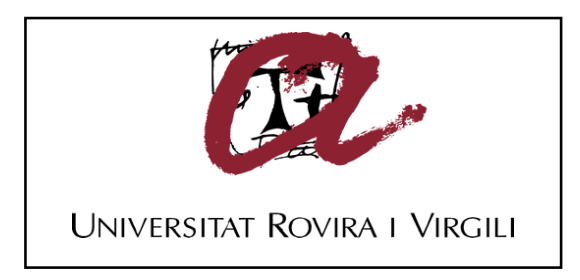

\title{
AUGMENTED REALITY FOR THE ENHANCEMENT OF SPACE PRODUCT ASSURANCE AND SAFETY
}

\author{
Raul Alarcon Ruiz
}

ADVERTIMENT. L'accés als continguts d'aquesta tesi doctoral i la seva utilització ha de respectar els drets de la persona autora. Pot ser utilitzada per a consulta o estudi personal, així com en activitats o materials d'investigació i docència en els termes establerts a l'art. 32 del Text Refós de la Llei de Propietat Intel·lectual (RDL 1/1996). Per altres utilitzacions es requereix l'autorització prèvia i expressa de la persona autora. En qualsevol cas, en la utilització dels seus continguts caldrà indicar de forma clara el nom i cognoms de la persona autora i el títol de la tesi doctoral. No s'autoritza la seva reproducció o altres formes d'explotació efectuades amb finalitats de lucre ni la seva comunicació pública des d'un lloc aliè al servei TDX. Tampoc s'autoritza la presentació del seu contingut en una finestra o marc aliè a TDX (framing). Aquesta reserva de drets afecta tant als continguts de la tesi com als seus resums i índexs.

ADVERTENCIA. El acceso a los contenidos de esta tesis doctoral y su utilización debe respetar los derechos de la persona autora. Puede ser utilizada para consulta o estudio personal, así como en actividades o materiales de investigación y docencia en los términos establecidos en el art. 32 del Texto Refundido de la Ley de Propiedad Intelectual (RDL 1/1996). Para otros usos se requiere la autorización previa y expresa de la persona autora. En cualquier caso, en la utilización de sus contenidos se deberá indicar de forma clara el nombre y apellidos de la persona autora y el título de la tesis doctoral. No se autoriza su reproducción u otras formas de explotación efectuadas con fines lucrativos ni su comunicación pública desde un sitio ajeno al servicio TDR. Tampoco se autoriza la presentación de su contenido en una ventana o marco ajeno a TDR (framing). Esta reserva de derechos afecta tanto al contenido de la tesis como a sus resúmenes e índices.

WARNING. Access to the contents of this doctoral thesis and its use must respect the rights of the author. It can be used for reference or private study, as well as research and learning activities or materials in the terms established by the 32nd article of the Spanish Consolidated Copyright Act (RDL 1/1996). Express and previous authorization of the author is required for any other uses. In any case, when using its content, full name of the author and title of the thesis must be clearly indicated. Reproduction or other forms of for profit use or public communication from outside TDX service is not allowed. Presentation of its content in a window or frame external to TDX (framing) is not authorized either. These rights affect both the content of the thesis and its abstracts and indexes. 


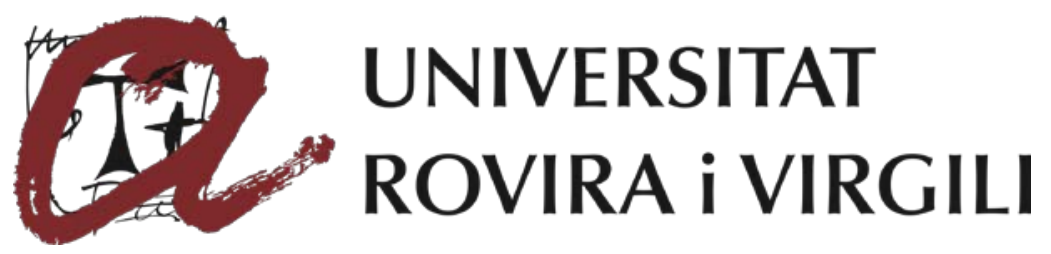

\section{Augmented Reality for the Enhancement of Space Product Assurance and Safety}

Raul Alarcon Ruiz

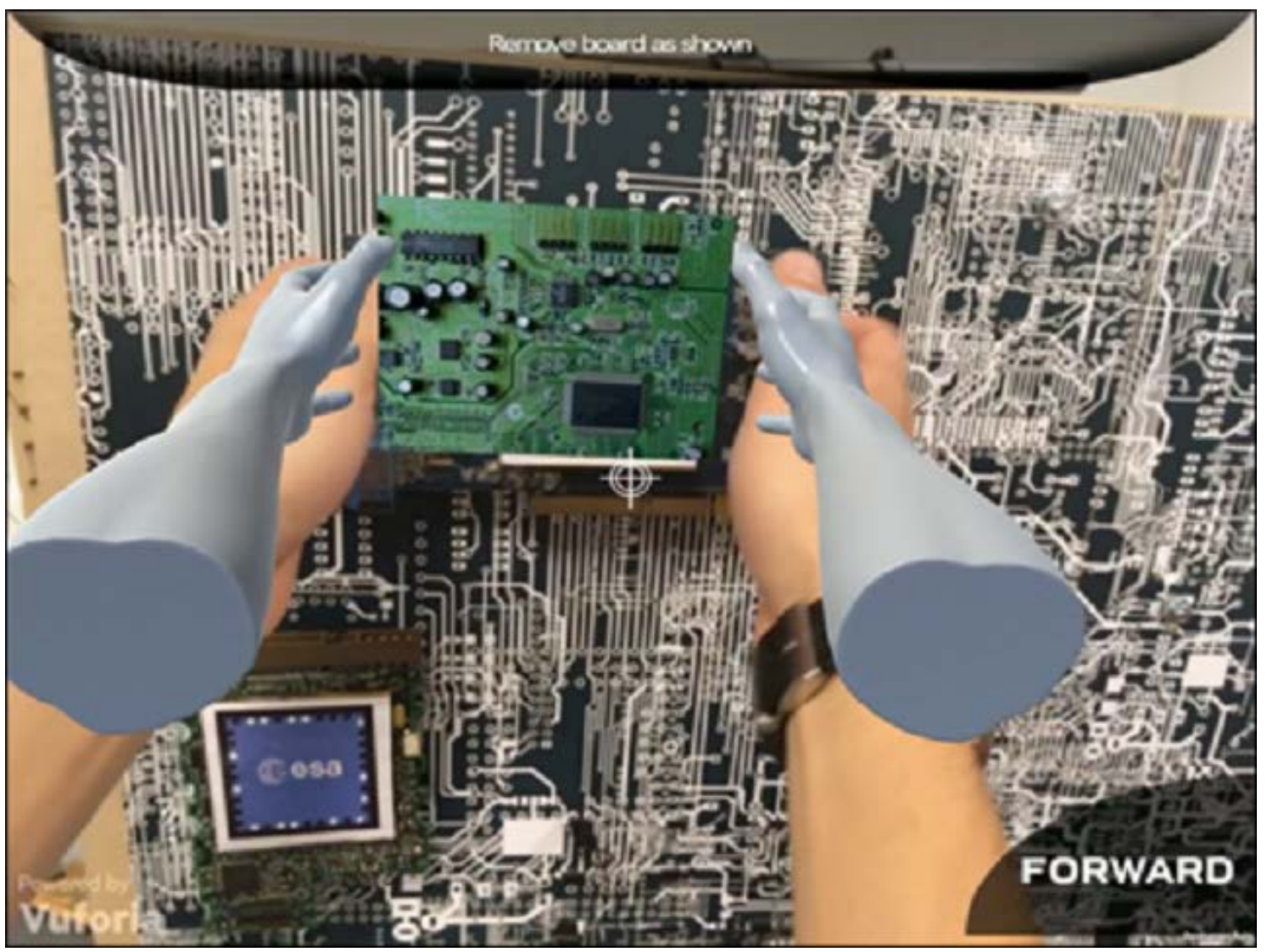

DOCTORAL THESIS 


\title{
Augmented Reality for the Enhancement of Space Product Assurance and Safety
}

\author{
DOCTORAL THESIS
}

Supervised by Dr. Josep Xavier Ruiz Martí, Dra. Josefa

Gavaldà Martínez, and Dr. Marc Marín Genescà

Department of Physical and Inorganic Chemistry

Digital Signal Processing in Aerospace and Biomedical Environments (SPABE) Research Group

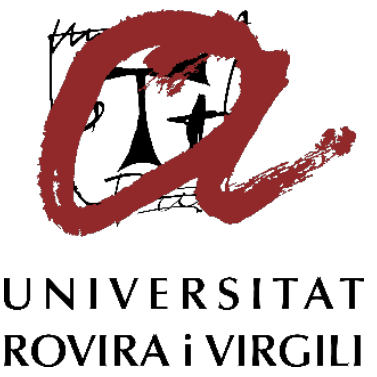

2021 
UNIVERSITAT ROVIRA I VIRGILI

AUGMENTED REALITY FOR THE ENHANCEMENT OF SPACE PRODUCT ASSURANCE AND SAFETY

Raul Alarcon Ruiz 


\section{UNIVERSITAT ROVIRA i VIRGILI}

\section{Department of Physical and Inorganic Chemistry}

C/ Marcel.lí Domingo s/n

Campus Sescelades

43007 Tarragona

Tel. +34977558107

We STATE that the present study, entitled "Augmented Reality for the Enhancement of Space Product Assurance and Safety", presented by Raül Alarcón Ruiz for the award of the degree of Doctor, has been carried out under our supervision at the Department of Physical and Inorganic Chemistry of this university.

Tarragona, $1^{\text {st }}$ March 2021

Doctoral Thesis Supervisors,

José Javier Ruiz Firmado digitalmente Martí - DNI por José Javier Ruiz

39645701A 39645701A(AUT

(AUT) Fecha: 2021.03.02

Dr. Josep Xavier Ruiz Martí

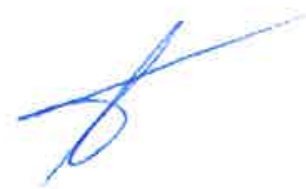

Dr. Marc Marín Genescà
Josefa Gavaldà Firmado digitalmente Martínez - DNI por Josefa Gavaldà $\begin{array}{ll}39852657 M & 39852657 M(A U T) \\ & \text { Fecha: 2021.03.02 }\end{array}$ $\begin{array}{ll}\text { (AUT) } & \text { Fecha: 2021.03.02 } \\ \text { 11:22:21 +01'00' }\end{array}$

Dra. Josefa Gavaldà Martínez 
UNIVERSITAT ROVIRA I VIRGILI

AUGMENTED REALITY FOR THE ENHANCEMENT OF SPACE PRODUCT ASSURANCE AND SAFETY

Raul Alarcon Ruiz 
UNIVERSITAT ROVIRA I VIRGILI

AUGMENTED REALITY FOR THE ENHANCEMENT OF SPACE PRODUCT ASSURANCE AND SAFETY

Raul Alarcon Ruiz

To Anna Beatriz and the future generation of explorers, may all travel safely and in peace as true crew mates of "Spaceship Earth" 
UNIVERSITAT ROVIRA I VIRGILI

AUGMENTED REALITY FOR THE ENHANCEMENT OF SPACE PRODUCT ASSURANCE AND SAFETY

Raul Alarcon Ruiz 


\section{Abstract}

A growing number of companies in the aerospace industry are already leading projects to deploy Augmented Reality (AR) to improve their workplace performance, knowledge transfer, as well as workforceproductivity. In parallel, national and international agencies in aerospace, such as the European Space Agency (ESA), are running studies to evaluate the application of AR to enhance the quality and cost effectiveness of space missions.

This thesis presents the results of a study performed to assess the maturity and potential business value of AR for application to space product assurance and safety activities. For this purpose, an on-line survey and interviews with product assurance and safety professionals were conducted. Moreover, it provides a detailed review of space industry use case requirements and the maturity readiness level of potentially involved technology components. Findings indicate that maturity of many components enabling AR may not fully satisfy the space industry's requirements, while, at the same time, there is great potential for impact and long-term benefits from AR introduction.

In order to demonstrate the application of $\mathrm{AR}$ in the field of space product assurance, a proof of concept demonstrator was developed and validated by implementing the main use case scenarios derived from the research.

Keywords: Augmented Reality, Space Product Assurance, Industrial Revolution 4.0 
UNIVERSITAT ROVIRA I VIRGILI

AUGMENTED REALITY FOR THE ENHANCEMENT OF SPACE PRODUCT ASSURANCE AND SAFETY

Raul Alarcon Ruiz 


\section{Acknowledgements}

Completion of this research would not have been possible without the invaluable support of a number of people and organisations.

The author would like to thank the European Space Agency (ESA), and in particular the European Space Research and Technology Centre (ESTEC) in The Netherlands, for funding this research.

Thanks to the supervisors of my doctoral studies, Professors Dr. Josep Xavier Ruiz Martí, Dra. Josefa Gavaldà Martínez, and Dr. Marc Marín Genescà, for their sustained interest, guidance and encouragement over the course of the doctoral programme.

My gratitude extends to Professor Dr. Fridolin Wild, head of the Performance Augmentation Lab of The Open University (UK), and Mrs Christine Perey (Perey Research and Consulting), for their support and association in this research.

I am also thankful to the International Astronautical Congress (IAC) for recommending the journal publication of this study, and to the independent reviewers of Acta Astronautica who helped to improve the original manuscript.

Thank you to all ESA colleagues who participated in the numerous presentations, questionnaires and interviews related to this work, for their valuable comments and suggestions.

Last but not least, thank you to my family and friends for their loving and endless support. 
UNIVERSITAT ROVIRA I VIRGILI

AUGMENTED REALITY FOR THE ENHANCEMENT OF SPACE PRODUCT ASSURANCE AND SAFETY

Raul Alarcon Ruiz 


\section{Table of Contents}

Abstract

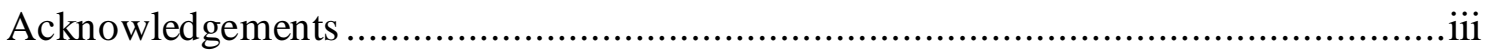

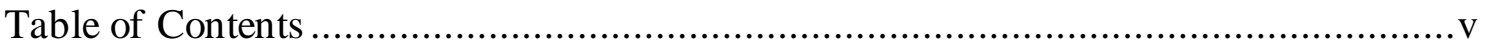

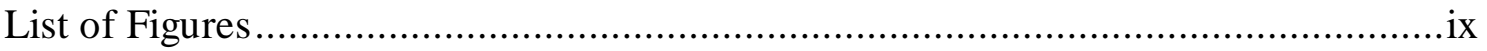

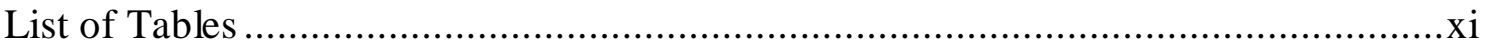

Acronyms and Abbreviations.....................................................................ii

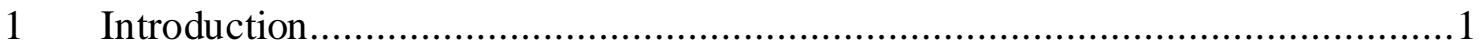

1.1 Motivation............................................................................. 4

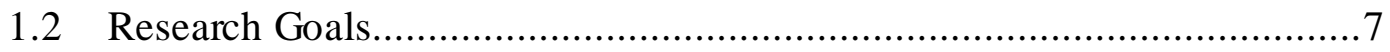

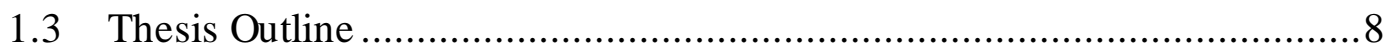

1.4 Peer Reviewed Publications ..........................................................

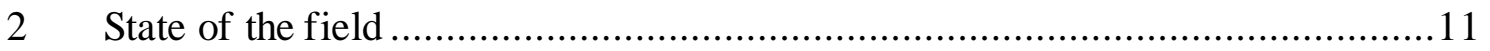

2.1 Technology Components of Augmented Reality (AR)...........................11

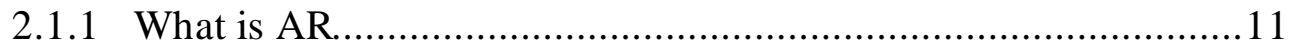

2.1 .2 AR Tracking................................................................

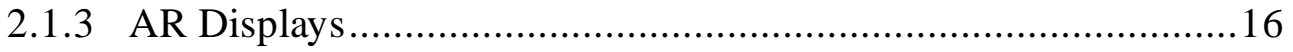

2.1.4 AR-enabling Software.....................................................18

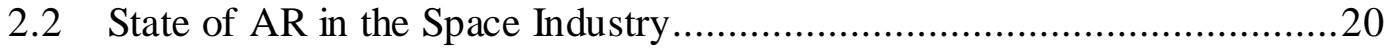

3 Adoption of AR for Product Assurance and Safety......................................23

3.1 Research Methodology ................................................................23

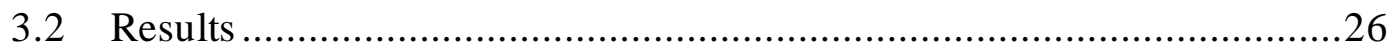

3.2.1 Desirability and Feasibility ....................................................26

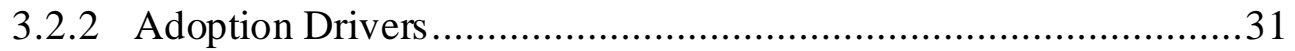

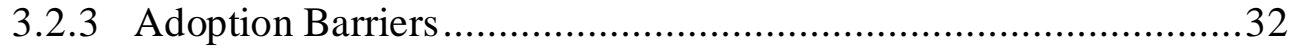

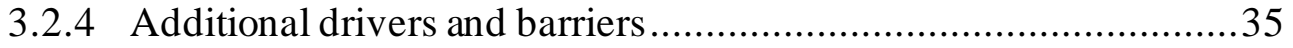




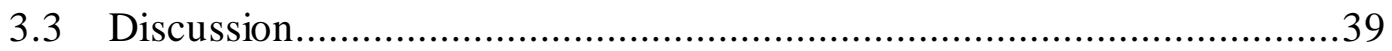

$4 \quad$ Technology Maturity Assessment........................................................ 41

4.1 Technology Maturity of AR Components ..........................................41

4.2 AR Technologies and their Readiness Levels.....................................4 41

4.2.1 Use Cases: delivering contextual sensitive instructions (procedural guidance) and operator training .........................................................43

4.2.2 Providing Configuration Control Instructions by Recognizing

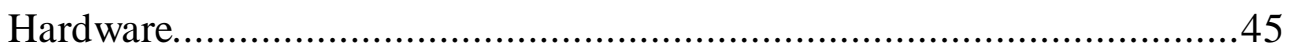

4.2.3 Real Time Recognition of Configuration Errors........................47

4.3 Technology Challenges and Future Trends ......................................49

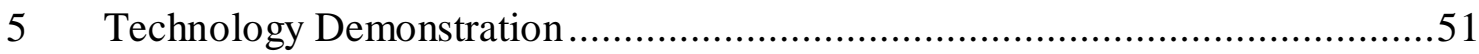

5.1 Prototype Requirements .............................................................51

5.1.1 Procedural guidance (operator training) ...................................51

5.1.2 Configuration control..........................................................53

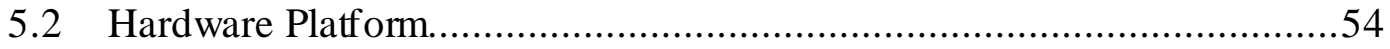

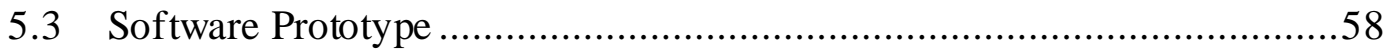

5.3.1 Procedural guidance..........................................................58

5.3.2 Configuration control......................................................60

5.4 Prototype Validation and Empirical Evaluation..................................6 65

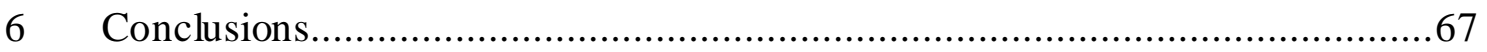

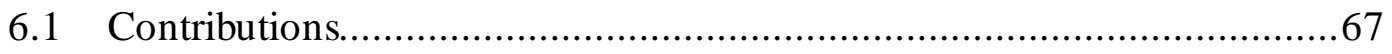

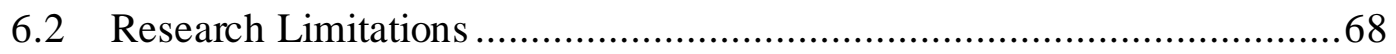

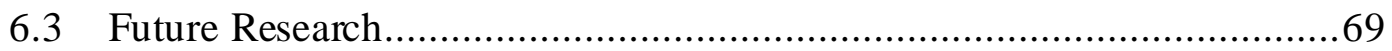

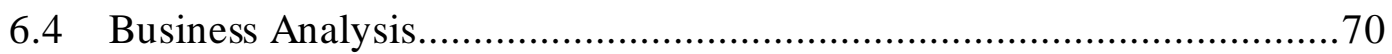

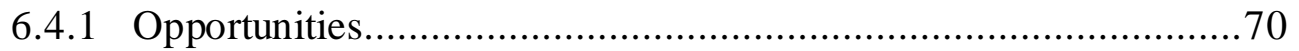

6.4.2 Key Performance Indicators................................................. 71

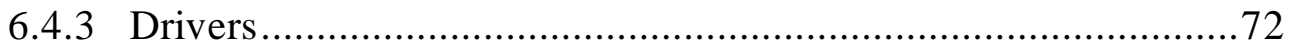




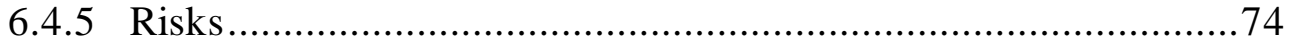

6.4.6 Return on Investment.....................................................76

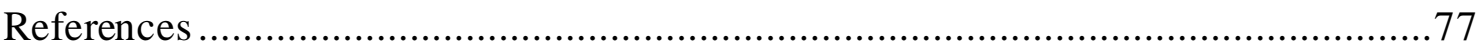

Appendix A Introduction to AR and Use Cases for Product Assurance and Safety ......83

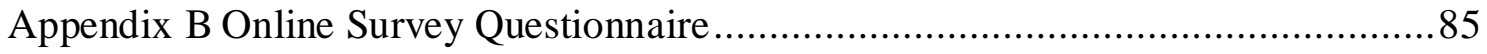

Appendix C Interview Guiding Questions ........................................................91

Appendix D Technology Maturity Review of AR Components .................................93

Appendix E Prototype Experiment Instructions.......................................................95

Appendix F Prototype Demonstration....................................................................111 
UNIVERSITAT ROVIRA I VIRGILI

AUGMENTED REALITY FOR THE ENHANCEMENT OF SPACE PRODUCT ASSURANCE AND SAFETY

Raul Alarcon Ruiz 


\section{List of Figures}

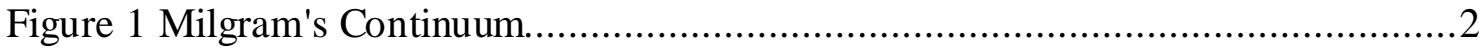

Figure 2 Potential benefits of applied mediated reality to enhance space PA\&S............5

Figure 3. Augmented Reality Visualisation Pipeline [13] .......................................12

Figure 4. Six Degrees of Freedom ...................................................................... 13

Figure 5. QR code for tracking (left) and circular markers (right) ...........................15

Figure 6. Head-Mounted Video Display Processing [12] ....................................... 16

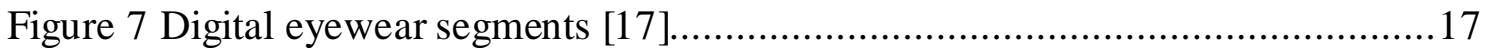

Figure 8 Using OnSight and wearing HoloLens mission scientists discuss rover

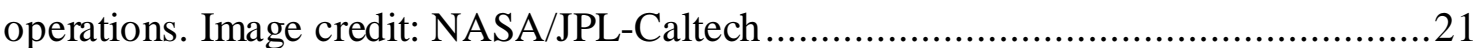

Figure 9 André Kuipers (NL) using Sidekick and wearing HoloLens to see and interact with instructions as well as a remote expert when performing complex procedures. Image

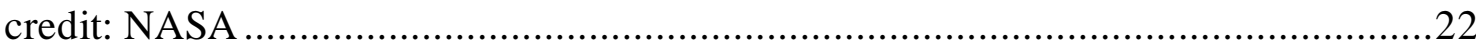

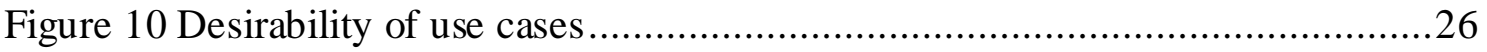

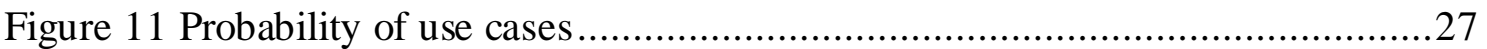

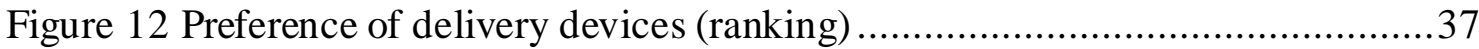

Figure 13 Physical layout of 4 panels emulating small satellite sides ........................54

Figure 14 Physical inputs (hardware components) to be displayed on surfacing panels55

Figure 15 Physical architecture of the hardware platform .....................................56

Figure 16 Hardware platform layout in ESTEC (lab environment)..........................57

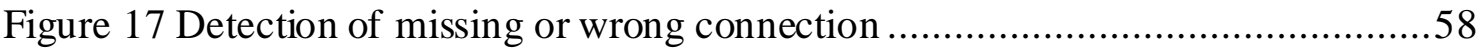

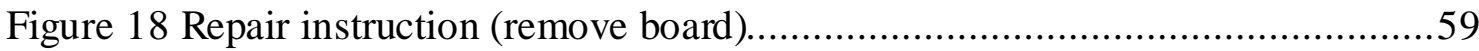

Figure 19 Identification of the correct replacement board......................................59

Figure 20 Remove wrongly connected cable.......................................................60

Figure 21 Highlight of correct and wrong components detected..............................61

Figure 22 View of component details and actions required...................................6

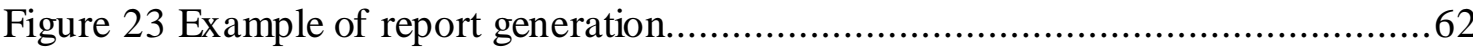

Figure 24 Navigational information overlaid virtually on the actual hardware............63 
UNIVERSITAT ROVIRA I VIRGILI

AUGMENTED REALITY FOR THE ENHANCEMENT OF SPACE PRODUCT ASSURANCE AND SAFETY

Raul Alarcon Ruiz 


\section{List of Tables}

Table 1 Most important drivers in the decision about the introduction of AR in space

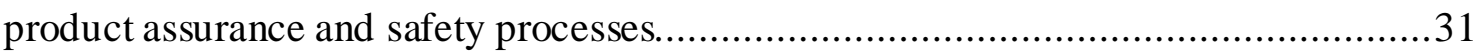

Table 2 Pearson correlation between use cases and drivers to adoption......................32

Table 3 Most important barriers in the decision about the introduction of AR in space

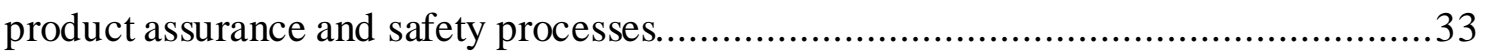

Table 4 Pearson correlation between cases and barriers to adoption...........................34

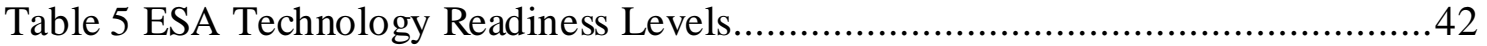

Table 6 TRL Assessment for Procedural Guidance and Training.............................44

Table 7 TRL Assessment for Configuration Control Instructions...............................46

Table 8 TRL Assessment for Recognition of Configuration Errors...........................47

Table 9. Specific requirements for the procedural guidance use case..........................52

Table 10. Specific requirements for test configuration setting and management ..........53 
UNIVERSITAT ROVIRA I VIRGILI

AUGMENTED REALITY FOR THE ENHANCEMENT OF SPACE PRODUCT ASSURANCE AND SAFETY

Raul Alarcon Ruiz 


\section{Acronyms and Abbreviations}

The abbreviations below are commonly used throughout this document:

AR

ARPASS

CAD

CMS

CV

DOF

ECSS

EN

ERP

ESA

ESTEC

EVA

GPS

HMD

ICT

IEEE

ISMAR

ISS

JAXA

M/AR

MAIT

MQTT

NASA

PA

PA\&S

PVAITV

RFID

QA

QMS

QR
Augmented Reality

Augmented Reality for Product Assurance and Safety Study

Computer Aided Design

Content Management System

Computer Vision

Degrees of Freedom

European Cooperation for Space Standardization

European Standard

Enterprise Resource Planning

European Space Agency

European Space Research and Technology Centre

Extra Vehicular Activity

Global Positioning System

Head Mounted Display

Information and Communication Technology

Institute of Electrical and Electronics Engineers

International Symposium of Mixed and Augmented Reality

International Space Station

Japan Aerospace Exploration Agency

Mixed and Augmented Reality

Manufacturing, Assembly, Integration and Testing

Message Queuing Telemetry Transport

National Aeronautics and Space Administration

Product Assurance

Product Assurance and Safety

Portable Virtual AIT Visualizer

Radio Frequency Identification

Quality Assurance

Quality Management System

Quick Response (code) 
TEC (ESA) Directorate of Technical and Quality Management

TEC-Q (ESA) Product Assurance and Safety Department

TRL Technology Readiness Level

URV Universitat Rovira i Virgili

VR Virtual Reality

WEAR Wearable Augmented Reality 


\section{Introduction}

The space sector plays a pivotal role in the efficient functioning of modern societies and their economic development through the use of satellite technology in navigation, telecommunications, meteorology, and Earth observation, which create new downstream applications and markets [1]. From being originally a low-volume business dominated by public organisations (i.e., the national space agencies), however, space is becoming a highly competitive and dynamic business environment where industry has an increasingly active role and demands higher effectiveness and efficiency to achieve low cost and reduced time-to-market, of special relevance nowadays considering the present global economy conjuncture.

Meanwhile, satellite life-cycles (from design, to manufacturing, to assembly, integration, verification, launch, operations, and decommissioning) continue to entail complex activities that are difficult to automate and need qualified workers that understand the specific processes involved. In particular, manufacturing, assembly, integration and testing activities are labour intensive, sometimes artisanal, and require following an established sequence of activities while interacting with physical objects. The quality of the product depends thus, among other factors, on the quality of the workmanship, which in turn is correlated to the skills and experience of the workers, the adequacy of the processes followed and, above all, providing the right information at the right time.

Moreover, space products are normally not serviceable once launched (unlike the International Space Station, for example), meaning that if there is a quality problem in orbit we may not be able to fix the degraded performance and will have to accept that the product does not meet the mission requirements. Therefore, if a product is designed, manufactured or assembled with low quality levels then we should expect to perform more rework and additional testing, which in turn have a programmatic impact on the 
development schedule and adds additional cost. There is hence a clear incentive to build reliable products right the first time and avoid any errors during development activities.

Information and communication technologies are extensively applied to product design in all industrial sectors, including space, and are currently well mature. In particular, the availability of powerful modelling and simulation tools have stimulated the development of virtual product models leading to interactive and immersive experiences in the field of Virtual Reality (VR). The integration of information technologies in product development activities, however, is a more challenging job since the worker needs to interact with a continuously changing real environment.

Mobile technologies, including advanced networks and smaller, more powerful devices, and the digital information they permit users to access are more and more pervasively converging with the physical world. Many new experiences are possible at the intersection of the physical and digital worlds. A continuum of experiences, in fact, that is so potentially diverse that it has its own taxonomy. The taxonomy, described in the work of Milgram et al. [2] defines Mixed Reality as all technology-assisted human experiences between but not including the fully virtual "reality" and an entirely physical world without any technology assistance.

When digital information is perceived in context with the user's environment in three dimensions as it changes within the real-time user's control to modify, simply by moving with respect to a target, the experience is called Augmented Reality (AR). Unlike VR, AR enhances the real environment by combining it with computer-generated sensory input such as images, sound, or even haptic media (e.g. tactile feedback). AR allows to track the user and objects location and provides dynamic instructions on a display (usually a see-through head-worn display) during the execution of a task, which can be combined with other activities such as speech recognition, annotation, and even the exchange of information with other users.

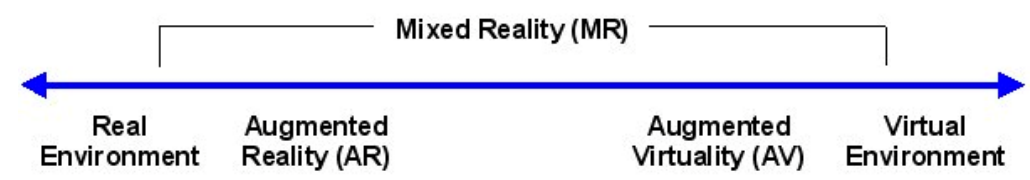

Figure 1 Milgram's Continuum 
AR is used in automotive, aviation, utilities, and other industries. It can support the diagnosis of a system in need of service, reduce risks in unfamiliar procedures such as landing an aircraft in foggy weather, or to assemble complex systems. In the space industry, AR also promises to offer enormous opportunities, for example in the satellite and launch vehicle development activities [3]. Since the satellites and launch vehicles are not mass produced, they require exceptionally careful fabrication in controlled environments and have stringent reliability and performance requirements. 


\subsection{Motivation}

The main role of space product assurance and safety (PA\&S) engineers is to assure the quality and safety of space hardware and software in order to enable mission success. In order to achieve this, they apply methods and tools during the design and development phase of space products (hardware and software), covering areas such as dependability (reliability, availability and maintainability), quality management and process control, materials, processes, mechanical parts and components qualification, and safety engineering. In particular, a key added value of PA\&S is to prevent errors before the manufacturing of space products, and to detect and mitigate or correct them should they occur.

Several studies [4] demonstrate that most errors in industrial manufacturing (and maintenance) activities are related to procedural errors, and many of these errors are due to negligence (human error). These errors are not due to lack of information, but to not having or having but not using the right information at the right time. The objective is then to provide workers with relevant information as efficiently as possible at the corresponding location, at the right time, and with the appropriate quality [5]. AR technology offers potential for achieving this objective, which in turn should lead to increased productivity by reducing time to completion (including manual and cognitive activities) and eliminating errors, and eventually reducing the mental workload, when compared to traditional media for task instruction.

The application of mediated reality to PA\&S management could therefore bring benefits by increasing the productivity, efficiency, accuracy of tasks, compliance with requirements, and safety of systems; as a result, it could prevent the occurrence of failures, non-compliances, knowledge transfer time, and overall production (and maintenance) costs. This is illustrated in Figure 2, although it is to be noted that the list presented is not comprehensive and provides only an example of areas of potential benefit. 


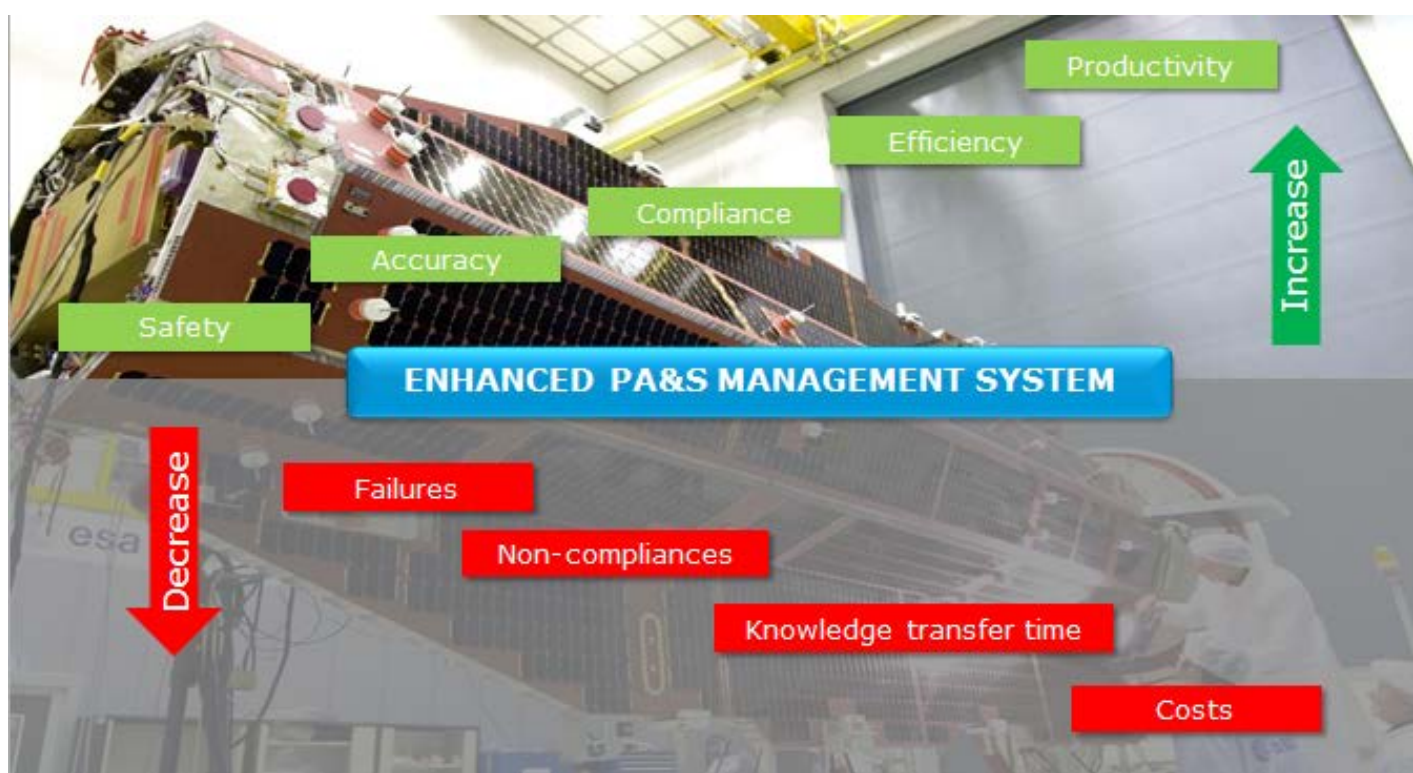

Figure 2 Potential benefits of applied mediated reality to enhance space PA\&S

Paradoxically, despite the potential benefits that can be inferred from the application of mixed reality technologies in an industrial environment, the industrial application to date can be considered very limited. As already pointed by Georgel [6], there is a strong correlation between the degree of success of an application and the industrial involvement, the user testing, and the scalability of the technology. For example, Willers research on AR support for Airbus' cable and water systems [7] concluded that tracking workers through the assembly process of large aircraft was not suited for stationary AR solutions because of missing user acceptance, lack of maturity of the head mounted display, and too expensive solution; moreover, the metallic environment surrounding the workers and the fact that state of construction is always changing were also factors affecting its lack of implementation. This illustrates that, in general, although there is a strong interest in AR, there are several adoption factors that prevent the wide implementation of AR.

Consequently, motivated by the potential benefits that AR can offer to the field of space product assurance and safety and the limited research found to analyse the user factors that determine the adoption of AR as a technological solution in the space engineering domain, the author performed a study to fill in such research gap, as well as to design and develop a low cost AR prototype to demonstrate the application of the technology in the field of PA\&S. 
The work presented in this thesis was developed under the frame of the ARPASS project (Augmented Reality in Product Assurance \& Safety Study) funded by the European Space Agency. The research focuses on specific scenarios proposed by ESA's Product Assurance and Safety Department (TEC-Q) based on their own experience in the design, development and operation of space programmes and backed up by existing research [8], in which the use of AR could improve product assurance and safety processes. 


\subsection{Research Goals}

The main goal of the research sought to address the following research questions:

1. Is the space PA\&S community ready to adopt AR? and

2. Is AR technology ready for use in PA\&S for space industry projects?

The hypotheses for the first question are that (1) AR is desired by the space PA\&S community, (2) AR is feasible to implement in the space PA\&S community, and (3) the $A R$ system characteristics have a negative effect on intention to use the technology. In order to verify such hypothesis, the following objectives were established:

a. Quantitative and qualitative survey to PA\&S engineers (potential users) to evaluate AR desirability, feasibility, adoption drivers and barriers.

b. Identify use cases with the highest potential for impact of AR on PA\&S work.

The hypothesis for the second question is that $A R$ is ready for application to space $P A \& S$. In order to verify such hypothesis, the following objectives were established:

a. Identify critical technology components required by the use cases identified in the PA\&S domain.

b. Assess the maturity of AR technology for application to such use cases.

In particular, the results of the research shall allow the ranking of selected use cases in order of priority to the stakeholders by determining the most likely drivers of adoption and the highest barriers to the introduction of AR.

A secondary goal of the research was to develop an AR technology demonstrator (proof of concept) based on the outcome of research question(1) above. The demonstrator was intended to implement critical functions derived from the most demanded scenario(s) for the demonstration of AR in a laboratory environment. 


\subsection{Thesis Outline}

The thesis is divided in 5 main chapters.

Chapter 2 presents the definition of AR and state of the field. It introduces the major technology components of AR and provides a state of the field literature related to AR implementation in the space sector.

Chapter 3 describes the research conducted to study the introduction of Augmented Reality within the space product assurance and safety activities [9]. The research presents the ranking of selected use cases in order of priority to the stakeholders and determines the most likely drivers of adoption and the highest barriers to the introduction of AR.

Chapter 4 provides an analysis of the technology maturity, including the main components and solutions against the identified use cases.

Chapter 5 presents the proof of concept demonstrator implemented as a result of Chapters 3 and 4 .

Chapter 6 provides the research conclusions, including its limitations and future work. Finally, the research presented in previous chapters facilitate the development of a business analysis for the implementation of AR in the space product assurance and safety domain. 


\subsection{Peer Reviewed Publications}

Some of the results of this dissertation have appeared in the following publications:

\section{Journals}

R. Alarcon, F. Wild, C. Perey, M. Marin Genescà, J. Gavaldà Martínez, J. Xavier Ruiz Martí, M. José Simon Olmos, D. Dubert, Augmented Reality for the enhancement of space product assurance and safety, Acta Astronautica, Volume 168, 2020, Pages 191199, ISSN 0094-5765, https://doi.org/10.1016/j.actaastro.2019.10.020

\section{International Conference}

The following paper was presented by the main author (speaker) at the $69^{\text {th }}$ International Astronautical Congress (IAC):

R. Alarcon, F. Wild, C. Perey, M. Marin Genescà, J. Gavaldà Martínez, J. Xavier Ruiz Martí, M. José Simon Olmos, D. Dubert, Augmented Reality for the enhancement of space product assurance and safety, Proceedings of the 69 $9^{\text {th }}$ International Astronautical Congress, 1-5 October 2018 (IAC-18.B5.1.11x47456)

\section{Pre-doctoral Work}

R. Alarcon, New mediated reality technologies to enhance PA\&S, Proceedings of NASA/ESA/JAXA Trilateral Safety and Mission Assurance Conference (TRISMAC), Rome, 2015

R. Alarcon, Augmented Reality in the Aerospace Industry, AREA Webinar (online), 2016 
UNIVERSITAT ROVIRA I VIRGILI

AUGMENTED REALITY FOR THE ENHANCEMENT OF SPACE PRODUCT ASSURANCE AND SAFETY

Raul Alarcon Ruiz 


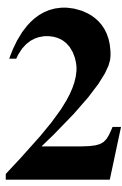

\section{State of the field}

\subsection{Technology Components of Augmented Reality (AR)}

\subsubsection{What is AR}

It is widely accepted that since the introduction of heads-up display technology for fighter pilots in the 1960s, the first reference to AR was coined by Caudell and Mizell [10] while working in Boeing's Computer Services when applying a heads-up display technology to aid workers putting together wiring harnesses. Since then AR has evolved significantly and is now a fast-growing technology already recognised as an emerging technology and one of the pillars of the Fourth Industrial Revolution (Industry 4.0) [11].

In 1997, Azuma [12] already defined AR as a variation of VR, where the user sees the real world, with virtual objects superimposed upon or composited with the real world. To this definition, Georgel [6] added that virtual components can be added to, or replaced from reality. However, we cannot restrict AR to visual perception, since not only images but sound and haptic media can be used to augment reality and enhance the user experience when interfacing with AR.

In visual oriented AR, camera-captured views from real-world environments are enriched (augmented) with digital 3D objects and effects in real time, in practice by manipulating video stream of the real world.

Figure 3 illustrates the idea of AR visualisation using graphical markers for defining the area to be augmented. The use of AR systems is becoming widespread thanks to the development of mobile devices such as tablets, smart phones and glasses that allow the user to interact with the real world. 


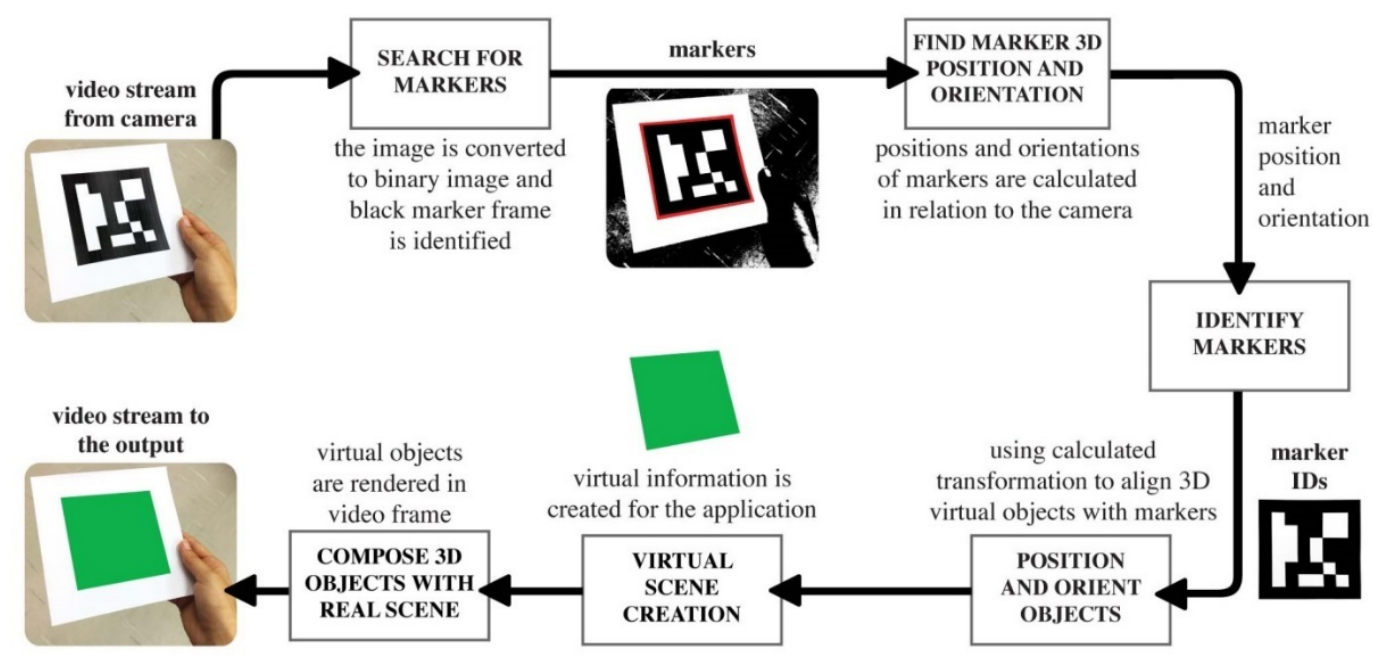

Figure 3. Augmented Reality Visualisation Pipeline [13]

The technological demands for AR are higher than for VR, with essential components being displays, trackers, graphic computers and software. Components such as tracking sensors are critical to sense the environment and track the viewer's relative movement; this is a complex task with yet several research on-going to improve accuracy, a wider input variety and bandwidth, and longer ranges. In terms of displays, we can have visual displays such as video see-through, optical see-through and projective displays; and also aural displays such as haptic audio (sound felt rather than heard). These displays can be head-worn, hand-held or spatial. The following sections present the main characteristics of tracking systems, displays, and AR-enabling software, which are differential factors compared to VR technology.

\subsubsection{AR Tracking}

One of the most important part of AR systems is their tracking devices. The tracking device allows the detection of the user's point of view and if needed his or her spatial position, and is essential to keep virtual objects aligned with the position of the real objects.

Tracking devices can be divided into 2 different types: sensor-based and visionbased tracking systems. These systems detect 1 to 6 degrees of freedom (DOF) which are the object's $x$ y $z$ coordinates and its orientation with the yaw, pitch and roll angles (see Figure 4). With HMDs or glasses, the view changes every time the user looks up, down, 
left or right. The change of orientation of the user's head are sent by the trackers to the CPU which then sends the right images to display on the screen.

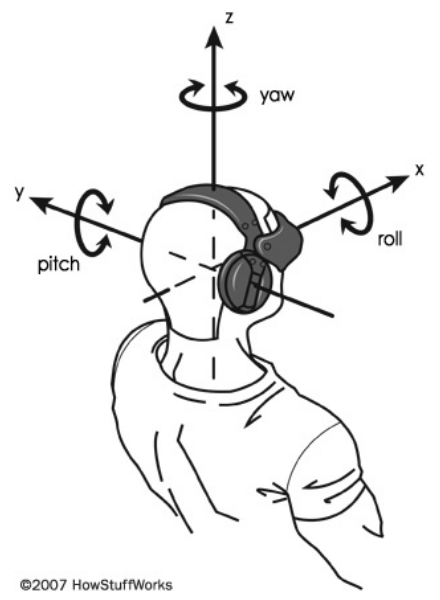

Figure 4. Six Degrees of Freedom

\subsubsection{Sensor-Based Tracking}

Sensor-based tracking systems use active sensors to track the position of the camera duringmotion. Each sensor has its own advantages and disadvantages and must be chosen according to its characteristics (accuracy, calibration, cost, range and resolution, temperature and pressure, etc.) and according to the use case. The following paragraphs describe the existing sensors.

\section{a) Mechanical}

Mechanical tracking systems are based on a physical connection between the target and a fixed reference point. An example of this kind of system is the BOOM display, an HMD mounted at the end of a mechanical arm with two points of articulation. The system can detect the position and orientation of the user through the arm.

\section{b) Magnetic}

An electric current is passed simultaneously through 3 perpendicular coiled wires that form an electromagnet. Magnetic sensor calculate how their magnetic field impacts the field of the other coils and find the orientation and the position of the emitter. 


\section{c) Acoustic}

Ultrasound transmitters and acoustic sensors are used to track the position of the camera. Ultrasound transmitters are worn by the user and sensors are fixed in the environment. Acoustic sensors calculate the user's position and orientation from the time taken by the sound to reach the sensors.

\section{d) Satellite Navigation Systems}

The GPS uses the information of at least 4 satellites to determine the position of the tracked object. With an accuracy of about 10-15 meters for the GPS or 4 meters for the Galileo system, satellite navigation is not suited for precise operations and are not adapted to indoor applications.

\section{e) Radio}

Radio tracking sensors measure the time-of-flight using electromagnetic waves. Electromagnetic waves provide long range motion, suffer negligible absorption losses in air and are unaffected by wind and air temperature. The advantage of electromagnetic waves over acoustic waves is that the wave velocity is a millions time faster. A $1 \mathrm{~mm}$ accuracy can be achieved using Radio Frequency Identification (RFID) systems while meter accuracy can be achieved using WiFi systems.

\section{f) Inertial}

In inertial tracking systems, tracking is based on the conservation of either a given axis of rotation (mechanical gyroscope) or a position (accelerometer).

\section{g) Optical}

Optical tracking systems use a video camera (visible light or infrared type). Only one video camera is sufficient for $2 \mathrm{D}$ tracking, but for $3 \mathrm{D}$ tracking two cameras placed at different angles are needed. Two images are thus used to compute the current position and orientation of the target object. Tracking is difficult with multiple similar objects in the scene. 


\section{h) Hybrid}

Hybrid trackers combine two or more sensors in order to improve accuracy. The weakness of each sensor is compensated by the strengths of the other ones. Combined tracking devices require however mutual calibration.

For instance, the performance of inertial tracking systems at high frequencies and fast movements is superior to every other tracker, but they do not provide any useful estimates at low frequencies. They are therefore often combined with other sensors that can track slow movements to correct the drift error of the gyroscopes and accelerometers. Thus, inertial tracking is typically combined with vision, ultrasound and magnetic tracking.

\subsubsection{Vision-Based Tracking}

Vision-based tracking use computer vision to calculate the camera pose using the video feed. This can be done with fiducial markers in prepared environments or markerless using natural features such as is the case for the most recent systems.

a) Marker-based tracking: artificial markers are placed in the scene in order to track the position of the camera during the acquisition. The position of the fiducials is easy to find thanks to their specific properties. For instance Naimark and Foxlin [14] use circular 2D bar-coded markers for tracking, and another example is the use of QR codes in AR systems (see Figure 5). QR codes are easily recognizable and thousands of different codes can be created for tracking. Steinbis et al. [15] presented a set of 3D cone fiducials for scalable indoor/outdoor tracking easily detectable and useful for large scenes.
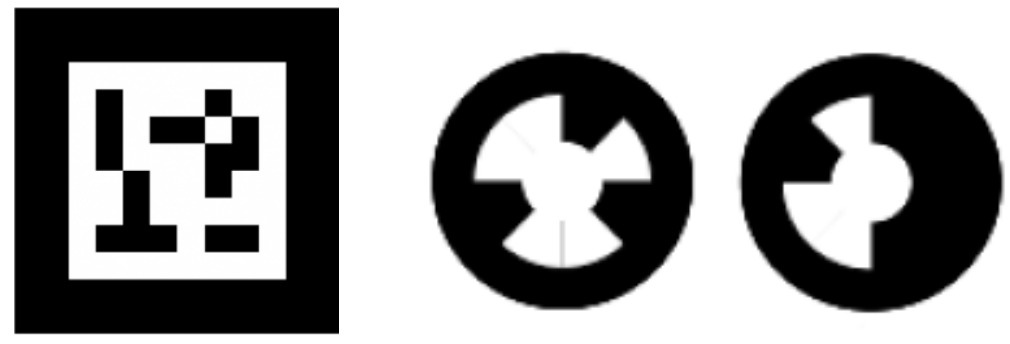

Figure 5. QR code for tracking (left) and circular markers (right) 
b) Markerless tracking: Tracking without using any artificial markers is possible handling the camera video feed. Natural features (interest points) can be detected in the real scene to track the camera pose. For example, a method developed by Vacchetti et al. [16] detect natural features in each frame and compare them with the reference frame.

\subsubsection{AR Displays}

AR systems require the use of specific display devices. In the following paragraphs, several display supports as well as the useful features for AR are presented.

There are three kinds of display:

a. Optical: AR overlays on a transparent surface. Optical combiners are placed in front of the user's eyes. Glasses, head-up displays or even aircraft cockpits are examples of optical display systems.

b. Video: The video flow of reality which comes from the camera is overlaid with virtual elements. Glasses, HMDs, tablets, smartphones and TV streaming are examples of video display systems.

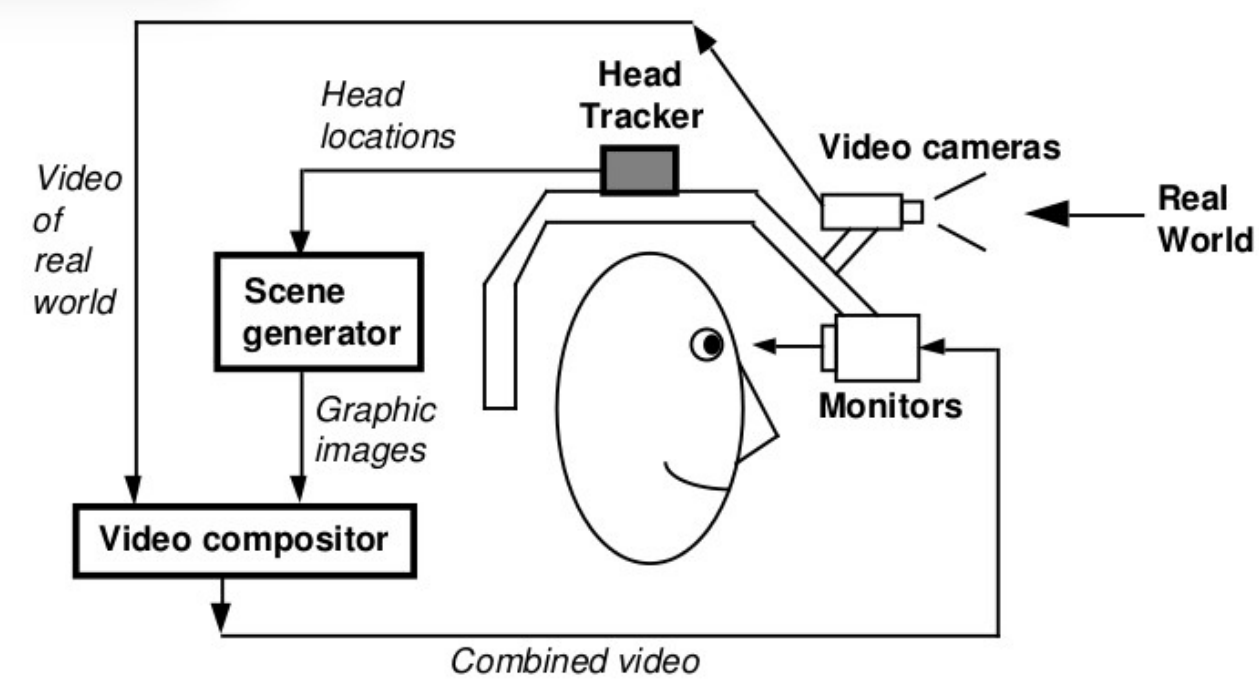

Figure 6. Head-Mounted Video Display Processing [12]

c. Projectors: Virtual elements are directly projected on the real scene using headmounted devices, handled or static projectors. 
In addition to companies providing low-level enabling technologies for head-mounted systems, there are also many approaches to delivering AR that involve some type of projection. Some systems project light on the user's pupil while others point the light on the physical world. In the latter segment, companies such as Tulip Technologies, Design Mill, OPS Solutions, Testia (an Airbus company) and DIOTA are among those that commercially offer specialized hardware for use of projection AR for enterprise deployment.

For optical see-through AR in a wearable, hands-free form factor the display is typically provided using a small projector that aims light on a reflective surface that is sending light to the human eye, or a display. The combination of light emitting and reflecting components are referred to loosely as the "optics” of the AR device. When integrated into the support, the unit is a display. Optics, displays and frames (in which the optics and displays are mounted) differ in many ways and there are dozens of providers in this segment as well.

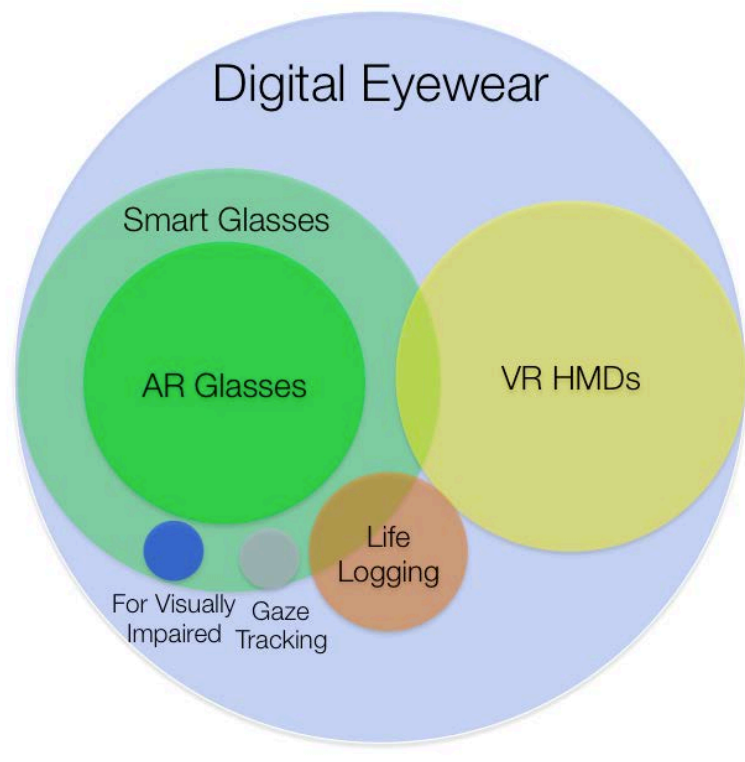

Figure 7 Digital eyewear segments [17]

Smart glasses are a wearable computing device in the form of computerized eyeglasses. Early smart glasses had limited functionality and typically were simply video monitors that were plugged into a video source. Modern devices typically possess enhanced data processing functionality similar to a smartphone or tablet and are able to run mobile applications. Modern smart glasses also include features such as AR overlays, GPS and mapping capability. Useful features in smart glasses typically include motion sensors and 
cameras. In the case of AR, smart glasses use sensors to track features in the real scene. Virtual elements are projected on the glasses and merged with the real scene. Virtual elements can either be text information or 3D models.

\subsubsection{AR-enabling Software}

Within the enterprise AR software segment, there are companies that offer components and solutions in four categories:

1. Real World Detection, Recognition and Tracking Technologies

2. Interaction Libraries

3. Authoring and Publishing platforms

4. Experience storage, discovery and delivery management systems

Companies in the first two of these categories sell and license their software primarily to other businesses within the AR ecosystem that offer more integrated components or complete integrated systems. The category of companies that provide enterprise-grade AR authoring and publishing systems offer a range of solutions; these include turnkey platforms for experience development, game development environments and mobile application development environments. The solutions these companies offer are optimized for more precise tracking and higher performance than required for consumer entertainment experiences. They also have varying degrees of integration with existing enterprise IT services (e.g., security, authentication) and they include varying levels of support for hands-free displays.

Many of the authoring platforms produce proprietary software clients that then deliver the AR experience to the user. The enterprise has the ability to brand the bespoke software client that runs on a device with or without the support of a server. With these software clients, the user can control functionality and interact with the content in the context of the physical world. This includes the ability to pause/freeze the experience, to capture photos or videos of the AR experience and the real world using the same software. Some systems also have the option to interact with workflow management (PLM) systems or to initiate or control real time collaboration sessions with remote experts without leaving the AR-assisted environment.

All AR experience management and delivery software must contain "AR execution engines”, software modules that ensure that all relevant sensor readings (capturing the context of the user in real time) are continuously connecting the real world 
to the digital assets. There are many flavours of AR experience management and delivery clients with different options for connecting to third party content as well as wearable device management middleware. These are not presented in the thesis. 


\subsection{State of AR in the Space Industry}

The application of AR to manufacturing of products and in particular assembly processes has been a focus of research since the early days of AR [18] [19] [20]. Assembly tasks are a paradigm of most claims made about the benefit of AR in industrial applications since they require spatial registration, interaction with objects, and a sequence of actions. It could therefore be inferred that the application of AR in labour intensive industries where products are highly customized, or processes cannot be done by automatic machines, are good candidates to implement AR.

Boeing and the Iowa State University published the results of a 48-participant randomized study [21] of AR on tablets when used in the context of first-time assembly of a complex object. The use of AR when performing a 46-step task ranging in complexity from selecting the correct parts, to properly aligning and fastening bolts through multiple parts reduced time to task completion by $30 \%$ and reduced errors (first time quality results improved 90\%). Studies such as this have repeatedly been reported in many industries in the context of scientific research project reports and workshops [22]. The settings and requirements for the use of AR differ dramatically from one use case to another and between industries so results may not be fully applicable to space industry requirements.

Prior work focusing on the introduction of AR in the space industry specifically for product assurance and safety was not found in the scientific literature. However, at the time of the study the review of literature showed that the enabling technologies for AR have long been studied and remain a popular subject of research among large space integrators for other use cases [23] [24].

One example is Project MOON (asseMbly Oriented authOring augmeNted reality) developed by Airbus Military in 2010 [25] to demonstrate that using an AR system to develop and deliver work instructions for A400M wiring harness assembly processes took up to $90 \%$ less time (more precisely from 30 hours to 3 hours). These dramatic time savings are made possible by reusing information directly from the digital models (3D models created in different phases of the product life cycle).

Since introducing it in January 2015, American technology giant, Microsoft, has shown the HoloLens head-worn personal computing and display system in several industrial AR use cases [26]. In partnership with NASA's Jet Propulsion Laboratory, Microsoft has showcased its Mixed Reality technology with real time Mars rover data [27]. The OnSight project (see Figure 8) demonstrates how rover data combined with 
specially-designed motion capture systems focusing on remote experts can be combined to create a 3-D simulation of the Martian environment. Using OnSight while wearing HoloLens, mission scientists can meet through augmented telepresence to discuss rover operations.

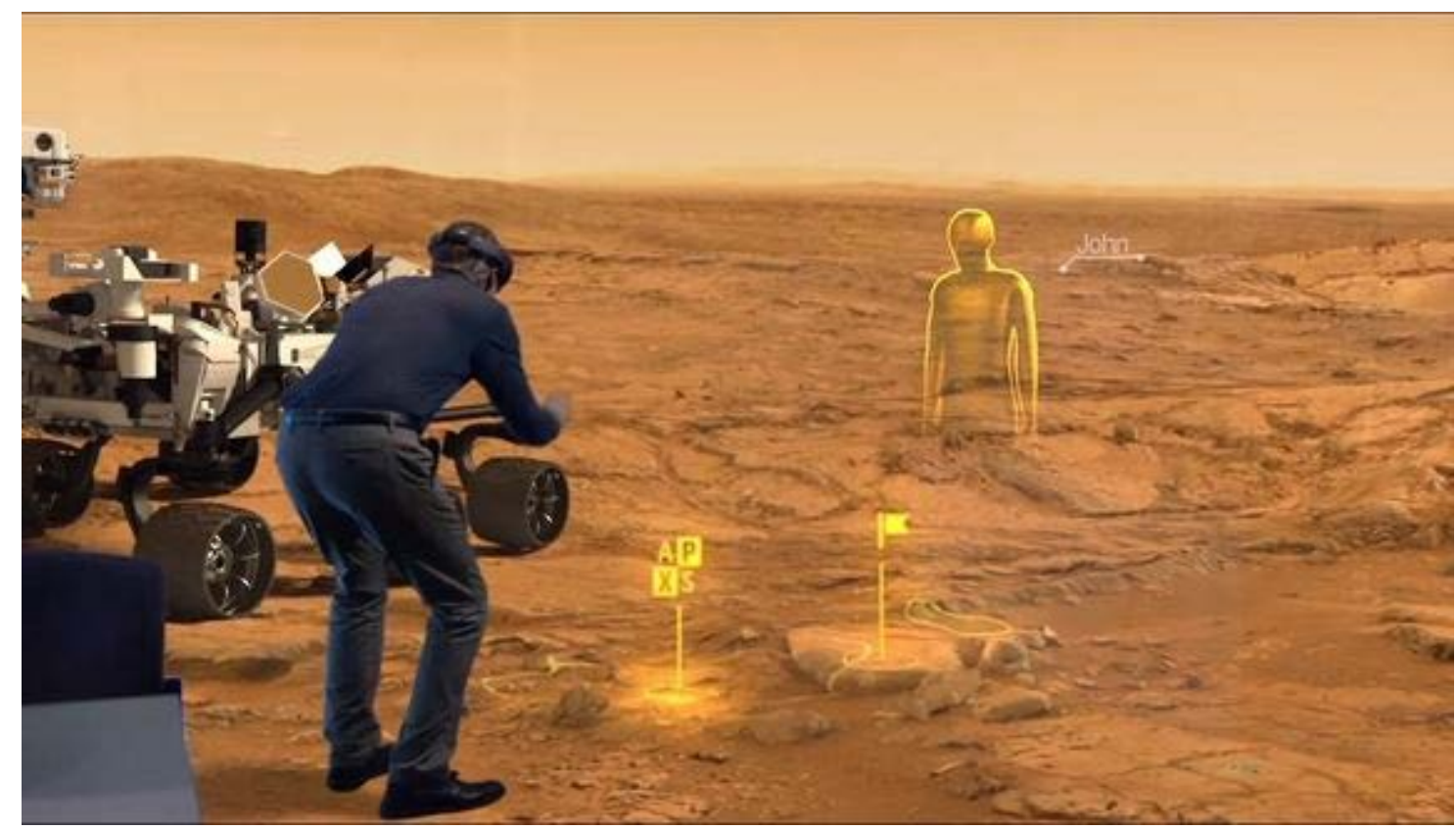

Figure 8 Using OnSight and wearing HoloLens mission scientists discuss rover operations. Image credit: NASA/JPL-Caltech

As of December 2015, Sidekick [28] was deployed at the International Space Station (ISS). Sidekick uses Microsoft HoloLens (see Figure 9) to provide virtual aid to astronauts while they are performing complex procedures by displaying virtual images overlaid on top of real objects and allowing their interaction. Members ISS crew also use HoloLens to access information pre-configured in the system and, in a second mode, to connect with remote experts via Skype. This allows voice, video and real-time virtual annotation. 


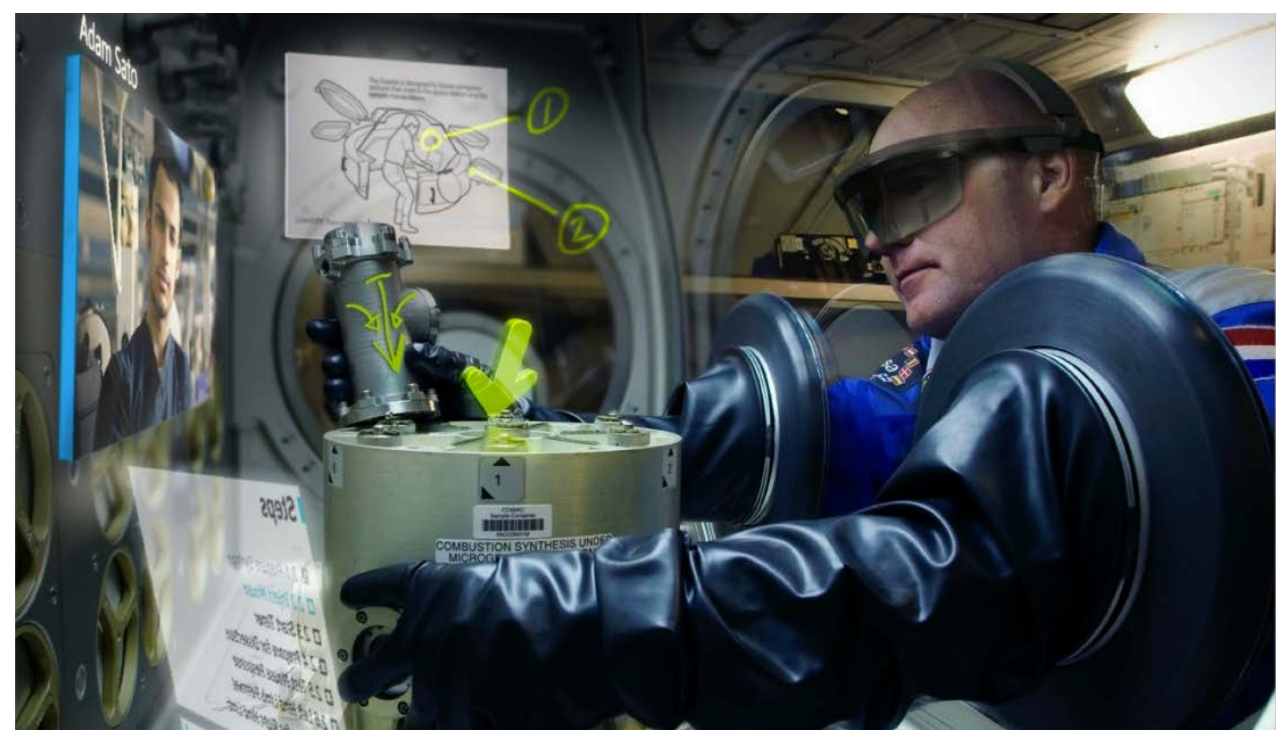

Figure 9 André Kuipers (NL) using Sidekick and wearing HoloLens to see and interact with instructions as well as a remote expert when performing complex procedures. Image credit: NASA

ESA also developed a wearable crew support technology, a mobile procedure viewer (mobiPV) [29], which enables procedure execution, 3D data visualization in AR, note-taking and peer-to-peer communications for collaboration. More recently, the ESAEdcAR project (Engineering data in cross platform AR) led by VTT Technical Research Centre of Finland through 2016 and 2017 [30] developed a new AR tool intended to improve the performance of manual tasks by displaying detailed visual instructions on the astronauts' Microsoft HoloLens platform, guiding them step by step to perform the necessary procedures in the right order. 


\section{Adoption of AR for Product Assurance and Safety}

\subsection{Research Methodology}

The research presented in this paper focuses on specific scenarios in which the use of AR could improve space industry product assurance and safety processes. The study was conducted from July to October 2016 using a multi-method mix approach, combining desk research with a quantitative (online) survey extended by follow-up qualitative semistructured (phone) interviews.

The online survey to assess the sample population's preference for different use cases was developed and implemented on the SurveyMonkey.com platform. To help ensure input gathered would be invariant of the different level of exposure to and prior experience of AR of the participants in the study, an introductory video was prepared(see Appendix A). The video provided an elevator pitch about the possibilities for AR in space product assurance and safety in space, including selected examples of AR applications in use in other, but related, fields. The video also introduced a selection of five animated mock-ups of possible use cases for space product assurance and safety that were selected from an initial set of ten. These presented mock-ups of use cases can be summarized as follows:

(1) AR can be used to support process management and operator training. A context sensitive overlay of procedural instructions (Q1) could be useful when a task is new, critical and complex, or occurs only very rarely. AR can be valuable to train the operator in a new procedure and also mitigate the risk of human error (Q2). When needed, an AR-assisted system could support the user in capturing last minute procedural changes. A red line recorded procedure (Q3) might use hands-free annotations with speech and camera input instead of requiring the writing or typing of notes. It is important to note 
that Q1, Q2 and Q3 can apply to either activities on ground that are part of spacecraft manufacturing, assembly, integration and testing, or in-orbit servicing operations performed by astronauts. The latter could even include future extraterrestrial operations (e.g. Moon or Mars).

(2) AR for quality inspection and testing (Q8) was depicted by showing how highlighting parts remaining to be tested could assist inspectors. The system may also show real time data as it is being captured during testing, using smart instruments.

(3) AR can be used for management of non-conformance reports. Such a report can be created immediately when parts or procedures inspected deviate from requirements or do not conform to regulation (Q5). Hands-free note taking could be created using speech recognition and photos captured (Q4).

(4) AR can add value to configuration management. Using AR-assisted system, the exact model of hardware can be recognized. This way, blueprints of components can be compared with the actual hardware (Q6). Systems could be designed to detect configuration errors and mismatched between specified parts and actual parts mounted immediately and prior to testing(Q7).

(5) Finally, AR-assisted systems could be used in supporting PA\&S managers in the field with remote experts with tele-tutoring (Q9). In this case a call with audio and video, essentially a mobile video call, can be established between the remote expert or desk agent, and a field product assurance and safety agent. The agent in the field may then make more rapid and informed decisions without leaving the site or stopping the inspection in progress.

The quantitative survey used the video in the introduction to brief participants to then survey a selection of 23 questions. Two times 9 questions were used to assess desirability (5-point Likert scale from 'very undesirable' to 'very desirable') and feasibility (5-point Likert scale from 'not probable' to 'very probable') of the use cases presented. The remainder of questions provided an opportunity to describe additional use cases, drivers and barriers to adoption, delivery platforms and an open question about the justification of the choice, as well as demographic information (age group and gender). The online survey questions can be found in Appendix B.

The participants recruitment was voluntary and non-anonymous. They were recruited from 60 invitees from ESA (Product Assurance and Safety Managers) and 44 invitees from other space agencies and ind ustry. The response rate was 54\% (34 responses from ESA, four from other agencies, and 18 from industry). The majority of respondents 
were male (47), with only nine female participants - a distortion that can be explained with the population sampled. Of the contributors, four were in the age bracket 30-39, 20 in 40-49, 26 in the bracket of 50-59, and five over 60, again a distortion that is normal for the target group. After responding to the online survey, participants were offered to participate in a follow-up phone interview (see Appendix C). Six follow up interviews were conducted with industry representatives and four with ESA personnel. The phone interviews were recorded upon agreement with the participants, transcribed and all results tabulated.

The statistical data collected from the survey was analysed using an $\mathrm{R}$ project for statistical computing script written to extract the $P$ values in SPSS statistical programming language. The univariate analysis of statistical data for the desirability and feasibility variables of use cases is represented graphically by box-and-whisker plots. Afterwards, the drivers and barriers for the adoption of AR are presented, followed by a Pearson correlation test with the use cases to support their selection. 


\subsection{Results}

\subsubsection{Desirability and Feasibility}

The core of the questions in the online survey set focus on desirability and feasibility of the use cases, represented through the animated mock-ups in the introductory video (providing key screen shots with the questions as a visual reminder).

The box-and-whisker plot represented in Figure 10 depicts the results for the five use cases and their specific aspects, totalling nine items. The 'hinges' in the plot cover the answers of $50 \%$ of the participants, with the line in the middle indicating the median. The 'whiskers' span a 95\% confidence interval. Outliers are depicted with a black dot. The connected red dots indicate the medians.

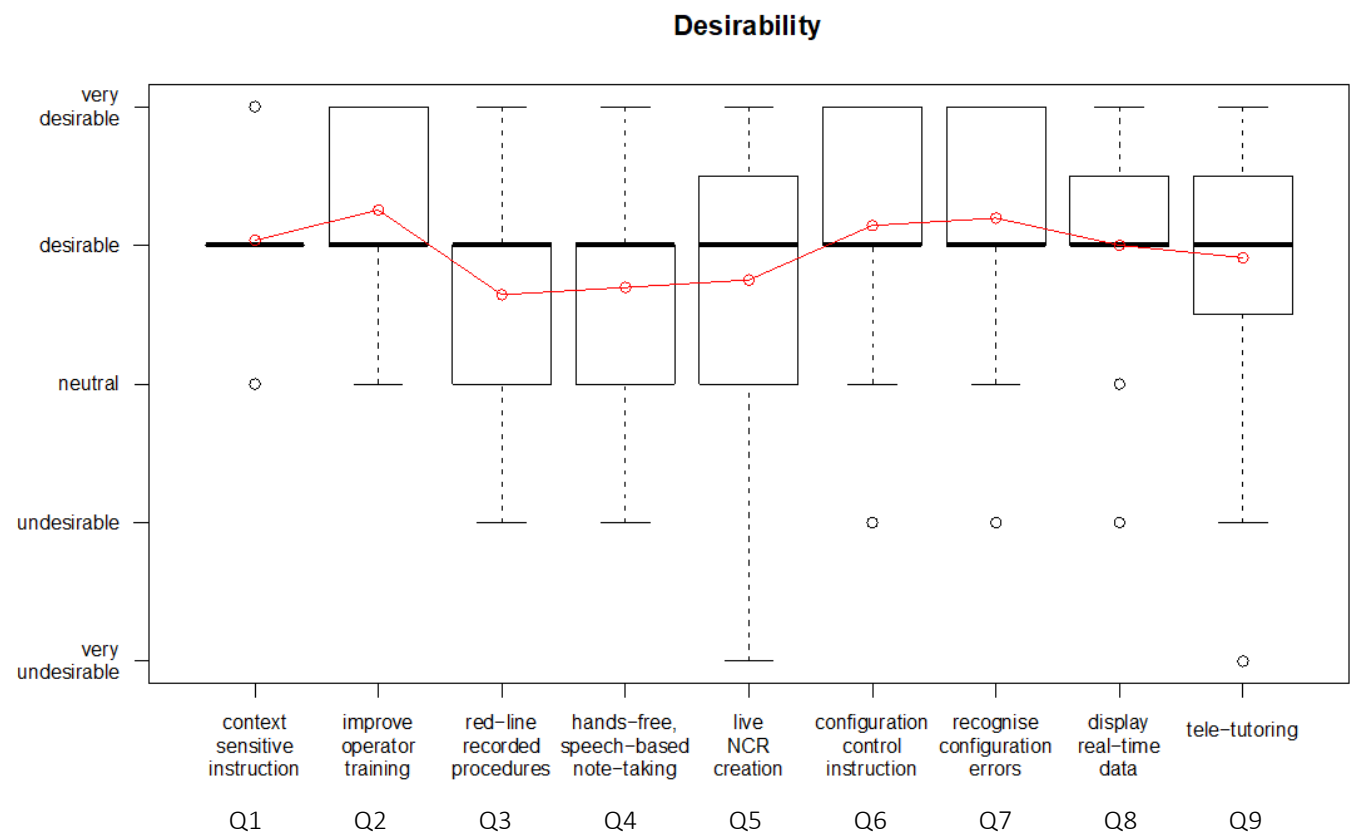

Figure 10 Desirability of use cases

The most desired functionalities are improving operator training (49), providing configuration control instruction by recognizing hardware (47), and the provision of realtime recognition of configuration errors (48).

The assessment of how feasible such introduction to space product assurance and safety within the next three to five years is likened, however, is quite different(see Figure 11). Consistently for all cases, participants are divided and answers span the full 
spectrum, with the majority (mean: $87 \%$, standard deviation: 4\%) of contributors considering it neutral, somewhat probable or somewhat improbable. The only case noteworthy is that an AR system providing real-time display of test data overlaid on the test item is not considered by anyone as 'very probable' (which in the other cases a mean of $4 \%$ of the respondents considered, with a standard deviation of $1 \%$ ).

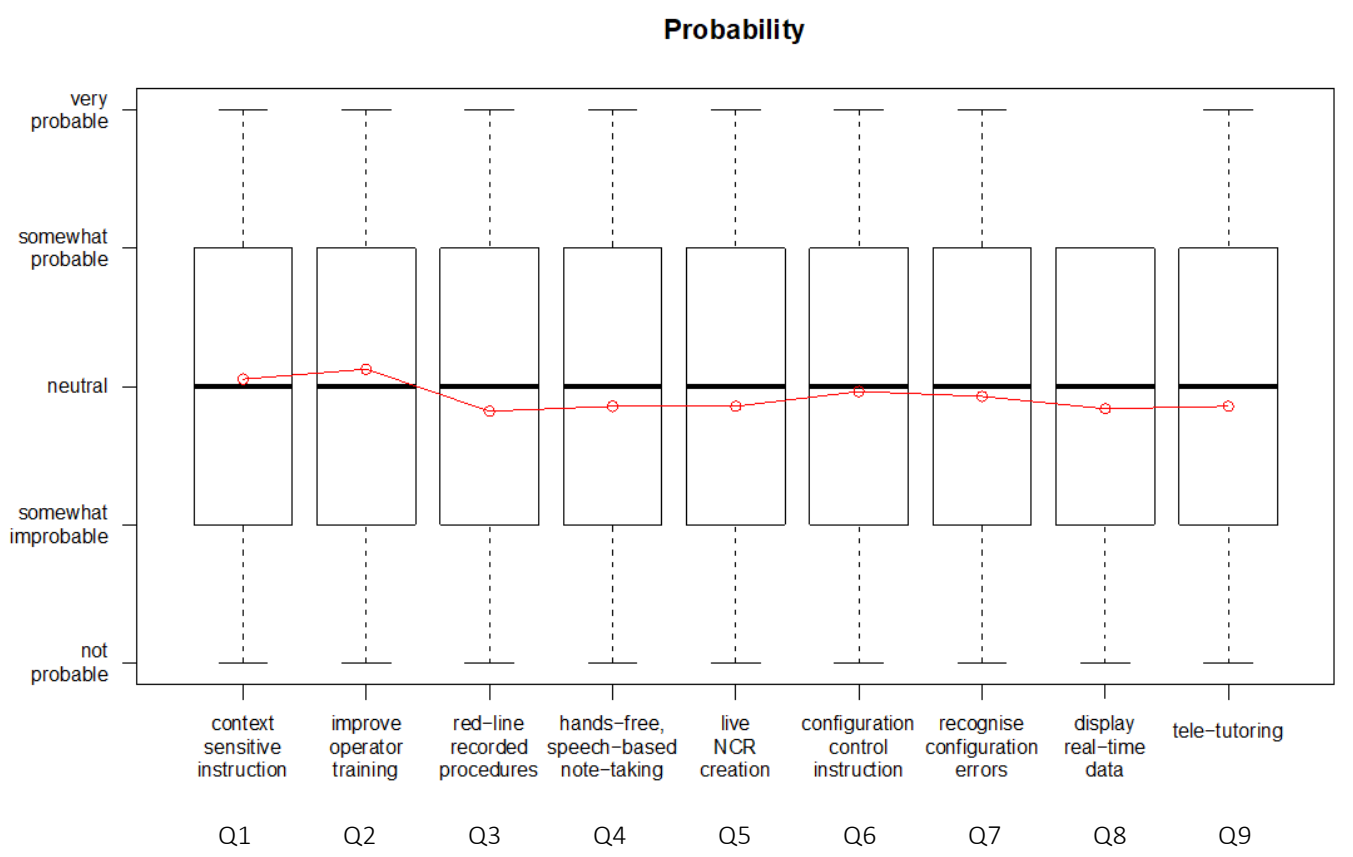

Figure 11 Probability of usecases

\subsubsection{Additional Use Cases Proposed}

A variety of additional use cases were proposed in the open question posed. The cases mentioned in the open-ended question fall into several groups, emphasizing different applications in product assurance and safety: use cases for capturing lessons learned, access to historical data for failure analysis and (fault) simulation, in support of test procedures, for use in auditing and reviews, for training, supporting the location of parts and the identification of parts and tools, or, more generally, repairs, improving safety, supporting remote interaction (with data). The following paragraphs provide a summary of those. 


\section{a) Lessons learned}

Documenting lessons learned and preparing knowledge transfer is a challenge, especially with long-term activities in assembly, integration, and testing (AIT), where time intervals between launches can be 10 years or more.

"Use for lessons learned and knowledge transfer e.g. long-term recurrent AIT activities like MTG, MetOP where it can be 10 years between launches and AIT team is no longer the same."

Moreover, Augmented Reality could facilitate discussions around such lessons learned and could become a medium in which recommendations can be expressed in a very visual, tangible way.

"In the Lessons Learned discussions along the recommendations communications this tool would also have some added value...”

\section{b) Access to historical data and simulation data for failure analysis}

When used to provide access to historical data and results of simulations, AR can support fault analysis in a better way, supporting the investigation of fault propagation pathways and facilitating root cause analysis. This can include previous results to more easily follow the evolution of results during repeated testing or test runs, but could also already be integrated directly into manufacturing, all with them aim to improve product assurance and safety. At the same time, this creates an accessible archive of such data, ready to be accessed when a non-conformance root cause investigation should be needed.

“Access to historical data, previous results, evolution of the results while doing a procedure (test procedure for example).”

“As-run procedure”

"Showing how AR can be used during manufacturing for fit checks simulations to enable S\&MA.”

“Simulations (units, systems), correlation with analysis (thermal, mechanical), most probable Failure Modes evaluation and its propagating effects, risks evaluation, teaching and learning, Root Cause Analysis, ...”

“To record activities to be used later in NC root cause investigation.”

“The ability to perform fault analysis in an augmented reality environment. In the video for example some schematics for a spacecraft are shown. We could choose one of 
those components and simulate a failure. The potential failure propagation path throughout the system could be highlighted in the schematic. This would support the identification of single point of failures, as well as the improvement of the design robustness and reliability. There exist ongoing European projects that may soon support model-based fault analysis. Once the model for the system under analysis and the tools for performing fault analysis with the support of those models, it shouldn't be difficult to integrate those models and tools in a augmented reality environment.”

\section{c) Test procedures}

Supporting the set-up, checking test facility readiness, and assisting in the actual test can be a further, separate use case - adding procedural guidance for “test procedures” and check list capabilities in addition to the access to test data listed already above in a separate group (“Test preparation/set-up, check of test specimen and test facility readiness”).

\section{d) Auditing}

Related, but on a different aggregation level and for a different audience are “auditing” procedures and reviews. Augmented Reality has an opportunity for providing quick access to evidence as well as "presenting information at reviews".

\section{e) Training}

Novel use cases in training arise, in particular, where an understanding needs to be fostered, providing "example of errors with illustration of their consequences” and adding “visual training based on feedback from student”.

\section{f) Locating parts}

Indoor navigation could be utilized "for directions to locate a part in stores".

\section{g) Repairs}

To support repairs, "non-standard repair instructions in the frame of an Major NC” can be provided in AR mode. 


\section{h) Safety}

Safety can be improved "to provide stay out zones e.g. safety warnings (e.g. live equipment, hot or cold equipment or protection from contamination, etc.)”.

\section{i) Remote interaction and data}

Participants made use case proposals for remoteinteraction with experts and using real-time exchange of data to the survey in several different application contexts. This is particularly with respect to communicating with remote sites (e.g. all Galileo uplink \& sensor stations), but also in the remote operation of testing equipment (microscope) or other equipment.

“Augmented Reality (real-time exchange of media \& data) would be very useful in the particular context of ground segment infrastructure located in remote sites (e.g. all Galileo up-link \& sensor stations). This technology might help to investigate hardware problems occurring in remote sites, where by definition is difficult to send specialists that can do this job on site."

"Interaction with expert allowing tech feedback integrated with expert to confirm" "For finding and presenting details of interfaces (e.g., voltage, current, signals)."

"Remote controlled microscope that allow expert to inspect a sample in different location. I have already seen this application about 10 years ago in a demo of a well know manufacturer. Since then I didn't came across to it but I assume is already on the market.”

\section{j) Identification of parts and tools}

On a lower level, the identification of parts and tools could be supported, including the "identification of tools for selection to ensure correct tool is selected" or even "for finding and presenting the software modules/code that controls a device”. Functionality would be needed "to cross reference names on consumables versus work sheet (e.g. adhesives) to ensure the correct one is used" or to identify "RED/Green tag items to ensure the items are in place as necessary." Also, the "part identification of small unmarked passive devices” was given special attention. This would support (visual) inspection and the detection of non-conformities during review. 
"Maybe simple tasks like in the incoming inspection of EEE parts/materials, to assure that they are OK, too. But I guess it is covered by the video somehow.” "Visual inspection of hardware during various stages of the product life cycle: MRR, IRR, TRR, DRB, shipment review, launch readiness...”

"To be able to detect non-conformities in documentation review, I realize that most documentation is in electronic form, nevertheless when assessing the compliance of the documentation it would be good to automatically highlight areas of concern / a reminder of the requirement.”

\subsubsection{Adoption Drivers}

Amongst the drivers to adoption surveyed, the reduction of error (77\%) and the increase of compliance (55\%) stand out. To lower the cost of performing a task (41\%), faster task completion (38\%), increase of precision (36\%), and the acceleration of the introduction of electronic work instruction are considered important arguments in the decision making about introduction of AR to space product assurance and safety. Table 1 also presents less prominent drivers to the adoption of AR.

Table 1 Most important drivers in the decision about the introduction of AR in space product a ssurance and sa fety processes

\begin{tabular}{lc}
\hline \multicolumn{1}{c}{ Drivers for introduction of AR } & \% of surveyed agree \\
\hline Reduction of error & $77 \%$ \\
Increase of compliance & $55 \%$ \\
Lower the cost of performing a task & $41 \%$ \\
Faster task completion & $38 \%$ \\
Increase of precision & $36 \%$ \\
Know when a task is finished & $20 \%$ \\
Approval of management & $25 \%$ \\
Increase in appeal of the workplace & $25 \%$ \\
Integration with systems already in use & $29 \%$ \\
Reduction of training needs on new tasks & $32 \%$
\end{tabular}

The most interesting correlation of specific driver's distribution in the answers to the conflated binary desirability levels (desirable and very desirable conflated to binary presence / absence) can be found for the drivers of increasing compliance and reducing error. They co-occur significantly with desirability of the use cases on improved operator 
training, red-line recorded procedure, live non-conformance report creation, recognition of configuration errors, as well as with tele-tutoring, see Table 2. Increased precision is connected with tele-tutoring only. Reduced need for training may come especially with support for automated recognition of configuration errors. All other drivers are not statistically significantly correlated with specific use cases. The correlation effects are weak, in exceptions moderate.

Table 2 Pea rson correlation between use ca ses and drivers to adoption

\begin{tabular}{|c|c|c|c|c|c|c|c|c|c|}
\hline & 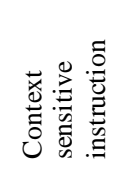 & 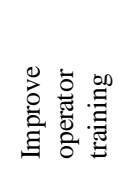 & 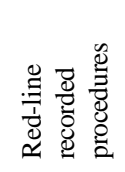 & 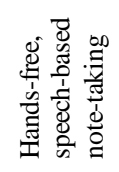 & 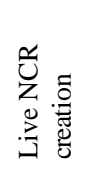 & 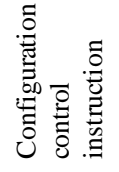 & 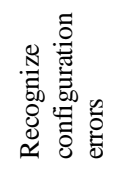 & 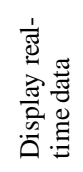 & 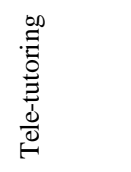 \\
\hline $\begin{array}{l}\text { Accelerate } \\
\text { introduction }\end{array}$ & 0.02 & 0.02 & -0.14 & 0.01 & 0.12 & -0.08 & -0.02 & 0.06 & 0 \\
\hline Lower cost & -0.13 & -0.07 & -0.06 & -0.06 & 0.12 & -0.03 & 0.13 & 0.2 & 0.15 \\
\hline $\begin{array}{l}\text { Faster task } \\
\text { completion } \\
\text { Reduced }\end{array}$ & 0.14 & 0.02 & 0.12 & 0.19 & 0.14 & 0.14 & 0.21 & 0.25 & 0.19 \\
\hline training need & 0.09 & 0.12 & 0.11 & -0.05 & 0.06 & 0.2 & $0.28 *)$ & 0.2 & 0.04 \\
\hline $\begin{array}{l}\text { Know } \\
\text { completion } \\
\text { Increase }\end{array}$ & 0.22 & 0.16 & 0.09 & -0.01 & -0.08 & -0.15 & -0.06 & 0.17 & 0.18 \\
\hline compliance & 0.19 & $0.27 *)$ & $0.31 *)$ & 0.16 & 0.12 & 0.19 & 0.25 & 0.1 & 0.31*) \\
\hline Reduce error & 0.1 & 0.22 & $\left.0.3^{*}\right)$ & 0.21 & $0.27 *)$ & 0.22 & $0.38 * *)$ & 0 & $0.27 *)$ \\
\hline $\begin{array}{l}\text { Increase } \\
\text { precision }\end{array}$ & 0.22 & 0.25 & 0.09 & 0.17 & 0.12 & 0.12 & 0.2 & 0.06 & $0.43 * * *)$ \\
\hline Interoperability & -0.05 & 0.1 & -0.11 & -0.11 & -0.16 & -0.05 & 0.03 & 0.16 & 0.09 \\
\hline $\begin{array}{l}\text { Social approval } \\
\text { Increase }\end{array}$ & 0.14 & 0.19 & 0.09 & -0.09 & 0.02 & 0.03 & 0 & 0.12 & 0.24 \\
\hline $\begin{array}{l}\text { workplace } \\
\text { appeal }\end{array}$ & 0.03 & 0.07 & 0.17 & 0 & 0.02 & -0.08 & -0.24 & 0.02 & 0.14 \\
\hline
\end{tabular}

\subsubsection{Adoption Barriers}

There were also many barriers to AR introduction cited by the study respondents. In the survey the respondents ranked importance of the barriers proposed in the study and were also invited to describe any others they felt should be considered.

High customisation costs (61\%) are expected to be the most prominent barrier to adoption, threatening to prevent the introduction of AR into workplaces and procedures. If AR systems are not integrated with other systems already in use (54\%), this can pose an obstacle. Table 3 also presents less prominent barriers to the adoption of AR, such as 
lack of standard, off-the-shelf solutions and wrong device choices (e.g. "cannot hold tablet while performing tasks, I need to use both hands”).

Table 3 Most important barriers in the decision about the introduction of AR in space product a ssurance and sa fety processes

\begin{tabular}{lc}
\hline \multicolumn{1}{c}{ Barriers for introduction of AR } & \% of surveyed agree \\
\hline High customisation costs & $61 \%$ \\
Lack of interoperability & $54 \%$ \\
No off-the-shelf solutions & $41 \%$ \\
Wrong device choices & $41 \%$ \\
Lack of IT support for AR technology & $30 \%$ \\
Lack of experience with similar technologies & $29 \%$ \\
Devices and software not certified or compliant with workplace & $29 \%$ \\
policy and regulations & \\
Insufficient precision and/or resolution of the technology & $27 \%$ \\
Unsupported by equipment manufacturer & $23 \%$ \\
Learning curve too high compared with the value it would offer & $21 \%$ \\
Negative past experiences & $11 \%$
\end{tabular}

Looking at the barriers, few statistically significant correlations can be found with specific use cases (see Table 4). Negative past experiences with similar technologies appear often together with desire for the use case of delivering context-sensitive instruction (desirable and very desirable levels conflated to binary presence for the correlation). Comparative bad learnability correlates significantly with the use case of recognition of configuration errors. Interestingly, the barrier of lack of availability of offthe-shelf solutions negatively correlates with this one, indicating that for this problem, off-the-shelf solutions may anyways not be appropriate (and bespoke software with custom requirements is needed). That equipment manufacturers do not support AR at the moment is seen as a specific barrier to this use case of recognizing configuration errors. Last, but not least, comparatively bad learnability is expected to be a barrier to a teletutoring use case for field support.

With regards to the impact of demographic factors such as age into the adoption of $\mathrm{AR}$, it is important to remark that almost $50 \%$ of respondents in the subject study were 
in the age bracket of 50-59, and no significant bias was detected compared with responses from other age brackets. The findings of Peleg-Adler, Lanir and Korman [31] suggest that older adults do not have any specific performance deficits in using AR; at least, not more than in using other types of technologies. As expected, older adults are generally slower in performance, but do not show any significant deficits in success rates compared to young adults. The authors conclude that AR has equal potential to be adopted by older adults and, in fact, perhaps be more easily accepted than other non-AR solutions.

Table 4 Pearson correlation between cases and barriers to a doption

\begin{tabular}{|c|c|c|c|c|c|c|c|c|c|}
\hline & 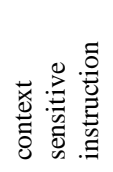 & 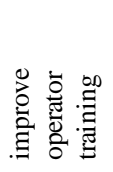 & 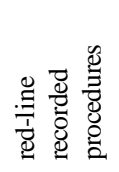 & 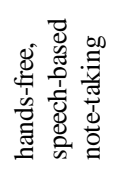 & 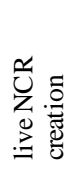 & 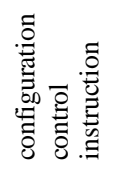 & 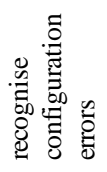 & 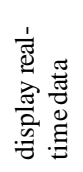 & 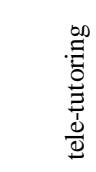 \\
\hline $\begin{array}{l}\text { Cannot hold } \\
\text { tablet }\end{array}$ & 0.20 & -0.02 & -0.14 & -0.03 & 0.09 & 0.02 & 0.10 & 0.03 & 0.09 \\
\hline $\begin{array}{l}\text { Comparative } \\
\text { bad learnability }\end{array}$ & 0.23 & -0.03 & -0.01 & 0.01 & -0.01 & 0.18 & $0.31 *)$ & 0.15 & 0.09 \\
\hline $\begin{array}{l}\text { High } \\
\text { customisation } \\
\text { costs }\end{array}$ & -0.23 & -0.09 & 0.04 & -0.15 & -0.04 & -0.12 & -0.13 & -0.14 & $-0.27 *)$ \\
\hline $\begin{array}{l}\text { No off-the-shelf } \\
\text { solutions }\end{array}$ & -0.09 & 0.05 & 0.02 & -0.03 & 0.09 & -0.21 & $\left.-0.27^{*}\right)$ & -0.05 & -0.06 \\
\hline $\begin{array}{l}\text { Negative past } \\
\text { experiences }\end{array}$ & $0.27 *)$ & 0.15 & 0.12 & 0.26 & 0.00 & 0.12 & 0.09 & 0.04 & 0.24 \\
\hline $\begin{array}{l}\text { Lack of } \\
\text { experience }\end{array}$ & -0.17 & 0.15 & -0.12 & 0.07 & -0.04 & 0.05 & 0.00 & -0.05 & -0.04 \\
\hline $\begin{array}{l}\text { Lack of IT } \\
\text { support }\end{array}$ & 0.11 & 0.19 & 0.10 & 0.04 & 0.10 & 0.18 & 0.05 & -0.07 & 0.02 \\
\hline $\begin{array}{l}\text { Insufficient } \\
\text { precision/ } \\
\text { resolution }\end{array}$ & -0.14 & -0.06 & -0.01 & -0.16 & -0.09 & -0.09 & 0.03 & 0.06 & -0.09 \\
\hline $\begin{array}{l}\text { Lack of } \\
\text { interoperability }\end{array}$ & 0.04 & 0.04 & 0.14 & -0.05 & 0.06 & -0.09 & -0.24 & -0.05 & -0.16 \\
\hline $\begin{array}{l}\text { Unsupported by } \\
\text { equipment } \\
\text { manufacturer }\end{array}$ & -0.07 & -0.07 & -0.04 & -0.11 & -0.13 & 0.14 & $\left.0.27^{*}\right)$ & 0.12 & -0.04 \\
\hline $\begin{array}{l}\text { Not certified/ } \\
\text { compliant }\end{array}$ & 0.07 & -0.09 & -0.04 & -0.10 & 0.05 & -0.04 & 0.00 & 0.12 & 0.05 \\
\hline
\end{tabular}

In the prompts for open comment, study participants raised range of additional drivers and barriers. Some suggested that focusing on "lean" management practices to maximize value while minimizing waste would be an additional driver of AR adoption. Others suggested that "reducing risk of performing an activity incorrectly would bring measurable value to their jobs.” Although the participants were not informed about possible implementation costs, reduction of total cost of space programs was brought forward, with the target to "lower overall cost (not just the 'one task' but the sum of all associated tasks) being the ultimate goal.” Establishment of new procedures might 
enhance work plans and verification of plausibility of data acquired during process steps. It was also suggested that AR would accelerate approval of critical step completion while reducing travel.

\subsubsection{Additional drivers and barriers}

In the prompts for open comment, study participants raised range of additional drivers and barriers. Some suggested that focusing on "lean" management practices to maximize value while minimizing waste would be an additional driver of AR adoption. Others suggested that "reducing risk of performing an activity incorrectly would bring measurable value to their jobs.”

Although the participants were not informed about possible implementation costs, reduction of total cost of space programs was brought forward, with the target to "lower overall cost (not just the 'one task' but the sum of all associated tasks) being the ultimate goal.” Establishment of new procedures might enhance work plans and verification of plausibility of data acquired during process steps. It was also suggested that AR would accelerate approval of critical step completion while reducing travel.

In addition to drivers, study participants expressed numerous other potential barriers including:

a. "We are involved in prototype systems only. These systems are good for mass production to also have less trained workers doing tasks”

b. "too complex and not user friendly tool. Unreliable tool with many failures. not trusty tool with respect to information inside. Too complex to use with respect to task to be done"

c. "Possible reluctance if seen as too much power to computers and computer scientists versus human technical experts - Beware of risks related to failures, unavailability or even impact of erroneous elements in such support”

d. "fear that it would mean that the operation is reliant on the availability of this service"

e. "Inherent errors of the system"

f. "This would need to be fully integrated across the complete space industry. As a stand alone for ESA this would only benefit small in-house activities. Major project primes would need to implement systems that were compatible between each other otherwise it will never be used.”

g. "Difficult and high cost to apply to one-shot programs" 
h. "1) Effect on the human factor: we rely on operators being well trained and using their experience/judgment. How to incorporate augmented reality and still keep the "critical spirit' of the person interfacing with/using the AR system and not totally relying on it? 2) Quality assurance concept for AR systems must be established and solidly demonstrated to be effective “

i. "Need to deploy it consistently through all the supply chain"

j. "The context recognition feature in which the Mediated Reality seems to be based reminds somehow to the former 'expert systems' of the past (now with sophisticated interfaces to interact with the system) which in fact needed a lot of compiled knowledge that made sense in very limited and specific fields. How such compiled knowledge is going to be available in order to provide results similar to the ones shown in the use cases? May the involved costs (compiled expertise, maintenance, IT support) to get the system is effective be worth against the benefits shown in the video? It is supposed that most of the local industries start almost from scratch in this kind of methodologies, so there's no clear synergy with other existing ones, and hence real disruptive applications or competitive advantages are demanded in favor of trusting on it."

$\mathrm{k}$. "Since I do not see the advantage at this moment in time of augmented reality in PA\&S it is somewhat difficult for me to answer this question.”

l. 'Process 'heritage' (which is many times understood, and sometimes abused). [...] Unfortunately, [the] space business really loves 'heritage' (which is many times understood, and sometimes abused). Anyway, the obvious side effect it is the reluctance to evolve. I really hope we can have AR in 5 years [...]”

m. "Cost and time to implement. Most of our hardware/spacecraft are not enough recurrent (production volume)”

\subsubsection{Delivery Media}

With respect to the preferred AR experience display technology in the workplace, optical head-mounted displays such as smart glasses, and tablets are clearly preferred by the survey participants over projection-based AR. There is a slight tendency towards smart glasses as the first choice, but this is counter balanced by a larger amount of people naming tablets as their second choice. As one respondentputs it: "Each proposed solution has specific advantages or drawbacks in some specific situations and scenarios.” 
Looking further at the mix of answers justifying the preference in device choice, this all points towards using a combination of multiple devices, see Figure 12, strongly depending on the use cases supported.

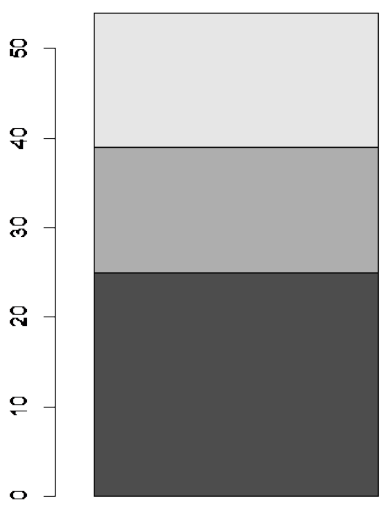

smart glasses

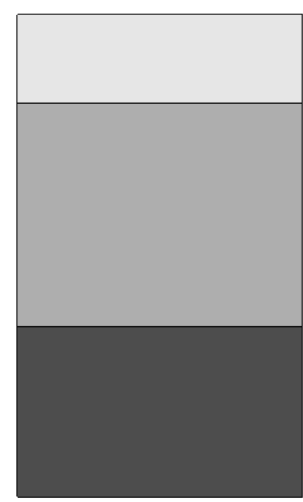

tablet

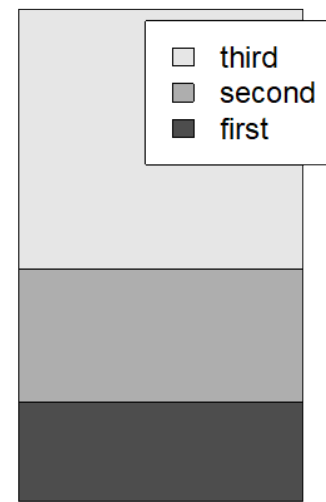

projection

Figure 12 Preference of delivery devices (ranking)

Various justifications were given for the ranking of device choice in the previous question. Those who prefer projection over the other delivery devices justify this choice with reducing distraction, delivering augmentation in place on the object, with no need to turn away from the current piece of work (by looking at "a paper procedure, a drawing, a PC”) and staying “task focused”. Both smart glasses as well as tablets can be obtrusive and there is a danger of dropping and damaging especially a tablet device.

Amongst those preferring tablets for delivery as a first choice, there are several different reasons named in the justifications. Tablets are widely used within and outside of the work environment and are easy to use for most users. Limited functionality of stationary projection and smart glasses, worries about obstruction, as well as lack of experience with smart glasses are repeatedly mentioned. Stationary projection, however, is also seen as limited in where it can be applied - they are deemed to be expensive and require "frequent maintenance". A big advantage is that on tablet systems, report creation becomes possible.

As for those preferring smart glasses, the most frequently named reasons it that they keep the hands free for the actual manual work tasks. They have most mobility, provide information directly to the operator, are deemed best for astronauts, and are not further impeding on the already “cramped space for working”. Tablets can be easily 
dropped onto delicate flight equipment, whereas stationary projection is seen as "limited to one activity”, may take long to set up, and may not scale in a market of units of one.

The selection of the display technology is non-trivial given its potential influence on overall system performance and safety, which is particularly important in high-risk and high-consequence industries, as discussed by Xua, Anders et al. [32]. On this regard, the requirements for an immersive AR system including sensing, registration and display must be derived from a holistic human factors approach [33]. 


\subsection{Discussion}

In summary, the use cases chosen as desirable and feasible by the study participants are the following:

1. Delivering contextually sensitive instructions (procedural guidance)

2. Improving operator training

3. Providing configuration control instruction by recognizing hardware

4. Real-time recognition of configuration errors

It is foreseen that other use cases may emerge from the list of those proposed by study participants as well as more opportunistically when operators and inspection personnel are exposed to the technology and begin to experiment with its benefits.

The survey participants and interviewees generally have interest in using AR to reduce errors and increase space industry compliance with policies and regulations. This said, the study focused narrowly on professionals involved in space product assurance and safety. There is a strong alignment between the roles of those who participated in the study and the drivers provided for AR introduction. Since AR introduction success depends highly on the use case chose, the results of this study cannot be immediately applied to all use cases since other professionals were not included in the study.

One of the highest perceived barriers to introduction of AR was the need for high customization. This perception is probably high because the participants are unfamiliar with the processes of AR implementation.

The study participants agreed that hands-free displays, such as projectors and smart glasses, are preferable over tablets for production deployment due to freedom to use both hands for a task while having the necessary information.

At the time of the research, AR is provided to end users on tablets and, in some industrial settings, using cameras integrated with light or laser projectors. In the future, hands-free displays should be commonplace and permit users to perform tasks with both their hands. Moreover, the networks of space product manufacturing and integration environments are unlikely to be capable of streaming video to a server in real time and very few systems are capable of archiving the actions of users locally. In the future, we expect network communications to permit highly accurate capture and secure systems will ensure the validity of the AR experience recordings. Network communications in testing environments will also make it possible for test equipment vendors to provide 
connected instruments. Connected instruments and tools will send live readings that can then be visualized in context with AR displays.

Current systems vary in their ability to recognize and to track the target object without interruption. Without markers, there is frequent latency in recognition and tracking is not persistent in all lighting conditions. Tracking may be lost with rapid user movement. This renders augmentations prone to disappearing and "jumping” under some conditions. In the future, model-based tracking will provide high accuracy recognition and highly stable visualizations.

Current high-performance AR display systems consume the device battery power quickly and, as a result, the devices do not have a lifetime of more than a few hours under continuous use conditions. This issue is going to be addressed using new semiconductors and more efficient algorithms. In the future, system optimization will improve and power consumption will decline. All vendors seek to deliver mobile AR display systems for 8 hour shifts before needing to be recharged.

Many smart glasses systems proposed for industrial settings are heavy for users to wear. There are several alternatives to explore for hands-free AR: projection AR and tablet-based systems using a harness or bracket mount. There are also new helmets and 'headband' form factors that distribute weight more comfortably. In the future, it is expected that high performance wearable, smart glasses class of AR display systems will be smaller and lighter. 


\section{4}

\section{Technology Maturity Assessment}

\subsection{Technology Maturity of AR Components}

As part of this research, the maturity of many current AR-enabling technology components and AR solutions was assessed. Appendix D contains a broad maturity review performed at the time of the research, without taking into consideration any particular use case requirements.

\subsection{AR Technologies and their Readiness Levels}

The present section focuses only on those technology components necessary to meet requirements for use cases that survey participants indicated would have the greatestnearterm potential for impact in space product assurance and safety:

1. Delivering contextually sensitive instructions (procedural guidance)

2. Improving operator training

3. Providing configuration control instruction by recognizing hardware

4. Real-time recognition of configuration errors

The European Space Agency applies the ECSS Adoption Notice of ISO 16290 for the definition of Technology Readiness Level (TRL), which are represented in Table 5. This standard [34], which is publicly available, was used for the qualitative assessment of the technology maturity of AR-enabling components. 
Table 5 ESA Technology Readiness Levels

\begin{tabular}{ll}
\hline TRL\# & ISO 16290 Level Definition \\
\hline TRL 1 & Basic principles observed and reported \\
TRL 2 & Technology concept and/or application formulated \\
TRL 3 & Analytical and experimental critical function and/or characteristic \\
& proof-of-concept \\
TRL 4 & Component and/or breadboard functional verification in laboratory \\
TRL 5 & Component and/or breadboard critical function verification in \\
TRL 6 & relevant environment \\
& Model demonstrating the critical functions of the element in a \\
TRL 7 & Model demonstrating the element performance for the operational \\
& environment \\
TRL 8 & Actual system completed and accepted for flight ("flight \\
& qualified")
\end{tabular}

According to ESA guidelines and best engineering practices, the required technology maturity must achieve an acceptable balance between the investment required and the development risks. Therefore, it is important to concentrate the technology readiness demonstration of critical elements, where the performance cannot rely on proven technologies, either because the element is new, or because it is used in new environmental conditions. For example, it is not the same the use of an AR application on ground than on board the ISS, or even on the surface of the Moon; the environmental challenges are completely different.

As a general rule, we can consider that when TRL 5-6 is reached for a given element, its feasibility and overall performance are demonstrated. As we can see in the following paragraphs, this is the case for most of the elements considered critical to 
implement the use cases identified as part of this research. However, this is not sufficient for application in an industrial environment, which is considered suitable after TRL 8 is achieved; that is, once the element is accepted in an actual operational environment and no latent defects are present.

\subsubsection{Use Cases: delivering contextual sensitive instructions (procedural guidance) and operator training}

In the procedural guidance use case, information and instructions provided in context permit the operator to complete the procedures more quickly and with fewer or no errors. The use of AR for operator training also requires that the procedures have contextuallysensitive instructions. Therefore, in this requirements analysis, the additional components required for procedural guidance and training system uses are assessed together.

There are innumerable possible procedures involving space program target objects of many different sizes, shapes and materials. The target object could need to be reviewed or inspected under a wide range of settings. In order to formulate concrete requirements, the following is assumed:

a. Target object is too large to move (it is stationary, either mounted or resting on the ground) and the user cannot (does not need to) hold the object

b. The setting is well lit on all sides and indoors

c. The operator has and is trained in the use of all tools necessary to perform the procedure

d. The object is made of material that is non-reflective (not shiny, the more rough in texture the better) and non-deforming (does not change shape); it is though acknowledged that this may be challenging for space hardware since reflective surfaces are common due to use of metals and different surface treatments

e. There can be no markers or alterations to the object for purpose of using AR

f. There is a digital instruction set with a 3D model of the target

g. The procedure is non-destructive

h. There is network coverage and amplebandwidth if remoteassistanceand/or recording are necessary 
Table 6 TRL Assessment for ProceduralGuidance and Training

\begin{tabular}{|c|c|c|c|}
\hline & \multirow{2}{*}{ Component } & \multicolumn{2}{|c|}{ Procedural Guidance and Training } \\
\hline & & Requirement & TRL \\
\hline \multirow{5}{*}{ 总 } & $\begin{array}{l}\text { Sensors to Detect } \\
\text { Context and } \\
\text { Objects and } \\
\text { Human/computer } \\
\text { Interaction }\end{array}$ & $\begin{array}{l}\text { High maturity level for high } \\
\text { accuracy recognition and tracking } \\
\text { in range of environmental } \\
\text { conditions }\end{array}$ & $\begin{array}{l}6 \text { to } 7 \text {, depending on type of sensor } \\
\text { and environmental conditions. } \\
\text { For example, Microsoft HoloLens } \\
\text { has been demonstrated in ISS. }\end{array}$ \\
\hline & $\begin{array}{l}\text { Chips (to } \\
\text { Accelerate } \\
\text { Computationally } \\
\text { Complex } \\
\text { Processes) }\end{array}$ & $\begin{array}{l}\text { Real time computation for } \\
\text { recognition, tracking, registration, } \\
\text { rendering and fluid performance of } \\
\text { interaction libraries }\end{array}$ & $\begin{array}{l}\text { 7, for real time recognition and } \\
\text { tracking of simple, high texture } \\
\text { objects and 2D markers. } \\
5 \text { to 6, for 3D spatial mapping and } \\
\text { reconstruction. } \\
6 \text { to } 7 \text {, for graphic rendering at levels } \\
\text { of resolution appropriate for current } \\
\text { displays }\end{array}$ \\
\hline & $\begin{array}{l}\text { Optics and } \\
\text { Components }\end{array}$ & $\begin{array}{l}\text { Wide Field of View, lightweight } \\
\text { (under } 500 \text { gms) and low power } \\
\text { consumption for full day/shift usage }\end{array}$ & $\begin{array}{l}5 \text { to } 6 \text {, depending on the type of } \\
\text { training }\end{array}$ \\
\hline & Speakers & $\begin{array}{l}\text { High fidelity sound producing } \\
\text { systems produce realistic auditory } \\
\text { experiences }\end{array}$ & 7 \\
\hline & $\begin{array}{l}\text { Display System for } \\
\text { AR Presentation }\end{array}$ & $\begin{array}{l}\text { Projection AR systems that are } \\
\text { robust in appropriate (stationary) } \\
\text { conditions, tablets and wearable } \\
\text { systems with all required } \\
\text { components integrated }\end{array}$ & $\begin{array}{l}\text { Between } 6 \text { and } 7 \text { depending on the } \\
\text { type of training and the system } \\
\text { proposed }\end{array}$ \\
\hline \multirow{2}{*}{ 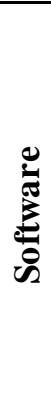 } & Object Recognition & $\begin{array}{l}\text { Works consistently without error } \\
\text { for common (previously recognized } \\
\text { and trained) targets in variable } \\
\text { conditions. }\end{array}$ & $\begin{array}{l}6 \text { or } 7 \text { depending on target object, } \\
\text { recognition technology and } \\
\text { environmental conditions }\end{array}$ \\
\hline & Object Tracking & $\begin{array}{l}\text { Works consistently without error } \\
\text { for any targets in variable } \\
\text { conditions }\end{array}$ & $\begin{array}{l}5 \text { to } 7 \text {, depending on target object, } \\
\text { tracking technology and } \\
\text { environmentalconditions }\end{array}$ \\
\hline
\end{tabular}




\begin{tabular}{|c|c|c|}
\hline \multirow{2}{*}{ Component } & \multicolumn{2}{|c|}{ Procedural Guidance and Training } \\
\hline & Requirement & TRL \\
\hline $\begin{array}{l}\text { Interaction } \\
\text { Libraries }\end{array}$ & $\begin{array}{l}\text { Touch for tablet, speech, hand } \\
\text { gesture, head-motion tracking for } \\
\text { wearable systems }\end{array}$ & $\begin{array}{l}8 \text { for touch, } 4 \text { to } 6 \text { for speech and } \\
\text { hand gestures, } 4 \text { and } 5 \text { for head- } \\
\text { motion tracking }\end{array}$ \\
\hline $\begin{array}{l}\text { AR Experience } \\
\text { Authoring Tools }\end{array}$ & $\begin{array}{l}\text { [for training] Low learning curve, } \\
\text { similar to or integrates directly in } \\
\text { existing and widely accepted } \\
\text { training material preparation } \\
\text { workflows }\end{array}$ & $\begin{array}{l}5 \text { to } 7 \text { depending on type of training } \\
\text { and complexity of tasks }\end{array}$ \\
\hline $\begin{array}{l}\text { Remote Assistance } \\
\text { Tools }\end{array}$ & $\begin{array}{l}\text { Intuitive to use and consistent } \\
\text { provided sufficient bandwidth and } \\
\text { network coverage. }\end{array}$ & 6 or 7 depending on the platform \\
\hline $\begin{array}{l}\text { AR } \quad \text { Experience } \\
\text { Capture Tools }\end{array}$ & $\begin{array}{l}\text { Capture via Remote Assistance } \\
\text { suffices }\end{array}$ & 4 or 5 \\
\hline $\begin{array}{l}\text { AR Experience } \\
\text { Management Tools }\end{array}$ & $\begin{array}{l}\text { Integrate with existing training } \\
\text { management systems }\end{array}$ & 5 or 6 \\
\hline
\end{tabular}

\subsubsection{Providing Configuration Control Instructions by Recognizing Hardware}

In this use case, the operator receives the correct test configuration and control instructions for each sample and does not run the risk of incorrectly configuring a test. The target object is a piece of test equipment that is used under a narrow range of conditions. In order to formulate concrete requirements, the following is assumed:

a. Test equipment is stationary and the user does not hold the test sample

b. The test equipment is operating in a consistently lit indoor environment

c. There can be markers attached to the test equipment for purpose of using AR

d. There is a network connection between the test planning suite and the AR display device

e. Field of View of 30 degrees is satisfactory 
Table 7 TRL Assessment for Configuration Control Instructions

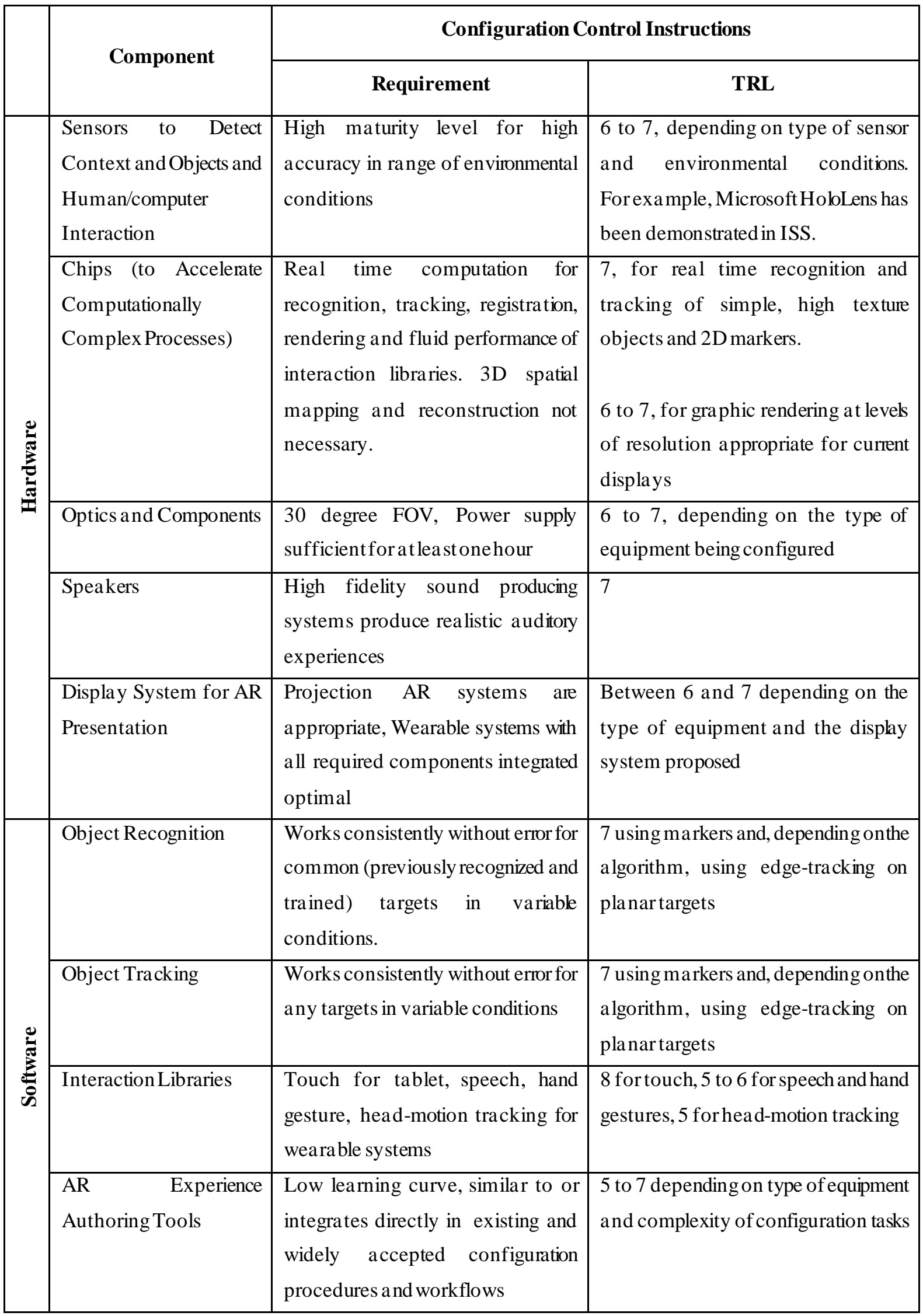




\begin{tabular}{|l|l|l|l|}
\hline \multirow{2}{*}{ Component } & \multicolumn{2}{c|}{ Configuration Control Instructions } \\
\cline { 2 - 4 } & \multicolumn{1}{|c|}{ Requirement } & \multicolumn{1}{c|}{ TRL } \\
\cline { 2 - 4 } $\begin{array}{l}\text { Remote Assistance } \\
\text { Tools }\end{array}$ & $\begin{array}{l}\text { Intuitive to use and consistent } \\
\text { provided sufficient bandwidth and } \\
\text { network coverage. }\end{array}$ & 6 or 7 depending on the platform \\
\cline { 2 - 4 } $\begin{array}{l}\text { AR Experience Capture } \\
\text { Tools Experience }\end{array}$ & Not required & N/A \\
\hline $\begin{array}{l}\text { AR required } \\
\text { ManagementTools }\end{array}$ & & N/A \\
\hline
\end{tabular}

\subsubsection{Real Time Recognition of Configuration Errors}

In this use case, the system is monitoring all test configuration and settings for each sample, confirms correct configuration settings, recognizes any configuration errors and alerts the user immediately. The target object is a piece of test equipment that is used under a narrow range of conditions. In order to formulate concrete requirements, the following is assumed:

a. Test equipment is stationary and the user does not hold the test sample

b. The test equipment is operating in a consistently lit indoor environment

c. There can be markers attached to the test equipment for purpose of using AR

d. There is a network connection between the test planning suite and the AR display device

e. Field of View of 30 degrees is satisfactory

Table 8 TRL Assessment for Recognition of Configuration Errors

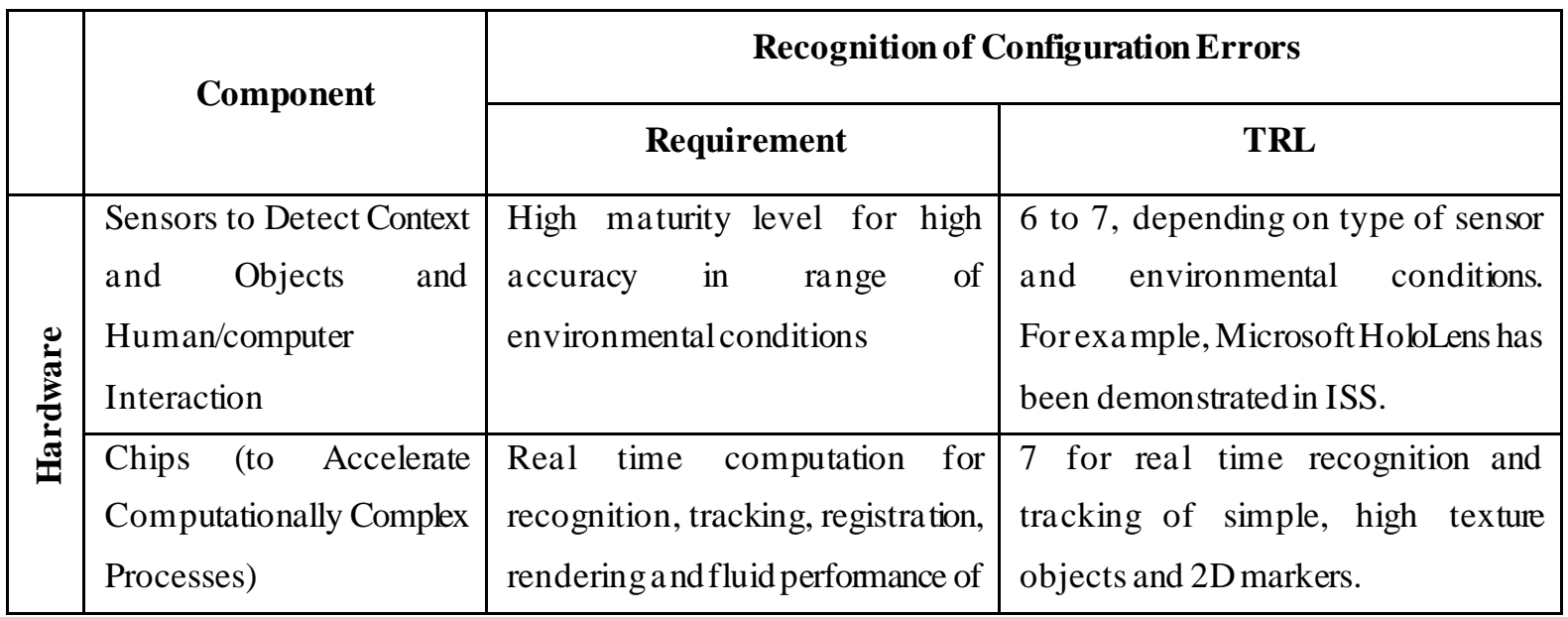




\begin{tabular}{|c|c|c|c|}
\hline & \multirow{2}{*}{ Component } & \multicolumn{2}{|c|}{ Recognition of Configuration Errors } \\
\hline & & Requirement & TRL \\
\hline & & $\begin{array}{l}\text { interaction libraries. 3D spatial } \\
\text { mapping and reconstruction not } \\
\text { necessary. }\end{array}$ & $\begin{array}{l}6 \text { or } 7 \text { for graphic rendering at levels } \\
\text { of resolution appropriate for current } \\
\text { displays }\end{array}$ \\
\hline & Optics and Components & $\begin{array}{l}30 \text { degree FOV, Power supply } \\
\text { sufficientforatleast onehour }\end{array}$ & $\begin{array}{l}6 \text { to } 7 \text {, depending on the type of } \\
\text { equipment being configured }\end{array}$ \\
\hline & Speakers & $\begin{array}{l}\text { High fidelity sound producing } \\
\text { systems produce realistic auditory } \\
\text { experiences }\end{array}$ & 7 \\
\hline & $\begin{array}{l}\text { Display System for AR } \\
\text { Presentation }\end{array}$ & $\begin{array}{l}\text { Projection AR systems are } \\
\text { appropriate, Wearable systems } \\
\text { with all required components } \\
\text { integrated optimal }\end{array}$ & $\begin{array}{l}\text { Between } 6 \text { and } 7 \text { depending on the } \\
\text { type of equipment and the display } \\
\text { system proposed }\end{array}$ \\
\hline \multirow{7}{*}{ के } & Object Recognition & $\begin{array}{l}\text { Once the target is detected, needs } \\
\text { to detect readings from network- } \\
\text { connected instruments }\end{array}$ & $\begin{array}{l}8 \text { using markers } \\
5 \text { to } 6 \text { for connected testing } \\
\text { instruments }\end{array}$ \\
\hline & Object Tra cking & $\begin{array}{l}\text { Works consistently without error } \\
\text { for any targets in variable } \\
\text { conditions }\end{array}$ & $\begin{array}{l}7 \text { using markers and, depending onthe } \\
\text { algorithm, using edge-tracking on } \\
\text { planar targets in consistently well-lit } \\
\text { environment }\end{array}$ \\
\hline & Interaction Libraries & $\begin{array}{l}\text { Touch for tablet, speech, hand } \\
\text { gesture }\end{array}$ & $\begin{array}{l}8 \text { for touch, } 5 \text { to } 6 \text { for speech and hand } \\
\text { gestures }\end{array}$ \\
\hline & $\begin{array}{l}\text { AR Experience Authoring } \\
\text { Tools }\end{array}$ & $\begin{array}{l}\text { Low learning curve, similar to or } \\
\text { integrates directly in existing test } \\
\text { equipment vendor's configuration } \\
\text { procedures and workflows system }\end{array}$ & $\begin{array}{l}5 \text { to } 7 \text { depending on type of equipment } \\
\text { and complexity of configuration tasks }\end{array}$ \\
\hline & Remote Assistance Tools & Not required & N/A \\
\hline & $\begin{array}{l}\text { AR Experience Capture } \\
\text { Tools }\end{array}$ & Not required & N/A \\
\hline & $\begin{array}{l}\text { AR } \quad \text { Experience } \\
\text { Management Tools }\end{array}$ & Not required & N/A \\
\hline
\end{tabular}




\subsection{Technology Challenges and Future Trends}

In most cases, AR is provided to end users on tablets and, in some industrial settings, using cameras integrated with light or laser projectors. In the future, hands-free displays will be commonplace and permit users to perform tasks with both their hands. At the time of preparation of this thesis, the networks of space product manufacturing and integration environments are able to stream video to a server in real time thanks to $5 \mathrm{G}$ and other high internet services, however few AR systems are implemented in the space sector. In the future, network communications will permit a more accurate capture, and secure systems will ensure the validity of the AR experience recordings.

Current systems vary in their ability to recognize and track the target object without interruption. At this stage of AR technology, simple feature descriptions are mainly used in camera real-time motion tracking [35]. However, without markers there is frequent latency in recognition and tracking is not persistent in all lighting conditions, particularly outdoors, and tracking may be lost with rapid user movement. This renders augmentations prone to disappearing and "jumping" under some conditions. In the future, model-based tracking will provide high accuracy recognition and highly stable visualizations.

Current high-performance AR display systems consume the device battery power quickly and, as a result, the devices do not have a lifetime of more than a few hours under continuous use conditions. This issue is going to be addressed using new semiconductors and more efficient algorithms. In the future, system optimization will improve and power consumption decline. All vendors seek to deliver mobile AR display systems for 8 hour shifts before needing to be recharged.

Many smart glasses systems proposed for industrial settings are heavy for users to wear. There are several alternatives to explore for hands-free AR: projection AR and tablet-based systems using a harness or bracket mount. There are also new helmets and 'headband' form factors that distribute weight more comfortably. In the future, the high performance wearable, smart glasses class of AR display systems will be smaller and lighter. 
UNIVERSITAT ROVIRA I VIRGILI

AUGMENTED REALITY FOR THE ENHANCEMENT OF SPACE PRODUCT ASSURANCE AND SAFETY

Raul Alarcon Ruiz 


\section{Technology Demonstration}

\subsection{Prototype Requirements}

A cost-efficient AR prototype demonstrator or breadboard was developed in association with The Open University (UK) to demonstrate the following scenarios as identified during the research phase:

1. Delivering contextual sensitive instructions (procedural guidance), which includes the case of operator training

2. Configuration control instructions through hardware recognition, including real time recognition of configuration errors

A user requirements document was issued, and a summary of specific breadboard requirements for the selected scenarios implemented are defined in the paragraphs below.

\subsubsection{Procedural guidance (operator training)}

In this case a context sensitive overlay of procedural instructions is available when a task is new, critical and complex, or occurs only very rarely. The same AR-assisted procedures can also be valuable to train an operator in a new procedure. 
Table 9. Specific requirements for the procedural guidanceuse case

\begin{tabular}{|c|c|c|}
\hline & Component & Requirement \\
\hline \multirow{5}{*}{ 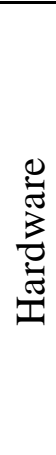 } & Sensors to detect context and objects & High maturity level \\
\hline & $\begin{array}{l}\text { Chips to accelerate Computer Vision (CV) } \\
\text { algorithms }\end{array}$ & Medium maturity level \\
\hline & Display for AR presentation & Mobile, Hands-free \\
\hline & Microphone & High fidelity, echo cancellation \\
\hline & Speakers & Consumer grade \\
\hline \multirow{4}{*}{ 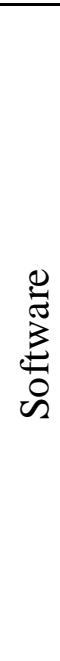 } & Object recognition & $\begin{array}{l}\text { High precision and accuracy, } \\
\text { highly varied light conditions, } \\
\text { speed is optional }\end{array}$ \\
\hline & Object tracking & $\begin{array}{l}\text { High precision and accuracy, } \\
\text { highly varied light conditions, } \\
\text { real time }\end{array}$ \\
\hline & AR Experience authoring tools & Stable, support for standards \\
\hline & AR Experience management tools & $\begin{array}{l}\text { Stable, integrated with existing } \\
\text { CMS and ERP }\end{array}$ \\
\hline \multirow{3}{*}{ 苞 } & 3D model as designed & Required \\
\hline & Digital instructions & Required \\
\hline & Interaction (User Interface) & $\begin{array}{l}\text { Speech, gesture, keyboard, } \\
\text { tactile }\end{array}$ \\
\hline
\end{tabular}




\subsubsection{Configuration control}

During quality inspection and testing, AR can guide QA engineers in validating whether hardware has been configured according to specification (i.e. also called configuration audit), helping to highlight in real time deviations from the hardware design (CAD files). The configuration control also includes a configuration fit-check of the components installed.

Table 10. Specific requirements for test configuration setting and management

\begin{tabular}{|c|c|c|}
\hline & Component & Requirement \\
\hline \multirow{5}{*}{ 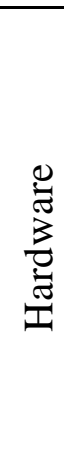 } & Sensors to detect context and objects & High maturity level \\
\hline & $\begin{array}{l}\text { Chips to accelerate Computer Vision (CV) } \\
\text { algorithms }\end{array}$ & Medium maturity level \\
\hline & Display for AR presentation & Mobile, Hands-free \\
\hline & Microphone & High fidelity, echo cancellation \\
\hline & Speakers & Consumer grade \\
\hline \multirow{4}{*}{ 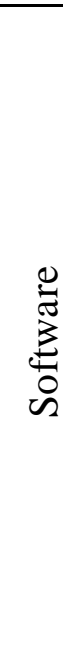 } & Object recognition & $\begin{array}{l}\text { High precision and accuracy, } \\
\text { highly varied light conditions, } \\
\text { speed is optional }\end{array}$ \\
\hline & Object tracking & $\begin{array}{l}\text { High precision and accuracy, } \\
\text { highly varied light conditions, } \\
\text { real time }\end{array}$ \\
\hline & AR Experience authoring tools & Stable, support for standards \\
\hline & AR Experience management tools & $\begin{array}{l}\text { Stable, integrated with existing } \\
\text { CMS and ERP }\end{array}$ \\
\hline \multirow{3}{*}{ 节 } & 3D model as designed & Required \\
\hline & Digital instructions & Required \\
\hline & Interaction (User Interface) & $\begin{array}{l}\text { Speech, gesture, keyboard, } \\
\text { tactile }\end{array}$ \\
\hline
\end{tabular}




\subsection{Hardware Platform}

The hardware platform is a collection of physical objects that is used during the validation of the breadboard model. This hardware simulator is required to reproduce a real-life small satellite on which users can perform task derived from the use cases.

The hardware platform emulates the basic configuration of a small satellite mock-up. The basic characteristics of the object are:

1. Large volume occupied (aprox $1.2 \mathrm{~m} \times 1.2 \mathrm{~m} \times 1.7 \mathrm{~m}$ )

2. Four surfaces (50x70 cm each) facing the viewer, each simulating a satellite side

3. Technical components on each surface face

The object needs to be large enough to simulate the movements that an operator would need to perform while operating on the satellite. Consequently, a cubical structure with four orthogonal faces was envisioned, each one equipped with technical components on the surface. These surfaces are mounted on a structure that holds all four surfaces, each presenting different configurations of physical components (see Figure 13). The hardware components are the objects that the AR application is able to identify and on which it provides guidance during the task.
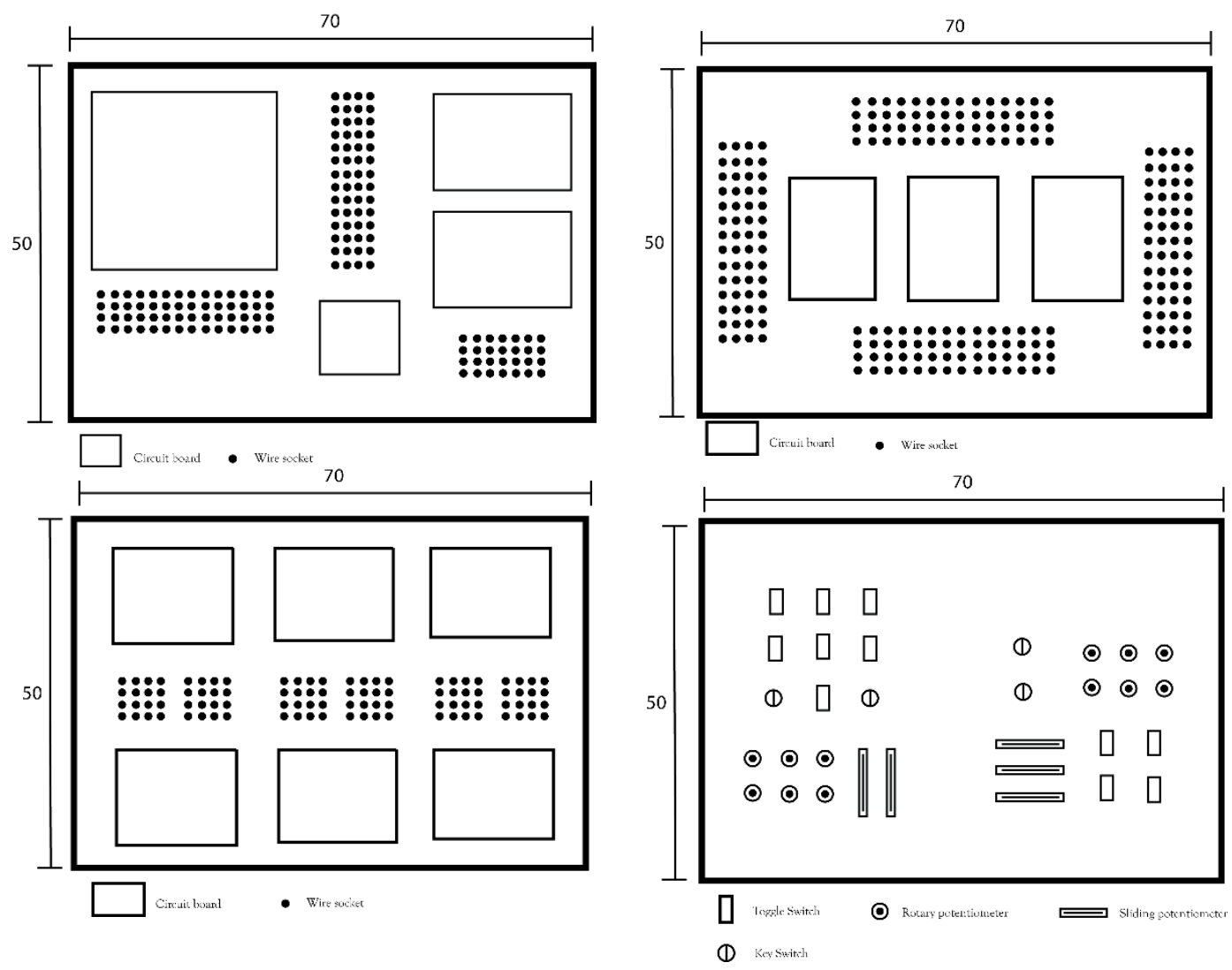

Figure 13 Physical layout of 4 panels emulating small sa tellite sides 
The hardware components displayed by the panels emulate the physical shape and interaction modality of components on which operators perform their tasks when working at these use cases on a satellite. The physical components identified are presented in Figure 14:

a. Circuit boards: flat rectangular electronic components that can be installed/uninstalled or swapped with other boards by unscrewing a few screws and pulling them out of the displaying panel. These components can be simulated by real - non-functioning circuits and boards or by similarly shaped pieces of plastic - see Figure 14 (a).

b. Wires: wire bundles can be easily recreated on an emulated machine by common electrical wiring - Figure 14(b). Bundled wires will be connected to connectors spread over the same panel or even from one panel to another. Wires are connected to socket connectors (like PCB connectors) to other connectors or to circuit boards.

c. Switches: electrical switches for turning on and off electrical components - Figure 14 (e).

d. Buttons: buttons are temporary switches that activate an electric/electronic function. Usually used in configuration panels, buttons can also be embedded inside circuitry for maintenance and repair of boards (during assembly and integration, not for use in orbit). Buttons can assume different shapes - Figure 14 (c).

e. Rotary / sliding potentiometers: physical components that can be manipulated by turning or sliding a knob. These components can also often be found in configuration panels, but in this scenario are meant to simulate the regulation of continuous variables like current, voltage, pressure, etc. - Figure 14 (d).

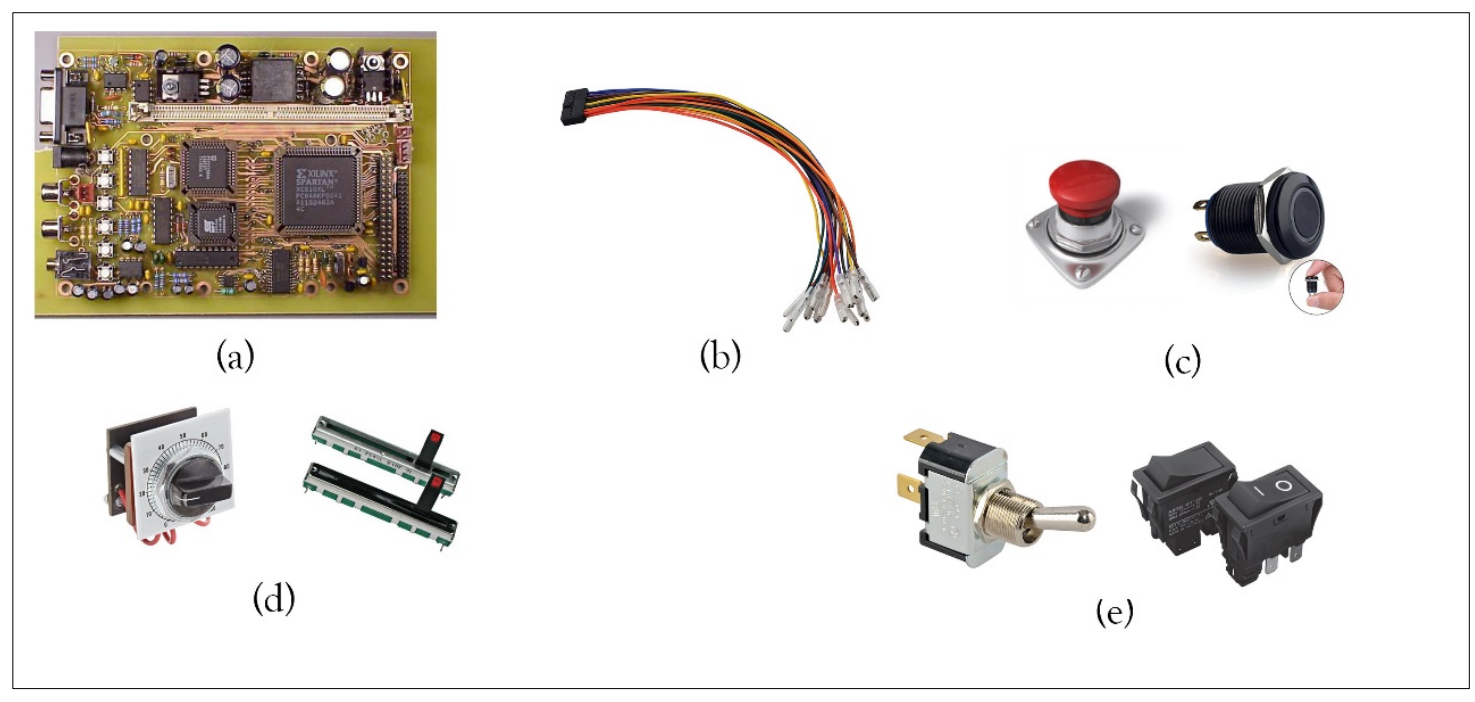

Figure 14 Physical inputs (hardware components) to be displayed on surfacing panels 
These hardware components are connected to a series of Arduino microcontrollers (see Figure 15), and their state is constantly updated on a central server through MQTT communication protocol. The microcontrollers sense every time interval (approx. 200 msec) the state of each physical input to which they are connected and stream the data to a Raspberry Pi via serial USB. A software client reads the data from the USB bus and posts the new data to the server thanks to the communication protocol. It is therefore possible to measure the state of the physical inputs in relation to the operation that are being carried out on the simulator. The data collected this way can be used both online by the AR prototype and offline for analysis purposes.

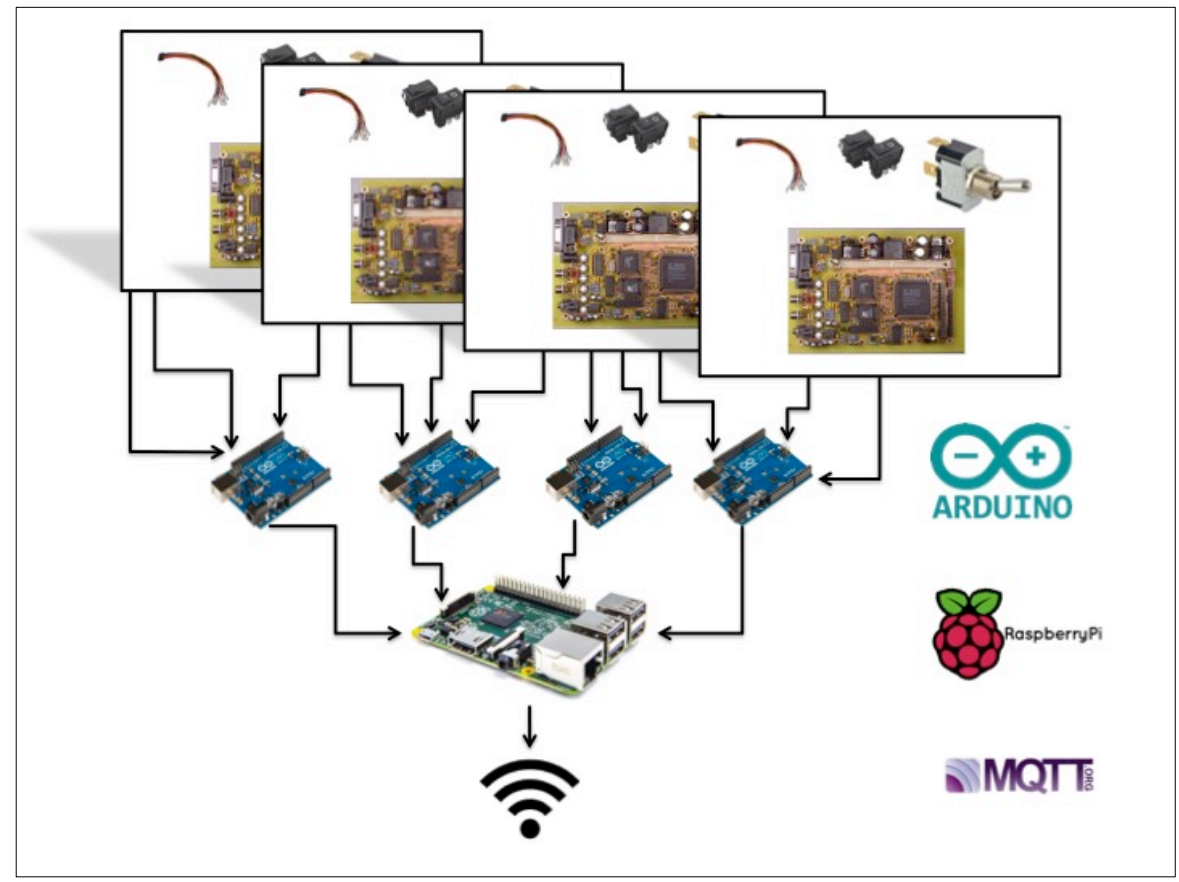

Figure 15 Physical architecture of the hardware platform

In the breadboard layout of Figure 16, the hardware platform uses a tripod with three bracket-mounted panels, simulating three of the four sides of a satellite. Several circuit boards are mounted with magnets onto the panels. As described, wire connections emulate the wire harness of a real satellite. 
UNIVERSITAT ROVIRA I VIRGILI

AUGMENTED REALITY FOR THE ENHANCEMENT OF SPACE PRODUCT ASSURANCE AND SAFETY

Raul Alarcon Ruiz

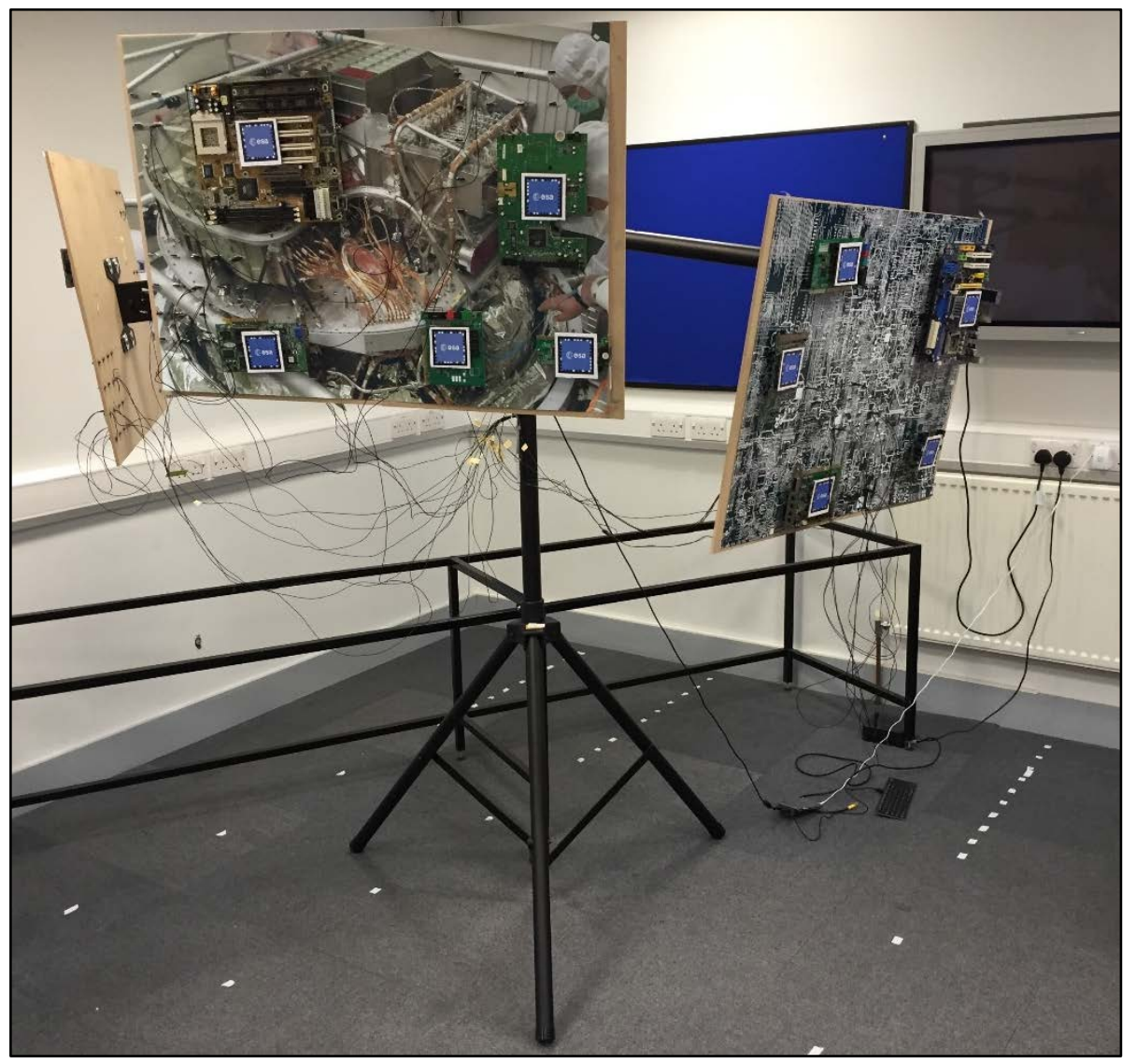

Figure 16 Hardware platform layout in ESTEC (lab environment) 


\subsection{Software Prototype}

The software prototype is a Unity3D application that can be deployed for tablets and smart glasses. The software aims at handheld systems (e.g. tablets) with the possibility to adapt it and deploy on smart glasses in future development.

The software prototype provides AR support for the use cases identified as candidates from the study. The user can choose between the two use cases at the beginning of the experience and the choice is not reversible unless quitting the application and restarting the experience.

\subsubsection{Procedural guidance}

The user points the device at the hardware platform (simulator) to identify the components in need of assistance; these will be signalled by the presence of red overlays, as shown in Figure 17. The user approaches one of the faulty components and visualizes a detailed view, which provides details of the fault. In this case there is a "Start Update Procedure" button that will start the procedure to update the configuration.

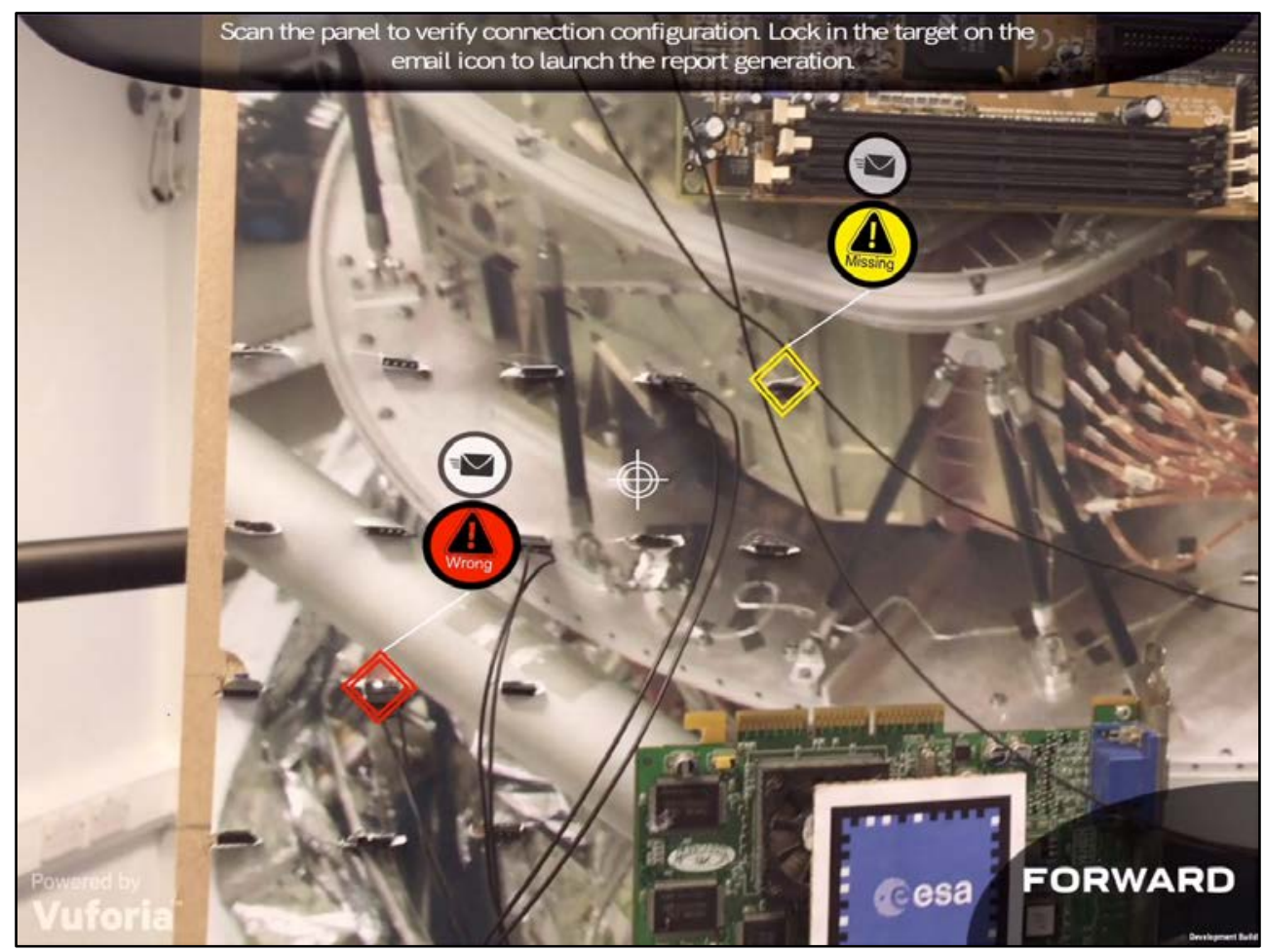

Figure 17 Detection of missing or wrong connection 
The application guides the user through text instructions, 2D and 3D animations overlaid on the object of interest. At each step the user will be shown an instruction on a particular step. When the step has been performed, the user presses the "Next" button on the interface to proceed with the following step. The tasks vary from replacing a board (see Figure 18 and Figure 19) to changing a wiring connection. The user will roam around the simulator until all the issues reported will be fixed.

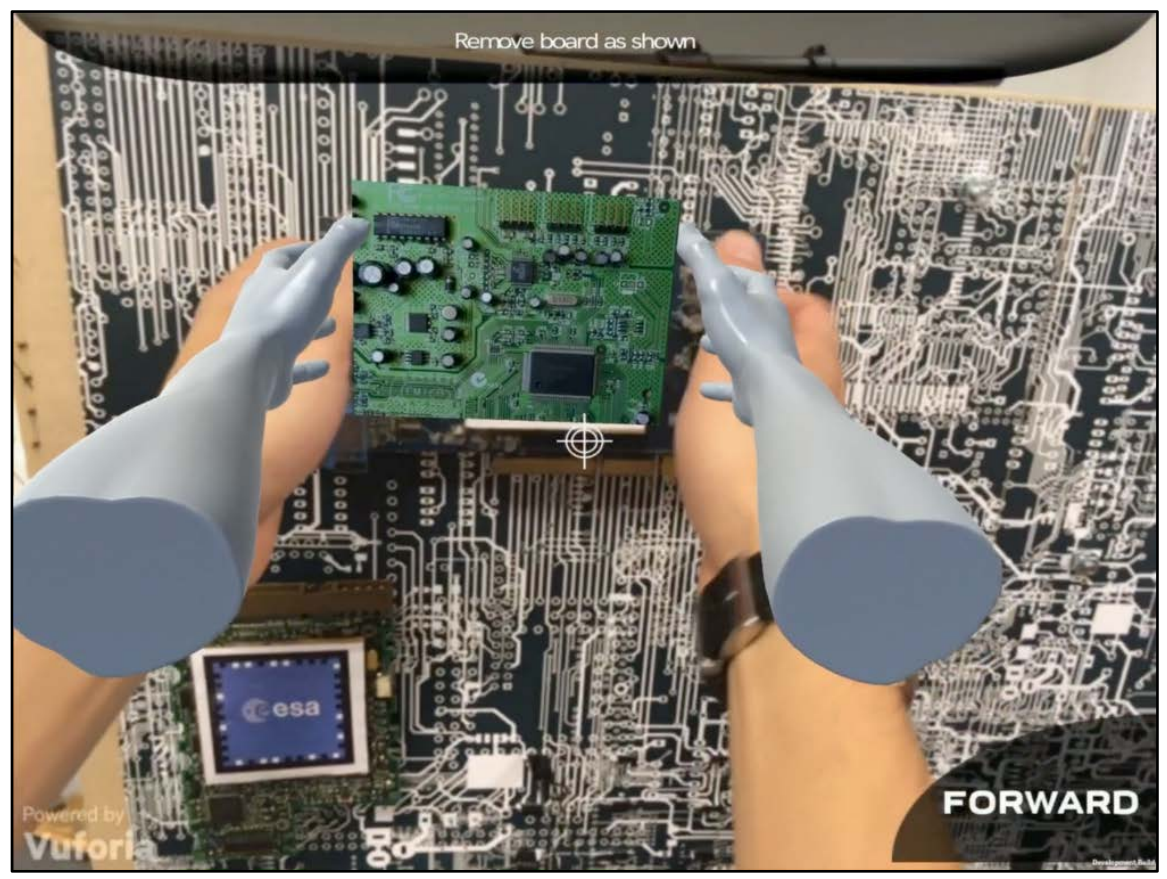

Figure 18 Repair instruction(removeboard)

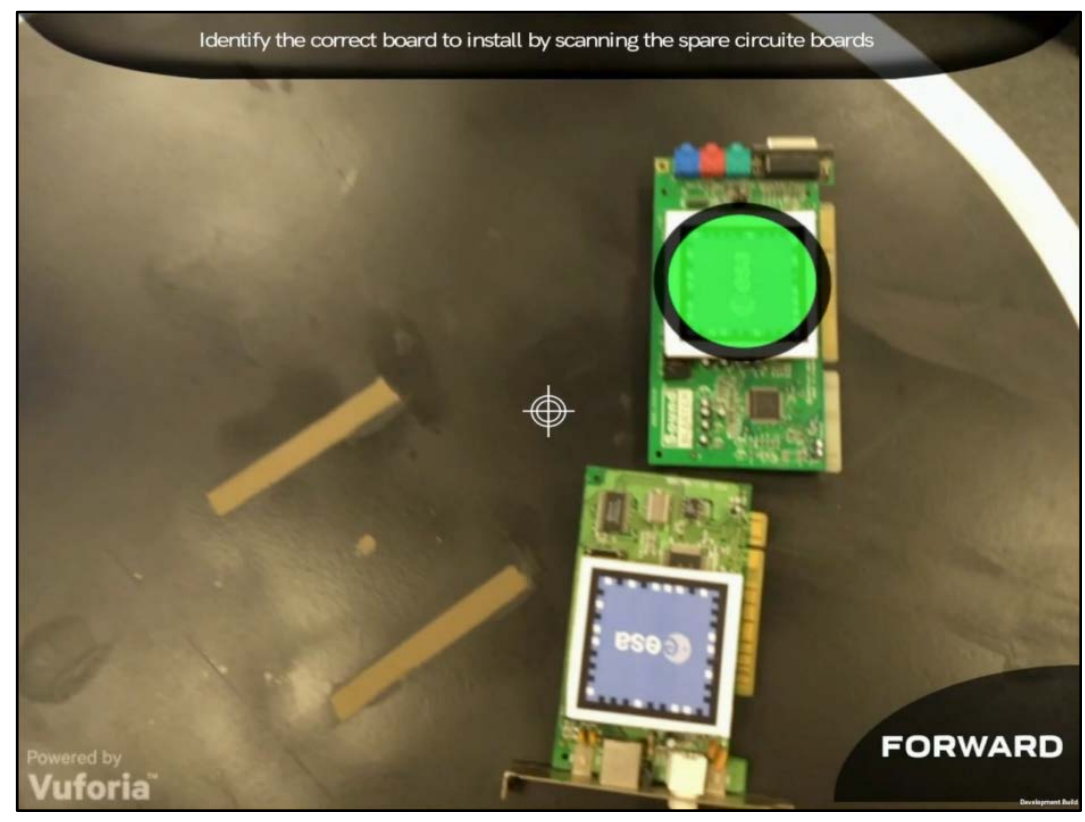

Figure 19 Identification of the correct replacement board 


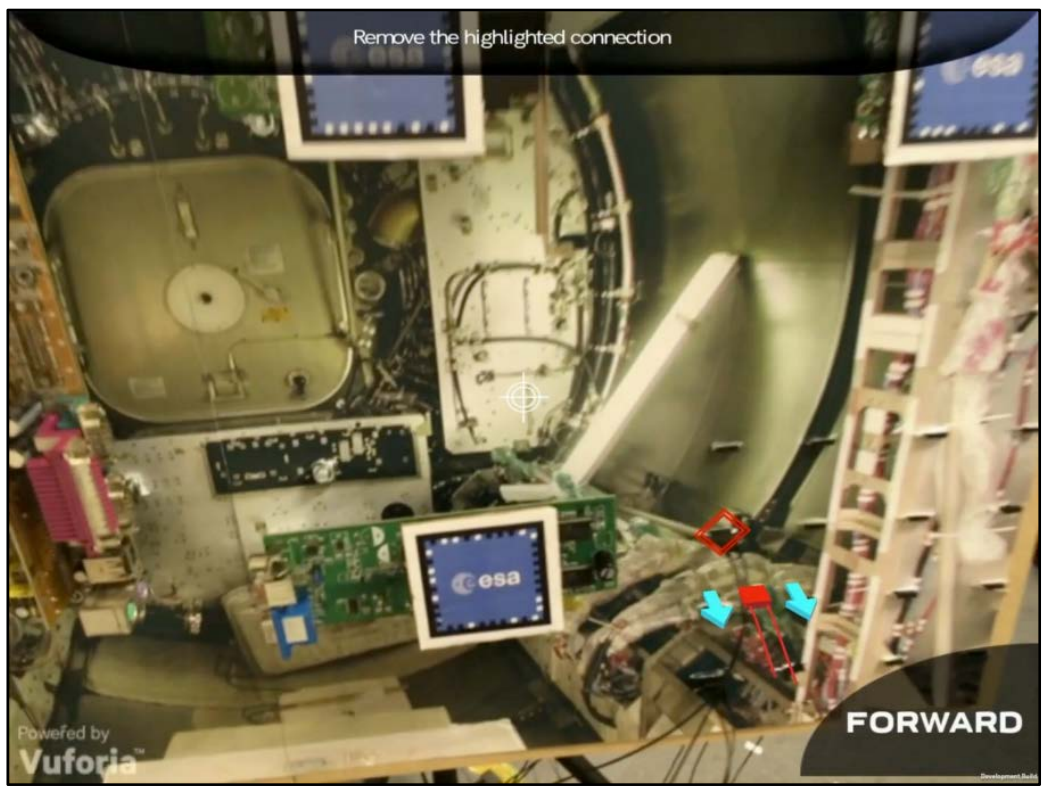

Figure 20 Remove wrongly connected cable

\subsubsection{Configuration control}

The user points the device at the hardware platform, expecting to have information about the machine. Firstly, the user stands about 1.5 to $2 \mathrm{~m}$ away from the simulator. This allows the device to frame a whole panel of the simulator.

\subsubsection{Phase 1: Configuration audit}

During the first phase of the task an overlay appears on the device providing information about the correct functioning and configuration of the physical components. During this phase, the circuit board checking, the visual overlays rendered by the application are simple graphical objects indicating through colour coding and/or large symbols, if the component follows specifications or not, as shown in Figure 21.

The application in this phase is able to detect if the wrong circuit board has been installed. Once a wrong configuration has been detected, the user walks closer to the component in need of attention. Pointing the device again towards the device, a more detailed view of the component is shown (see Figure 22). The view provides information about the component and the slot it is installed in, last time it was installed, checked and tested. On a side view, provides information about the fault and the correct configuration required. 
UNIVERSITAT ROVIRA I VIRGILI

AUGMENTED REALITY FOR THE ENHANCEMENT OF SPACE PRODUCT ASSURANCE AND SAFETY

Raul Alarcon Ruiz

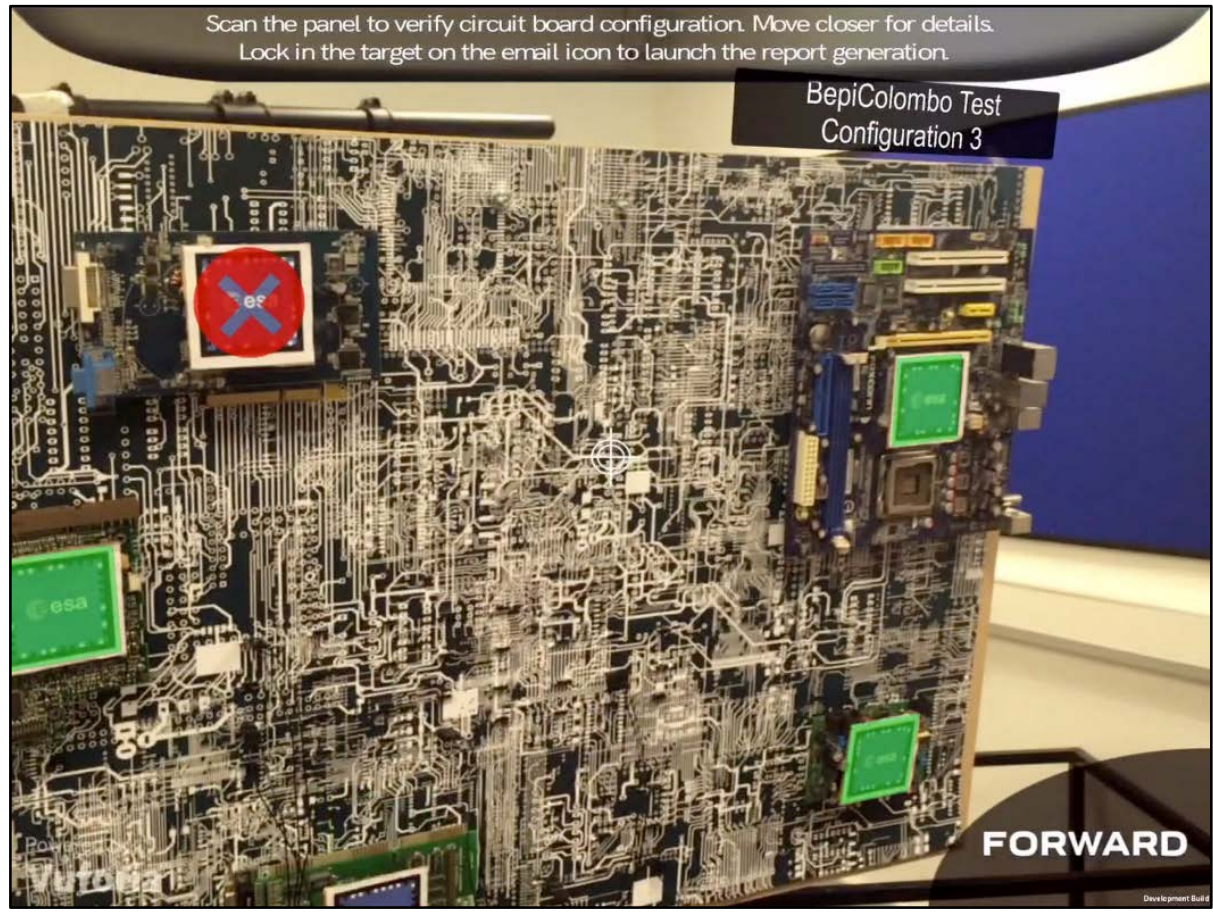

Figure 21 Highlight of correct and wrong components detected

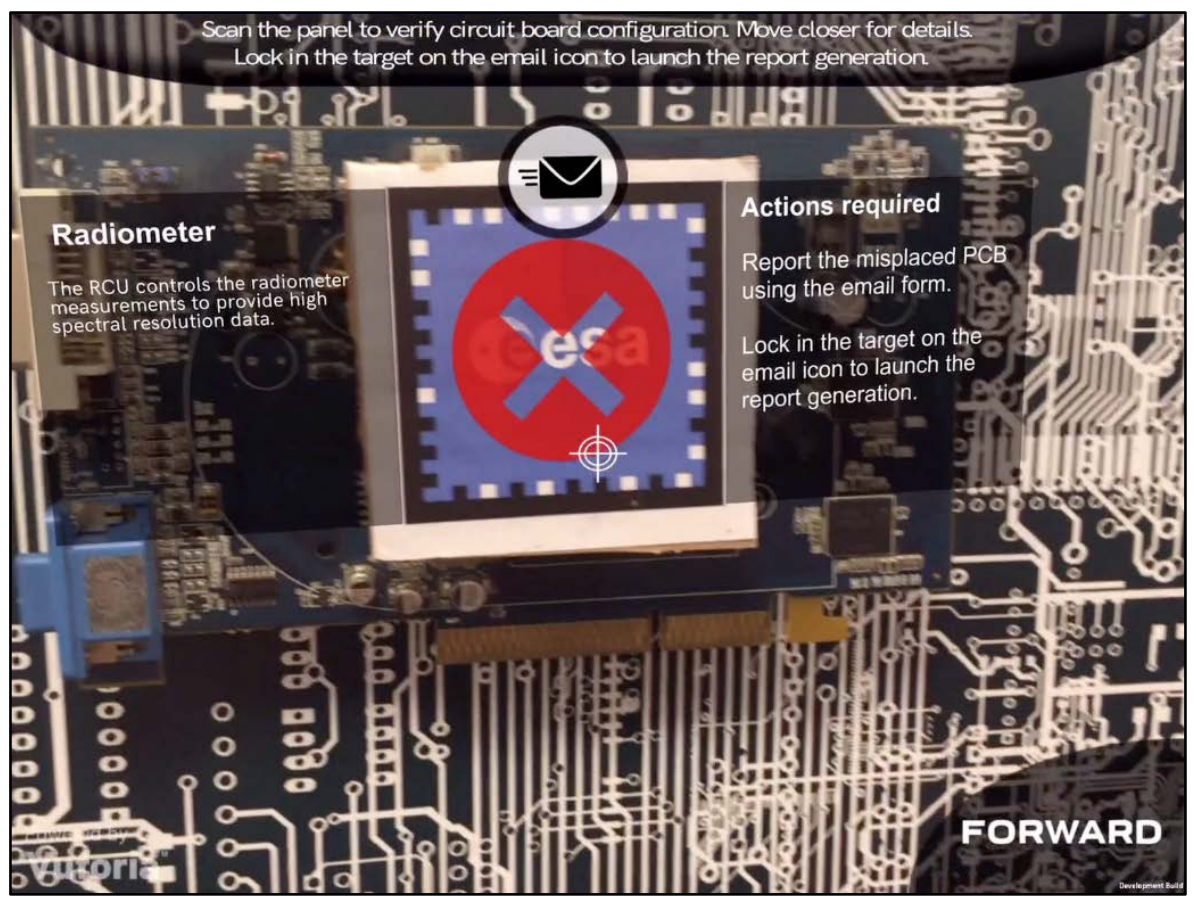

Figure 22 View of component details and actions required 
A virtual button under the overlays allows the user to send a report. A new view pops up on the device screen that allows the user to send the report via email to the authority in charge, including a photo of the fault with the overlays indicating the type of fault is attached to the email (see Figure 23). It is to be noted that, as the application is aware that the fault is a wrongly installed circuit board, the email should already be filled with information about the type of fault, the component installed and the code of the component needed The user is able to fill the email with more information if needed.

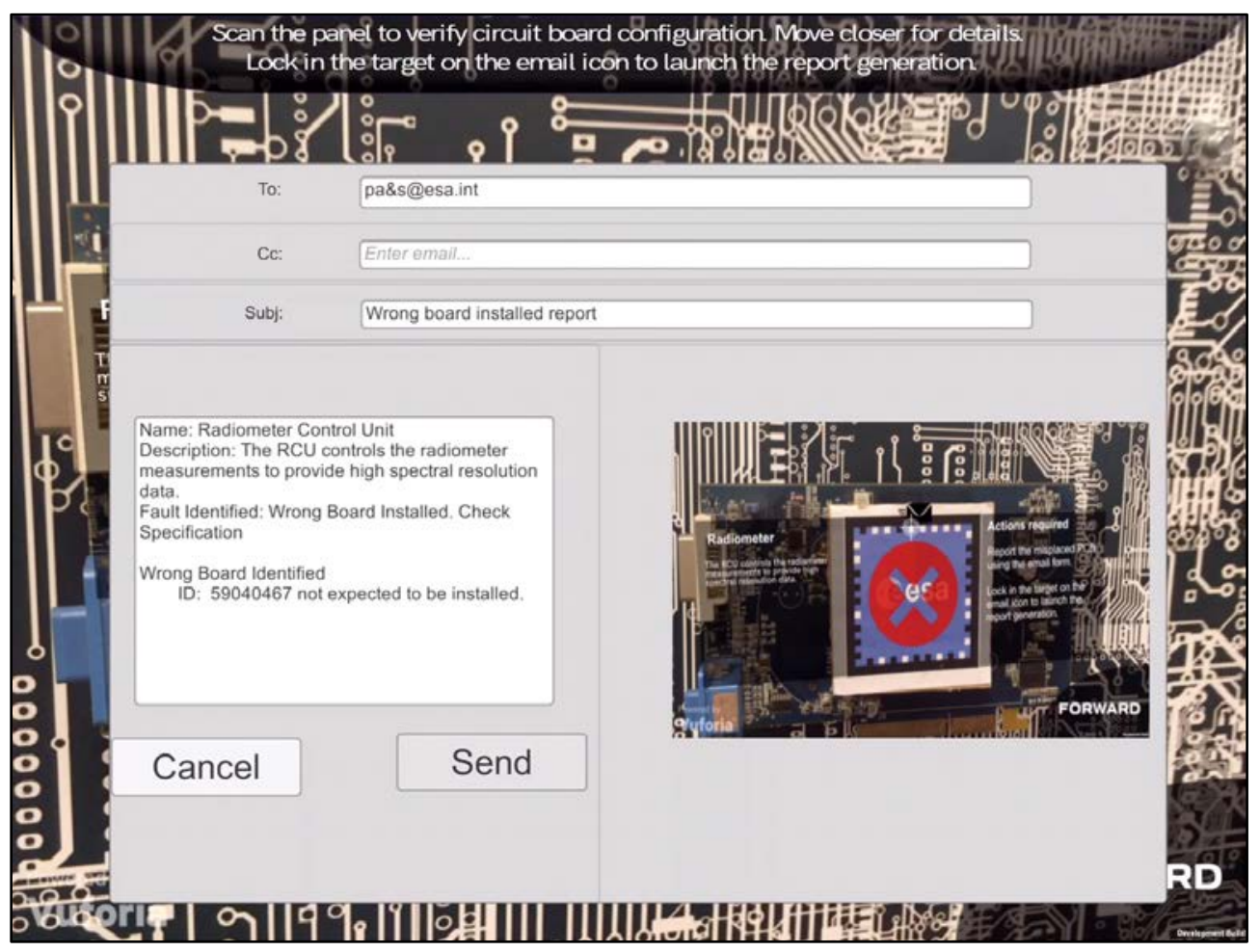

Figure 23 Example of report generation

The user is able to walk around the hardware platform, as shown in Figure 24, to have an overview of the whole environment in order to detect other misconfigurations. This first phase of the task ends when all boards wrongly installed have been detected and documented. 


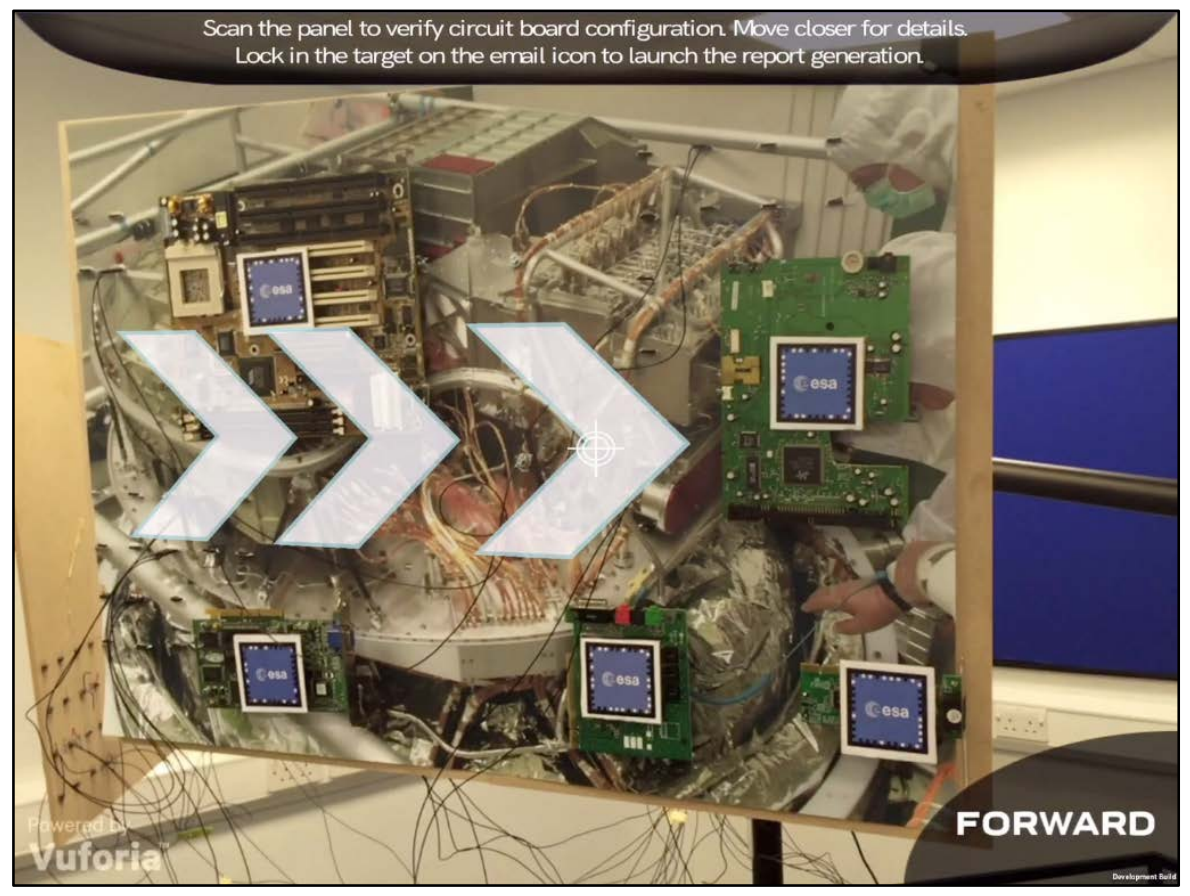

Figure 24 Na vigational information overlaid virtually on the actual hardware

\subsubsection{Phase 2: Configuration fit check}

The second phase of the task involves the electrical fit check (testing) of wiring connections and the correct functioning of the assembled circuits. In order to do this the user starts the procedure by approaching the configuration panel (guided by the AR application). A series of instructions guide the user through the procedure:

1. Pointing the device towards the simulator in order to identify the physical input to manipulate by means of an overlay

2. Performing the operation suggested (rotating a potentiometer, toggling a switch, etc.)

3. Pressing the "next" button

4. Repeating $1-3$ until the configuration procedure is complete.

After a fixed amount of time, the testing procedure time will be over and it will be possible to check the results. The application will simulate the wireless download of test results and will be able to display the faults identified.

As done in phase 1, the user roams around the hardware platform scanning for faults through the overview (see Figure 24) and then get closer to the faulty component in order to read details about the wrong connection and report about it (see Figure 23). Pressing the button "Send Report" activates an email form with the details about the misconfiguration already loaded, with an attached photo. 
Once all the faulty wiring connections have been documented, the user will start the third stage: functional testing. This is meant to test that all the internal component of the satellite are working as expected. The hardware platform provides a networked interface to access real-time readings from the sensors installed. The readings can be programmed to be directly connected to the physical inputs available on the four boards, or to be a function on combination of those variables. This is meant to simulate dependency of internal variables of the satellite on more than one configuration parameter.

At the beginning of this stage, the user configures the simulator for functional testing by means of a procedure similar to the one describe before. Once the equipment has been configured, the user starts the procedure. The application suggests that the procedure will remain active while the user monitors and detects faults around the simulator. The user is then suggested to roam around the simulator to visualize the internal real-time readings. The user visualizes a representation of the internal state of the components during the testing procedures and makes sure that everything works as expected. The data simulated in this case are, for each board: input current (IA), input voltage (IV), temperature (T), output current (OA), output voltage (OV).

The user points the device at each panel to visualize an overview of the data. The overview provides insight about the compliance of the values to the expected ones through color-coding: compliant values are in green, and not compliant are in red.

In order to report the non-compliant reports, the user approaches the faulty parts, visualizing a more detailed view. The detailed view contains: a description of the variable measured, numerical values updated in real-time, and a trend view of the variable during the testing procedure. A button "Send Report" will appear under the non-compliant variables, prompting to email the non-conformance. 


\subsection{Prototype Validation and Empirical Evaluation}

A set of experiment instructions were prepared to perform the validation of the proof of concept, and to serve as a guide for experimental demonstration (see Appendix E). Visual demonstration of the prototype in a laboratory environment is available in Appendix F.

An experiment was designed to evaluate human task performance (efficiency and effectiveness) and speed of knowledge transfer using representative control groups in three different phases:

1. Phase 1: using control group 1. These are potential users of the application (PA\&S engineers) non familiar with AR technology. Gather sample data and run experiment comparing a traditional method to perform a task against the performance of the task with AR support.

2. Phase 2: using control group 1 , repeat the experiment after a prototype update based on results from Phase 1.

3. Phase 3: use control group 2 to repeat the experiment using the updated prototype. This new control group shall be unbiased, i.e. non-familiar with the prototype or AR technology.

Limited research resources prevented running the above experiment and is identified as possible future research (see Chapter 6). 
UNIVERSITAT ROVIRA I VIRGILI

AUGMENTED REALITY FOR THE ENHANCEMENT OF SPACE PRODUCT ASSURANCE AND SAFETY

Raul Alarcon Ruiz 


\section{Conclusions}

\subsection{Contributions}

While AR is considered one of the key disruptive technologies in the mix catering for an Industry 4.0, it is by far not clear how AR can be best applied in space product assurance and safety to improve operational performance in real working environment. This research sought to close this gap by evaluating the readiness of the space domain, the technology, and to demonstrate the application of AR for PA\&S (initially, in a laboratory environment).

The results of the research presented in Chapter 3 reveal that professionals in the area of PA\&S have relatively low awareness of AR, but once exposed to the concept believe that it has potential to improve compliance and reduce errors. The research concludes that only a limited number of use cases are desirable and feasible for adoption by the PA\&S community, limited to delivering contextually sensitive instructions (procedural guidance), and configuration control (including real-time recognition of configuration errors).

In parallel with the survey of space industry professionals, the project also conducted detailed research into the requirements of the space industry use cases and the maturity of the technology components. This research reveals that the maturity of many components is insufficient for implementation of AR technology and systems in the space industry broadly. 


\subsection{Research Limitations}

One of the main limitations of the research conducted is that results are dependant of the immediate benefits perceived by the implementation of AR in the workplace, which are specific for the PA\&S community and cannot be easily extrapolated to other business units or industrial environments.

The research results may also depend on the working conditions at the time of the evaluation. For example, if the surveys were conducted during the SARS-CoV-2 (COVID-19) pandemic in the period of 2020-2021 probably more users would have considered remote $A R$ support (expert tele-tutoring) a more desirable use case. This simply stems out of the limitations for travel and the need to provide remote support to local workers.

The scope of the research did not differentiate between on ground and in-orbit product assurance and safety use cases, however the focus has been on the former since most of the professionals interviewed were mainly working on spacecraft manufacturing, assembly, integration and testing.

The author also believes that the research could have benefitted from the empirical evaluation of the AR prototype demonstration in a more realistic environment other than laboratory. To this end, an empirical experiment was foreseen (see Chapter 5), however research resources and author assignments prevented from moving this forward. Nevertheless, a laboratory environment is usually not representative enough, since it is not conditioned by the multiple constraints that industry faces and lacks the experience of real time operations. 


\subsection{Future Research}

This research provides a stepping stone to evaluate the operational performance as a result of AR implementation in a realistic working environment since the AR system design characteristics depends on the intended application and specific technology solutions chosen. For example, variables such as depth perception, calibration, ergonomic design, integration with an existing workflow, among others, depend on the particular use of the application. The research could intend to answer the following questions:

a. AR will improve the efficiency in the performance of an activity, when compared to a traditional media used in the real environment.

b. AR will improve the accuracy in the performance of an activity, when compared to a traditional media used in the real environment.

c. AR will improve the speed of transition from novice to experienced worker in the performance of a space PA\&S task, when compared to the traditional media used in the real environment.

Collaboration between research centres and industry will be key to success. As already mentioned, there is a strong correlation between the degree of success of AR applications and the industrial involvement, the user testing, and the scalability of the technology. If none of the three mentioned factors is sufficiently nurtured, experience shows that the AR application is doomed to fail.

This collaboration could be materialised through internship of a research student in an industrial organisation for a limited duration (1 to 2 years, for example). Any industrial organisation that intends to start or is currently developing an AR prototype for MAIT activities is an ideal candidate to initiate this cooperation.

The research did not foresee future extraterrestrial exploration use cases. On this regard, for example, AR-support for maintenance operations on Mars such as the one reported in Ravagnalo et al. [36] should help reduce the amount of preparatory training and mitigate the impact of inevitable communication delays with ground, thus making astronauts more autonomous. Moreover, the use of AR applied to future human extraterrestrial EVAs can also be applied to geological site inspections in support to sustainable lunar exploration [38]. In general, extraterrestrial exploration provides a broad range of future research and innovation activities in the field of AR. This will be particularly required in the frame of the NASA Artemis programme in collaboration with commercial and international partners. 


\subsection{Business Analysis}

Before AR in can be introduced in the field of space product assurance, the complete business case must be evaluated by stakeholders and, if supported, investments made. The business case for AR in space product assurance and safety must include at least estimates of:

a. Opportunities: Educated assumptions concerning use cases upon which the anticipated AR introduction benefits are based.

b. Key Performance Indicators: the metrics with which impact from the introduction of AR can be measured and an estimate of their change

c. Drivers: Justification of the operational impacts of AR introduction(derived directly from primary research).

d. Investments and Risks: Description and details of the investments required, possible barriers to be overcome and the possible risks of moving forward, but also the impact of not investing in the introduction of AR.

e. Return on Investment: an estimate of the time frame in which the benefits of investments proposed will exceed the investment.

\subsubsection{Opportunities}

There is no room for error and only very small margins for delays in space programs. For space industry professionals, there is and always will be the requirement for processes to be performed without error and on schedule or within short time windows. Added to these very rigid constraints is the fact that many different people employed by numerous product and service providers and suppliers are involved in complex space programs and projects. The suppliers must be able to certify compliance during and at the conclusion of any procedure. Under these conditions, everything possible must be done to reduce risk to materials, to people, to schedules and to sensitive and costly payloads.

Currently, space program and product testing, inspection and validation procedures are frequent and rigorous. However, there remain some project failures and delays. Some of these failures and delays are the direct result of lack of inspector or supplier experience or training, incorrect configurations or settings of test equipment and unrecognized errors in project assembly or during testing and inspection procedures. 
In the context of the space industry constraints and demands, there are very significant opportunities for technology-based solutions to lower risk of errors and delays. Augmented Reality could be added to the myriad of technological components currently in space program use for product assurance and safety. As presented below (Return on Investment), introducing solutions based on the existing Augmented Reality components in support of error risk reduction can be justified in a single project or mission.

The key to demonstrating the magnitude of the potential impact of Augmented Reality is to select the one or few use cases that are best suited to be met with the existing technology and least likely to encounter significant barriers. Focusing on those use cases will ensure that results of early investment in proof of concepts and pilots will address needs of users and stakeholders. The participation of leaders and promotion of results to all space industry stakeholders impacted by AR introduction are also critical components of the opportunity and must accompany any change management programs.

At this time, the greatest opportunity is with the use of AR for procedural guidance, operator training improvements, providing configuration control instructions by automatically recognizing equipment (and targets of testing), and real time detection of configuration errors.

This study also confirmed that there are dozens of other potentially valuable use cases. This strongly suggests that, once introduced for a few, specific use cases in space industry programs, the potential for expansion of AR as a daily tool for lowering space industry risk of error and delays is great.

\subsubsection{Key Performance Indicators}

The key performance indicators for Augmented Reality introduction in the use cases include:

a. Reduction of errors to zero

b. Reduction of delays due to quality assurance and safety inspection and testing measured in terms of hours, days or weeks

c. Increase of supplier and component compliance with space industry regulations, agency and project targets to $100 \%$, full compliance

d. Reduction of project or program failures due to errors or delays due inspection and non-compliance from current levels to zero 
Use of AR-assisted systems with current levels of maturity in any project or supplier could measurably improve these indicators within the first year of introduction in space prime and supplier workflows and procedures.

\subsubsection{Drivers}

The survey of space industry professionals revealed that the most important driver for AR introduction is the potential for the technology to reduce incidence of errors. Seventyseven percent of respondents chose this driver of Augmented Reality use. The second leading driver is the potential to increase compliance with industry regulation. Fifty-five percent of respondents feel that increased compliance is a metric that can benefit from use of AR. Other drivers considered but found less important include:

a. Reduced need for training on new tasks (32\%)

b. Increase integration of data between other systems already in use (29\%)

c. Approval of management and co-workers (25\%)

d. Increase in appeal of the space industry workplace to younger employees (25\%)

e. Confirmation of task completion (know immediately, when task/test is finished, 20\%)

It is noteworthy that the most popular use case emphasizes the use of AR to improve operator training. This leads to conclude that the respondents feel that insufficient or low quality training is an important reason for errors in product assurance and safety. It can be foreseen that when the operators are trained with AR-assisted systems as part of their preparation for performing their jobs, they will recommend that programs be modified to bring the same AR-assisted systems to the workplace. Further, if the operators are comfortableand confident that they will be able to resolve unexpected questions or reduce errors while performing tasks with AR assistance with less formal training, the period for training could be reduced, saving the space industry and suppliers significant resources to perform the same or higher level of service.

The mission of ESA PA\&S is to prevent, reduce or eliminate errors and risk in space programs. The introduction of AR-assisted systems in space industry program is fully in alignment with the agency's strategic business goals. This is another important driver for ESA to support the safe but prompt introduction of technologies. 


\subsubsection{Investments}

Introduction of new procedures and technologies and changes to existing protocols always require investment of time and resources. This section estimates the investment levels that AR projects may require.

There are no off-the-shelf AR-assisted systems ready for deployment in space industry programs, therefore purchase of "standard" components with fixed pricing cannot be the basis for estimating the necessary investments. Pricing is strictly on a "per project" basis. Software and hardware engineering fees are based on time and materials for designing and implementing custom projects.

Many pilot and proof of concept systems are using Android tablets or iPads. These cost per device is between 150 and 500 EUR, depending on the model. Wearable hardware for displaying AR is another option to be considered if the operator must have both hands free and a brace or bracket is not available or convenient. Wearable AR displays cost between 500 and 5 kEUR per device (and in some cases more). General purpose projection AR system pricing is not publicly available, however, is likely to be comparable to a high end wearable AR display ( $5 \mathrm{kEUR}$ ) before the cost of installation and calibration.

Prior to AR experience authoring, digital content must be created or, if available, then adapted for use in experiences. Both the content preparation and the authoring of AR experiences are manually intensive processes. Therefore, it is estimated that up to $70 \%$ of the total project cost may be due to content preparation and AR experience authoring services. Approximately $20 \%$ of the total project cost is for project design and management, including testing and end user training.

For example, typical AR projects in automotive and manufacturing industry vary from 15 to 20 kEUR for prototypes that demonstrate a use case on a standard tablet with one or a few target objects in specific configurations and using markers, to over half a million EUR for hardened and fully integrated solutions deployed to 100 or more operators on wearable displays.

Large-scale projects for developing entirely new custom products in industrial settings that span entire lines of equipment require tens of millions of EUR to be invested over several years. 
Like other technology investments, AR development and introduction involves a mixture of fixed and variable costs. Fixed costs include purchase of software licenses (for authoring experiences, device maintenance/management and other services) and hardware, such as displays and servers to run the authoring software. Variable costs include preparing content and authoring experiences, maintenance fees for devices and software, cloud-based content storage and additional bandwidth for delivery of assets to devices, if assets are not stored locally (on device).

Despite the uncertainty in the size of investment directly for AR components, it is clear that its introduction is closely tied to and leverages other ICT infrastructure investments. Services such as network coverage and bandwidth, data management and security systems must be adapted to include AR experience users and devices. These investments for other mission-critical ICT systems are justified on the basis of operational requirements. The use of these resources for delivering AR is an indirect benefit of those investments.

\subsubsection{Risks}

New technologies can introduce new and unexpected risks. This section identifies the risks of moving forward with AR-assisted systems at their current levels of maturity, and the risks of not investing at this time or in the future. There is a lack of quantitative data about the benefits or risks due to AR. It is not unusual for the champion or sponsor of a project to promise benefits to users or management that the technology is not able to fulfil due to unanticipated and untested conditions in production environments. This is a risk to professional credibility and may weaken the individual or team's ability to attract resources and staff in the future.

Another barrier to introduction of AR in the space industry includes the risk of operators and managers resisting the need to change their way of working to include new information access and display methods. Changing to procedures that take less time may raise concerns about technology replacing humans or reducing the need for operators, hence threatening employment. Change management programs can anticipate and mitigate this risk in some circumstances. Where the measurable benefits of AR include increased safety and lower risk, stakeholders are likely to embrace the new technology more quickly. 
Predictability is another important factor that will impact user acceptance. If the systems being introduced are highly robust and mature, they will deliver consistent results and operators will more easily increase in confidence. However, when the components are not mature, there can be frequent need for replacements, improvements and adjustments. Programs and policies that prevent immature technology introduction in production environments may become a required component in large and long-term AR introduction projects.

Possible reduction to safety of operators or equipment due to distraction or increased cognitive load is another potential barrier that has been raised but is difficult to assess and reliably factor into the risk landscape. Systems must not obscure the vision of the operator, produce excessive cognitive load or produce fatigue that could increase other risks due to inattention. Testing in production environments can help manage the risk of user interfaces being distracting. Studies to quantify the cognitive load and risks due to distraction are being conducted but it is too early to generalize about any findings that could apply to the space industry. Systems that turn off the AR experience when a person is walking or driving could be valuable to mitigate this risk.

In many industrial settings, such as for space assembly and integration activities, the systems must not have any cables to power sources or for off-board computing. Cables for wearable devices could too easily be caught on components on the outside of the payload or target object, either damaging the object or putting the user's safety at risk.

One risk that cannot be underestimated relates to personal data protection. In the EU and other countries this is well regulated, and labor unions' regulations may also have specific requirements on the use of the employee data.

Finally, there are no established guidelines or policies for assessing or mitigating project risks due to breaches in data or system security from intentionally malicious agents using AR software or hardware to enter a space industry program's information systems. While there are no known cases of such events, the risks are present at levels similar or equal to those with other new technology introduction programs. Compliance with standard industry security measures must be enforced with all AR projects [37]. While certifying device hardware and software for security may have an additional cost, the systems in place for management of security at the enterprise level are significantly larger and new AR device testing and evaluations would impose low additional pressure on existing resources. 
Risk management should also consider the consequences of not implementing ARassisted systems in a timely manner on the successful execution of space industry projects (i.e. cost of opportunity). When stakeholders become aware of the benefits of new technologies that are not implemented in their programs, they may perceive the lack of vision and commitment of leaders to improving operations. Every new error or incident that could have been avoided with the introduction of contextually relevant information could be considered as part of the risk of not advancing the introduction of AR.

\subsubsection{Return on Investment}

It is not possible, given the level of information available at the time of writing and considering the wide variety of use cases for AR, to provide an accurate estimate of the time frame in which the benefits of investments proposed to deploy and introduce AR will exceed the investments.

Based on the own experience of the author, failures during assembly and integration, including launch campaign testing, may cause a severe delay to the program and compromise other activities with negative effects for different stakeholders (e.g. other space agencies, industrial partners, funding member states, etc). Missing a launch window, or a delay of months due to equipment repair, for example, may incur costs of millions of EUR, besides the obvious potential impact on the image of governments and industry. 


\section{References}

[1] OECD, The Space Economy at a Glance 2011, OECD Publishing, 2011.

[2] P. Milgram, F. Kishino, A Taxonomy of Mixed Reality Visual Displays, IEICE Trans. on Information and Systems (Special Issue on Networked Reality), 1994, E77-D (12): 1321-1329.

[3] E. Ras, F. Wild, C. Stahl, A. Baudet, Bridging the Skills Gap of Workers in Industry 4.0 by Human Performance Augmentation Tools: Challenges and Roadmap, Proceedings of the 10th International Conference on Pervasive Technologies Related to Assistive Environments (PETRA '17), Greece, 2017, pp. 428-432. DOI: $10.1145 / 3056540.3076192$

[4] U. Neumann, A. Majoros, Cognitive, performance and systems issues for augmented reality applications in manufacturing and maintenance, IEEE Virtual Reality Annual International Symposium, Atlanta, Georgia, 1998, pp. 4-11.

[5] G. Reinhart, C. Patron, Integrating Augmented Reality in the Assembly Domain Fundamentals, Benefits and Applications, CIRP Annals - Manufacturing Technology, 2003, 52(1), 5-8.

[6] P. Georgel, Is there a reality in Industrial Augmented Reality? 10th IEEE International Symposium on Mixed and Augmented Reality, pp. 201-210, 2011.

[7] D. Willers, Augmented Reality at Airbus, International Symposium on Mixed \& Augmented Reality, 2006.

[8] J. Steven Newman, Failure-Space: A systems engineering look at 50 space system failures, Acta Astronautica, Volume 48, Issues 5-12, 2001, pp. 517-527. https://doi.org/10.1016/S0094-5765(01)00071-6

[9] R. Alarcon, F. Wild, C. Perey, M. Marin Genescà, J. Gavaldà Martínez, J. Xavier Ruiz Martí, M. José Simon Olmos, D. Dubert, Augmented Reality for the enhancement of space product assurance and safety, Acta Astronautica, Volume 
168, 2020, $\quad$ Pages 191-199, ISSN 0094-5765, https://doi.org/10.1016/j.actaastro.2019.10.020

[10] T.P. Caudell, D.W. Mizell, Augmented reality: an application of heads-up display technology to manual manufacturing processes, Proceedings of the 25th Hawaii International Conference on System Sciences, Kauai, Hawaii, 1992, pp. 659-669 vol.2.

[11] H. Lasi, P. Fettke, H-G. Kemper, T. Felt, M. Hoffmann, Application-Pull and Technology-Push as Driving Forces for the Fourth Industrial Revolution, Business and Information Systems Engineering 6(4), 2014, 6-239.

[12] R.T. Azuma, A Survey of Augmented Reality, Presence: Teleoperators and Virtual Environments, 6(4), 355-385, 1997.

[13] B. Reis, P. Borges, L. A. Vasconcelos, J. M. Teixeira, V. Teichrieb, J. Kelner, MarkerMatch: an Embedded Augmented Reality case study, XII Symposium on Virtual and Augmented Reality, Recife, 2010

[14] L. Naimark, L. and E. Foxlin, Circular data matrix fiducial system and robust image processing for a wearable vision-inertial self-tracker, Proceedings of the 1st International Symposium on Mixed and Augmented Reality, page 27. IEEE Computer Society, 2002.

[15] J. Steinbis, W. Hoff, T.L. Vincent, 3D Fiducials for Scalable AR Visual Tracking, 7th IEEE/ACM International Symposium on Mixed and Augmented Reality, 183 184,2008

[16] L. Vacchetti, V. Lepetit, F. Fua, Stable Real-Time 3D Tracking Using Online and Offline Information. IEEE Trans. Pattern Anal. Mach. Intell. 26(10), 1385-1391 (2004)

[17] O. Inbar, Smart Glasses Market 2015: towards 1 billion shipments, published by AugmentedReality.org for Augmented World Expo, 28/05/2015, https://www.slideshare.net/comogard/smart-glasses-2015-for-distribution (accessed 25 February 2021) 
[18] R. Steffan, U. Schull, T. Kuhlen, Integration of Virtual Reality based Assembly Simulation into CAD/CAM environments. Proceedings of the 24th Annual Conference of the IEEE, 1998, Vol. 4, pp. 2535-2537.

[19] S. Takata, H. Isobe, H. Fujii, Disassembly Operation Support System with Motion Monitoring of a Human Operator, Annals of CIRP, 50(1), 2001, 305-308.

[20] S. J. Henderson, S. K. Feiner, Augmented reality in the psychomotor phase of a procedural task, 10th IEEE International Symposium on Mixed and Augmented Reality, Basel, Switzerland, 2011, pp. 191-200.

[21] T. Richardson, S.B. Gilbert, J. Holub, F. Thompson, A. MacAllister, Fusing SelfReported and Sensor Data from Mixed-Reality Training, The Interservice/Industry Training, Simulation and Education Conference(I/ITSEC), Orlando, Florida, 2014, Paper No. 14158.

[22] F. Wild, C. Perey, K. Helin, P. Davies, P. Ryan, Advanced Manufacturing with Augmented Reality, Proceedings of 1st AMAR Workshop, Munich, Germany, 2014.

[23] K. Helin, T. Kuula, C. Vizzi, J. Karjalainen, A. Vovk, User Experience of Augmented Reality System for Astronaut's Manual Work Support, Front. Robot. AI, 2018. https://doi.org/10.3389/frobt.2018.00106.

[24] W. Guest, F. Wild, A. Vovk, P. Lefrere, R.. Klemke, M. Fominykh, T. Kuula, A Technology Acceptance Model for Augmented Reality and Wearable Technologies, J. Univers. Comput. Sci. 24, 2018, 192-219.

[25] J. Serván, F. Mas, J.L. Menéndez, J. Ríos, Using Augmented Reality in AIRBUS A400M shop floor assembly work instructions, 4th Manufacturing Eng. Society International Conference, Cádiz, Spain, 2011, pp 633-640, vol. 1431.

[26] H. Xue, P. Sharma , F. Wild. User Satisfaction in Augmented Reality-Based Training Using Microsoft HoloLens. Computers 2019, 8(1), 9; 25 January 2019. doi.org/10.3390/computers801000 
[27] Jet Propulsion Laboratory, NASA, Microsoft Collaborate to Bring Science Fiction to Science Fact, 25 June 2015, https://www.jpl.nasa.gov/news/news.php?feature=4642 (accessed 24 May 2019)

[28] Jet Propulsion Laboratory, NASA, Microsoft Collaborate to Bring Science Fiction to Science $\quad$ Fact, 25 June https://www.jpl.nasa.gov/news/news.php?feature=4642 (accessed 31 October 2016)

[29] K. Chintamani, B.V. Lierde, S. Maloney, P. Kiernan, D. Martinez Oliveira, M. Wolf, Wearable crew support technology on the International Space Station: the mobile Procedure Viewer (mobiPV), Proceedings of the 58th Annual meeting Human Factors and Ergonomics Society, Lisbon, Portugal, 2014, pp. 279-290.

[30] VTT, Augmented reality increases maintenance reliability at a space station, 27/04/2017, https://www.vttresearch.com/media/news/augmented-realityincreases-maintenance-reliability-at-a-space-station (accessed 24 May 2019)

[31] R. Peleg-Adler, J. Lanir, M. Korman, The effects of aging on the use of handheld augmented reality in a route planning task, Computers in Human Behavior, 81 (2018) 52-62.https://doi.org/10.1016/j.chb.2017.12.003

[32] J. Xua, S. Anders, A. Pruttianan, D. France, N. Lau, J. A. Adams, M. B. Weinger, Human performance measures for the evaluation of process control human system interfaces in high-fidelity simulations, Applied Ergonomics, Volume73, November 2018, pp. 151-165. https://doi.org/10.1016/j.apergo.2018.06.008

[33] D. Cashen, E. Robb, Augmented Reality Human-Machine Interface: Defining Future AR System Technology, SID Symposium Digest of Technical Papers, 2015, pp. 23-28.

[34] Adoption Notice of ISO 16290, Space systems - Definition of the Technology Readiness Levels (TRLs) and their criteria for assessment, ECSS-E-AS-11C, $01 / 10 / 2014$ 
[35] W. Sun, C. Mo, High-speed real-time augmented reality tracking algorithm model of camera based on mixed feature points, Journal of Real-Time Image Processing (2020). https://doi.org/10.1007/s11554-020-01032-4

[36] L. Ravagnolo, T. Kuula, A. Vovk, F. Wild, W. Guest, B. Limbu, R. Klemke, M. Ransley, J. Razool, C. Smith, M. Fominykh, Evaluation Process and Results for Space case, Deliverable D6.12, WEKIT Project (2019), http://wekit.eu/wpcontent/uploads/2019/04/WEKIT_D6.12.pdf

[37] D. McSporran, Augmented-reality technologies are here: Defense organizations must acknowledge the security concerns, 20/11/2019, https://militaryembedded.com/cyber/cybersecurity/augmented-realitytechnologies-are-here-defense-organizations-must-acknowledge-the-securityconcerns (accessed 25 February 2021)

[38] F. Rometsch, Design of an AR-IoT Toolf or Future Human Space Exploration (MSc Thesis), TU Delft, July 2020 
UNIVERSITAT ROVIRA I VIRGILI

AUGMENTED REALITY FOR THE ENHANCEMENT OF SPACE PRODUCT ASSURANCE AND SAFETY

Raul Alarcon Ruiz 


\section{Appendix A Introduction to AR and Use Cases for Product Assurance and Safety}

\section{Description}

An introductory video to Augmented Reality (AR) and potential use cases of AR applied to space product assurance and safety is complementary to the research. It was displayed prior to the online survey. The aim is to ensure input gathered by survey participants in the study would be invariant of the different level of exposure to and previous experience of AR. It also provides examples of industrial applications of AR.

\section{Filename:}

Introduction to AR for PA.mp4

\section{Link:}

https://www.dropbox.com/sh/4yv5f5f61kpe1et/AAAw_dIRgXgQkb0LborbGHtga?dl=0 
UNIVERSITAT ROVIRA I VIRGILI

AUGMENTED REALITY FOR THE ENHANCEMENT OF SPACE PRODUCT ASSURANCE AND SAFETY

Raul Alarcon Ruiz 


\section{Appendix B Online Survey Questionnaire}

1. Rate the desirability and likelihood of the following statements for PA\&S for Space:

a. Augmented Reality displays the context sensitive instructions about procedures.

Level of Desirability

1 - Very undesirable

2 - Undesirable

3 - neutral

4 - Desirable

5 - Very desirable

PA\&S for Space will introduce this in the next 3 to 5 years.

Level of Probability

1 - Not probable

2 - Somewhat improbable

3 - Neutral

4 - Somewhat probable

5 - Very probable

b. Augmented Reality supports live documentation of last minute procedural changes (red line recorded procedures)

1 - Very undesirable

2 - Undesirable

3 - neutral

4 - Desirable

5 - Very desirable

PA\&S for Space will introduce this in the next 3 to 5 years.

Level of Probability

1 - Not probable

2 - Somewhat improbable

3 - Neutral

4 - Somewhat probable 
5 - Very probable

c. Augmented Reality system provides hands-free, speech-based note taking.

1 - Very undesirable

2 - Undesirable

3 - neutral

4 - Desirable

5 - Very desirable

PA\&S for Space will introduce this in the next 3 to 5 years.

Level of Probability

1 - Not probable

2 - Somewhat improbable

3 - Neutral

4 - Somewhat probable

5 - Very probable

d. Augmented Reality system provides live non-conformance report (NCR) creation with support for voice and visual recording.

1 - Very undesirable

2 - Undesirable

3 - neutral

4 - Desirable

5 - Very desirable

PA\&S for Space will introduce this in the next 3 to 5 years.

Level of Probability

1 - Not probable

2 - Somewhat improbable

3 - Neutral

4 - Somewhat probable

5 - Very probable

e. Augmented Reality system provides configuration control instruction by recognizing hardware.

1 - Very undesirable

2 - Undesirable 
3 - neutral

4 - Desirable

5 - Very desirable

PA\&S for Space will introduce this in the next 3 to 5 years.

Level of Probability

1 - Not probable

2 - Somewhat improbable

3 - Neutral

4 - Somewhat probable

5 - Very probable

f. Augmented Reality system provides virtual interactive panels on real hardware.

1 - Very undesirable

2 - Undesirable

3 - neutral

4 - Desirable

5 - Very desirable

PA\&S for Space will introduce this in the next 3 to 5 years.

Level of Probability

1 - Not probable

2 - Somewhat improbable

3 - Neutral

4 - Somewhat probable

5 - Very probable

g. Augmented Reality system provides real-time recognition of configuration errors.

1 - Very undesirable

2 - Undesirable

3 - neutral

4 - Desirable

5 - Very desirable

PA\&S for Space will introduce this in the next 3 to 5 years.

Level of Probability 
1 - Not probable

2 - Somewhat improbable

3 - Neutral

4 - Somewhat probable

5 - Very probable

h. Augmented Reality system provides real time display of test data overlaid on test item.

1 - Very undesirable

2 - Undesirable

3 - neutral

4 - Desirable

5 - Very desirable

PA\&S for Space will introduce this in the next 3 to 5 years.

Level of Probability

1 - Not probable

2 - Somewhat improbable

3 - Neutral

4 - Somewhat probable

5 - Very probable

i. Augmented Reality system provides desk PA support to field PA through realtime exchange of media and data.

1 - Very undesirable

2 - Undesirable

3 - neutral

4 - Desirable

5 - Very desirable

PA\&S for Space will introduce this in the next 3 to 5 years.

Level of Probability

1 - Not probable

2 - Somewhat improbable

3 - Neutral

4 - Somewhat probable

5 - Very probable 
2. Are there other use cases that you think would be valuable but were not illustrated in the short animated video? Please describe in short sentences with key words [text field]

3. Drivers to adoption: What do you think would justify the investment necessary to put in place Augmented Reality systems like those illustrated for PA\&S?

Check all that apply:

Accelerate introduction of electronic work instructions

Lower cost of performing the tasks

Faster task completion

Lower need for training on new tasks

Immediately know when the task (test) is finished

Increase compliance

Reduce error

Increase precision

Integrated with other systems already in use

Approval of management and co-workers

Increase appeal of our workplace to younger employees

Other [provide explanation]

4. Barriers to adoption: What would prevent you or your industry from using Mediated Reality in your workplace or procedures?

Check all that apply:

Can't hold the tablet while performing tasks (I need to use hands)

Learning curve is too high compared with the value it would offer

High cost of customization of systems

Lack of standard, off-the-shelf solutions

Negative past experiences with similar technologies

Lack of experience with similar technologies

Lack of IT support for this technology

Insufficient precision and/or resolution of the technology

Not integrated with other systems already in use

It's not currently provided by the manufacturer of equipment

Devices and software not certified or compliant with workplace policy or regulation

Other [provide explanation] 
4. Which delivery platform do you think would be best to use for initial introduction in your workplace?

a. Tablet

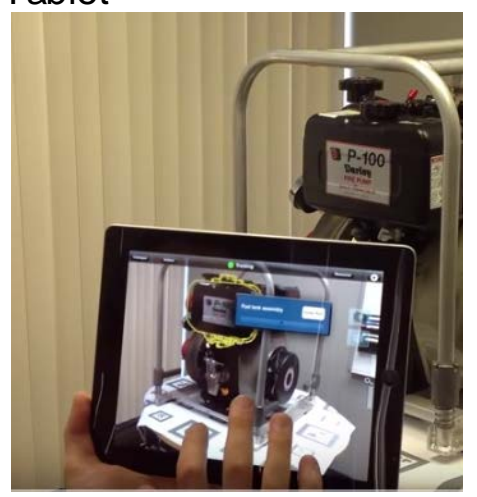

Source: NGRAIN http://www.ngrain.com

b. Projection AR (stationary)

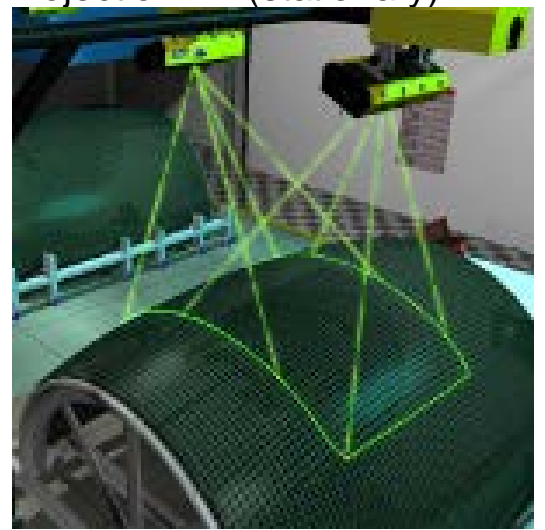

source: Advanced Aerospace Assembly http://a3l.uk.com/

c. Hands-free personal displays

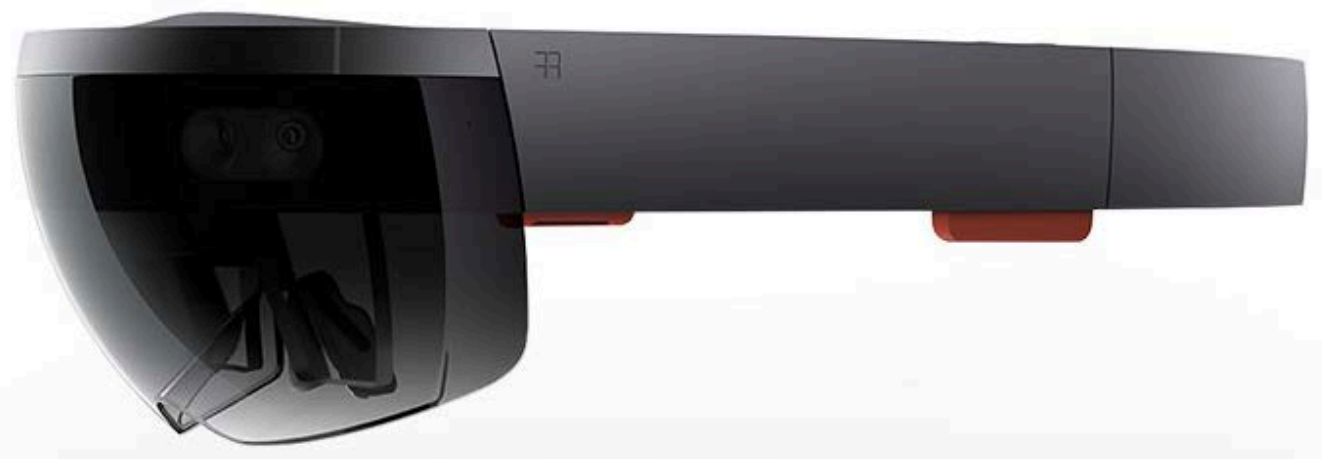

source: cc-by Microsoft Sweden 


\section{Appendix C Interview Guiding Questions}

1. Prior to the short animated sequence we shared with you, have you ever been shown/seen a concept video in which AR is used for PA\&S?

2. Have you attempted to implement or successfully deployed any of the technologies suggested in the conceptual figures in your enterprise?

3. Have you tried any technology for viewing information in Augmented Reality view first hand in a laboratory or production setting?

4. If so, please describe the situation/setting, when this was (date), what was the purpose?
a. Who was providing the demonstration?
b. Who was the champion for this?
c. What were your impressions at that time?

5. What is the current status of Augmented Reality in your company's space program?

6. Is real-time data available from machines, devices, or other instruments in your company?

7. What do you think would justify the investment necessary to put in place Augmented Reality systems like those illustrated for PA\&S?

8. How could AR help you with your job tasks or those of colleagues and project collaborators?

9. Can you provide any examples where you believe the use of AR would have prevented or reduced the effects of a failure or errors?

10. Can you provide any examples where you believe the use of AR would have helped to increase quality or compliance?

11. What would prevent you or your industry from using Augmented Reality in your workplace or procedures?

12. Would you be able to participate in hands-on testing with a prototype? 
UNIVERSITAT ROVIRA I VIRGILI

AUGMENTED REALITY FOR THE ENHANCEMENT OF SPACE PRODUCT ASSURANCE AND SAFETY

Raul Alarcon Ruiz 


\section{Appendix D Technology Maturity Review of AR Components}

\begin{tabular}{|c|c|c|c|}
\hline & Component & Current Technology & Maturity \\
\hline \multirow{5}{*}{ 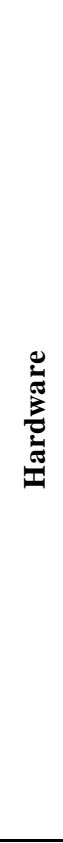 } & $\begin{array}{l}\text { Sensors to Detect } \\
\text { Context and Objects } \\
\text { and Human/computer } \\
\text { Interaction }\end{array}$ & $\begin{array}{l}\text { Highly diverse and rapidly changing to increase detection } \\
\text { of context with } 3 \mathrm{D} \text { and depth sensing technologies as well } \\
\text { as other sensing systems }\end{array}$ & $\begin{array}{l}\text { Since the category of components is highly diverse, it follows that the maturity is as well. } \\
\text { Sensors for capture of sounds and speech are very mature. Systems for image recognition } \\
\text { using RGB camera are stable and considered relatively mature. Other sensors and } \\
\text { technologies such as depth sensing and bio sensing range from stable to very immature. }\end{array}$ \\
\hline & $\begin{array}{l}\text { Chips (Accelerate } \\
\text { Computationally } \\
\text { Complex Processes) } \\
\end{array}$ & $\begin{array}{l}\text { Semiconductor manufacturers provide high performance } \\
\text { solutions highly suitable and increasingly optimized for } \\
\text { graphics such as needed in AR processes }\end{array}$ & $\begin{array}{l}\text { Semiconductors are powerful in tablets and projection AR but they consume more power } \\
\text { than can be provided for continuous use on lightweight mobile (especially wearable) } \\
\text { devices. Lack of software optimization is an issue as is the high cost in low volumes. }\end{array}$ \\
\hline & $\begin{array}{l}\text { Optics and } \\
\text { Components }\end{array}$ & $\begin{array}{l}\text { Many solutions (most but not all based on waveguide } \\
\text { technology) are suitable for industrial devices and use } \\
\text { cases. Numerous and diverse alternatives are available but } \\
\text { unproven. }\end{array}$ & $\begin{array}{l}\text { The near-to-eye optics for head-mounted displays currently available perform tolerably well } \\
\text { indoors and with relatively narrow field of view. } \\
\text { Some work remains to improve performance in bright light conditions, weight and field of } \\
\text { view. }\end{array}$ \\
\hline & Speakers & $\begin{array}{l}\text { High fidelity sound producing systems produce realistic } \\
\text { auditory experiences }\end{array}$ & Available today \\
\hline & $\begin{array}{l}\text { Display System for } \\
\text { AR Presentation }\end{array}$ & $\begin{array}{l}\text { Tablets are mobile, robust and inexpensive but not } \\
\text { wearable (and thus, not hands-free). } \\
\text { Vendors of wearable and projection AR must integrate } \\
\text { from a wide range of components. } \\
\text { Most wearable displays for AR presentation (smart } \\
\text { glasses) are suitable for short periods (over } 100 \text { gms) and } \\
\text { in controlled settings. }\end{array}$ & $\begin{array}{l}\text { High resolution screens on general purpose (or ruggedized) tablets and using projection AR } \\
\text { are suitable today. } \\
\text { Projection AR is also quite mature for indoor and fixed, well-lit workplace conditions. } \\
\text { Wearable systems vary highly in maturity but none are optimized for general purpose uses. }\end{array}$ \\
\hline 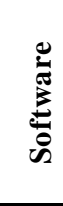 & Object Recognition & $\begin{array}{l}\text { Works well for planar objects and targets that are visible to } \\
\text { the human eye and meet criteria for the recognition } \\
\text { technology in use. }\end{array}$ & $\begin{array}{l}\text { Beyond planar targets with highly unique features, this technology component is highly } \\
\text { variable. Current software can be trained for high precision and accurate markerless } \\
\text { recognition of text (characters) and specific, highly textured (not smooth) objects and highly } \\
\text { consistent environmental conditions. Recognition of very small, shiny and/or moving or } \\
\text { deforming objects is still very immature. }\end{array}$ \\
\hline
\end{tabular}




\begin{tabular}{|c|c|c|}
\hline Component & Current Technology & Maturity \\
\hline Object Tracking & $\begin{array}{l}\text { Current object tracking technology depends on the target. } \\
\text { Technologies for planar (flat) object tracking are relatively } \\
\text { stable and common. 3D object tracking is improving and } \\
\text { reliable where the system for extracting natural features is } \\
\text { well developed. Tracking shiny or deforming objects is not } \\
\text { possible with off-the-shelf technologies. }\end{array}$ & $\begin{array}{l}\text { Similarly to the object recognition, the maturity depends on the target object and setting } \\
\text { 3D object tracking is reaching maturity for some targets but resilience (or rapid recovery } \\
\text { when trackables are lost) is a known issue. } \\
\text { When the pose of the user with respect to the target object changes rapidly, existing tracking } \\
\text { technologies are also susceptible to failure and cause the user experience to decline. }\end{array}$ \\
\hline Interaction Libraries & $\begin{array}{l}\text { Currently touch is most common with gaze } \\
\text { tracking/interaction, hand gesture, head-motion tracking } \\
\text { being studied }\end{array}$ & $\begin{array}{l}\text { Touch is most mature and popular. Alternatives for wearable systems are usually available } \\
\text { in combination (e.g., speech and gesture, gesture and eye gaze). }\end{array}$ \\
\hline $\begin{array}{l}\text { AR } \quad \text { Experience } \\
\text { Authoring Tools }\end{array}$ & $\begin{array}{l}\text { Some software platforms are beginning to use web } \\
\text { interfaces for content management. Others use special AR } \\
\text { software development kits and mobile authoring and } \\
\text { publishing environments to produce stand alone } \\
\text { applications. }\end{array}$ & $\begin{array}{l}\text { This segment is highly diverse and variable in terms of maturity. Most solutions are not user } \\
\text { friendly, hence require developers to acquire new skills. Some solutions are available for } \\
\text { full integration. } \\
\text { Some standards have been proposed but not implemented in commercial systems. }\end{array}$ \\
\hline $\begin{array}{l}\text { Remote } \\
\text { Tools }\end{array}$ & $\begin{array}{l}\text { Highly developed point to point connectivity using the } \\
\text { head worn camera, provided that the networks are } \\
\text { available. }\end{array}$ & $\begin{array}{l}\text { The maturity level is relatively high in conditions where bandwidth and network coverage } \\
\text { are high. Usability is highly variable, especially in loud or dark environments. Support for } \\
\text { transmitting symbols, live gestures and visual overlay to an AR-assisted system is relatively } \\
\text { rare. Capture/recording of audio with images is widely available but video recording is not } \\
\text { widely available. }\end{array}$ \\
\hline $\begin{array}{ll}\text { AR } & \text { Experience } \\
\text { Capture Tools }\end{array}$ & $\begin{array}{l}\text { Do not exist commercially for video and experience } \\
\text { capture but photo capture is available in some remote } \\
\text { assistance systems }\end{array}$ & Below threshold levels so may not be used to archive actions of users. \\
\hline $\begin{array}{l}\text { AR } \quad \text { Experience } \\
\text { Management Tools }\end{array}$ & $\begin{array}{l}\text { Simplistic but some are capable of integration with } \\
\text { existing CMS and ERP }\end{array}$ & Below threshold levels for space industry. \\
\hline
\end{tabular}




\section{Appendix E Prototype Experiment Instructions}

\section{Experiment 1 : Configuration Control}

Thank you for participating in this experiment. Please note that this experiment is not aboutyou (e.g. how quick or smartyou are), butrather about the usability and usefulness of Augmented Reality supported training in comparison to traditional paper \& pencil. Your participation will help improve such software systems.

You will be given a number of tasks. Please try to solve them by yourself. Do not ask for help.

Imagine that the hardware demonstrator you see in front of you would be a real satellite, Bepi Colombo. The names and part numbers of the components are made up. This experiment is not about whether these make sense (or are real), but about configuration control: whether the right components are mounted.

For each of the panels, you will find a blueprint of the layout of the components on the panel. Your task is to check whether the correct components are installed. Each component is labelled (either on the back or on the side) a part number. You need to check whether the correct component is installed. Then use the checklist to report, whether the correct component is installed. The number and name of the panel is written on label on the side. 


\section{Panel 1:}

\section{Bepi Colombo Processing Panel}

Move to panel 1, the Bepi Colombo Processing Panel. Please check each component against the blueprint. Use the checklist to indicate whether the correct component is installed.

Blueprint:

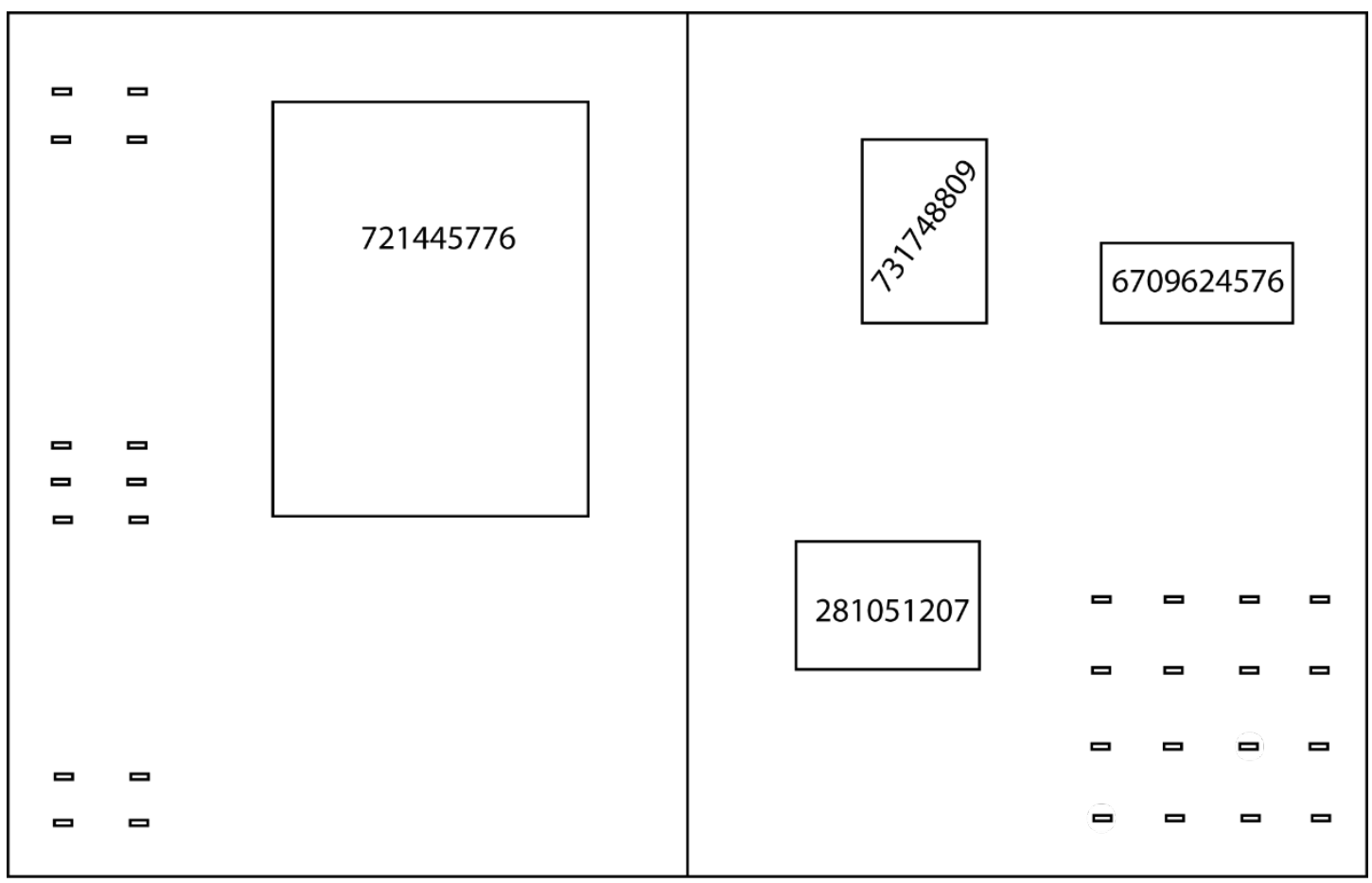

Checklist:

\begin{tabular}{|l|c|}
\hline Component & Correct? \\
\hline A/D converter unit (\#721445776) & $\square$ \\
\hline Power Subsystem (\#731748809) & $\square$ \\
\hline Starr-Flex PCB (\#281051207) & $\square$ \\
\hline RAM JDB87-R35 (\#6709624576) & $\square$ \\
\hline
\end{tabular}




\section{Panel 2:}

\section{Bepi Colombo Subsystem 2}

Now move to panel 2, the Bepi Colombo Subsystem 2. Please check each component against the blueprint. Use the checklist to indicate whether the correct component is installed.

Blueprint:

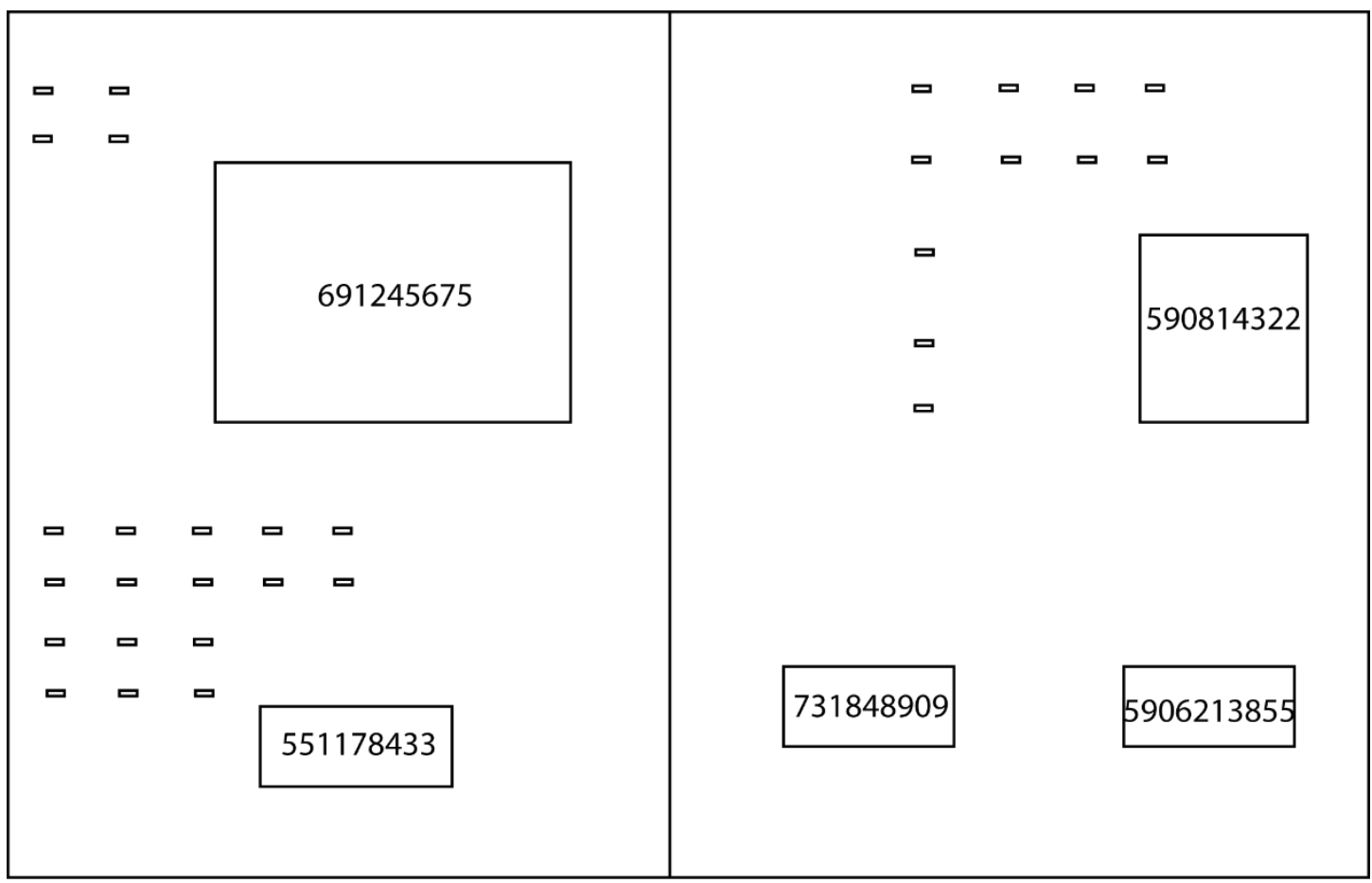

$\underline{\text { Checklist: }}$

\begin{tabular}{|l|c|}
\hline Component & Correct? \\
\hline Thermocontrol Subsystem (\#691245675) & $\square$ \\
\hline Data Management System (\#551178433) & $\square$ \\
\hline Solar Array Control (\#731848909) & $\square$ \\
\hline Attitude Control Subsystem (\#590814322) & $\square$ \\
\hline Orbit Control Subsystem (\#5906213855) & $\square$ \\
\hline
\end{tabular}




\section{Panel 3:}

\section{Bepi Colombo Test Configuration 3}

Now move to panel 3, the Bepi Colombo Test Configuration 3. Please check each component against the blueprint. Use the checklist to indicate whether the correct component is installed.

Blueprint:

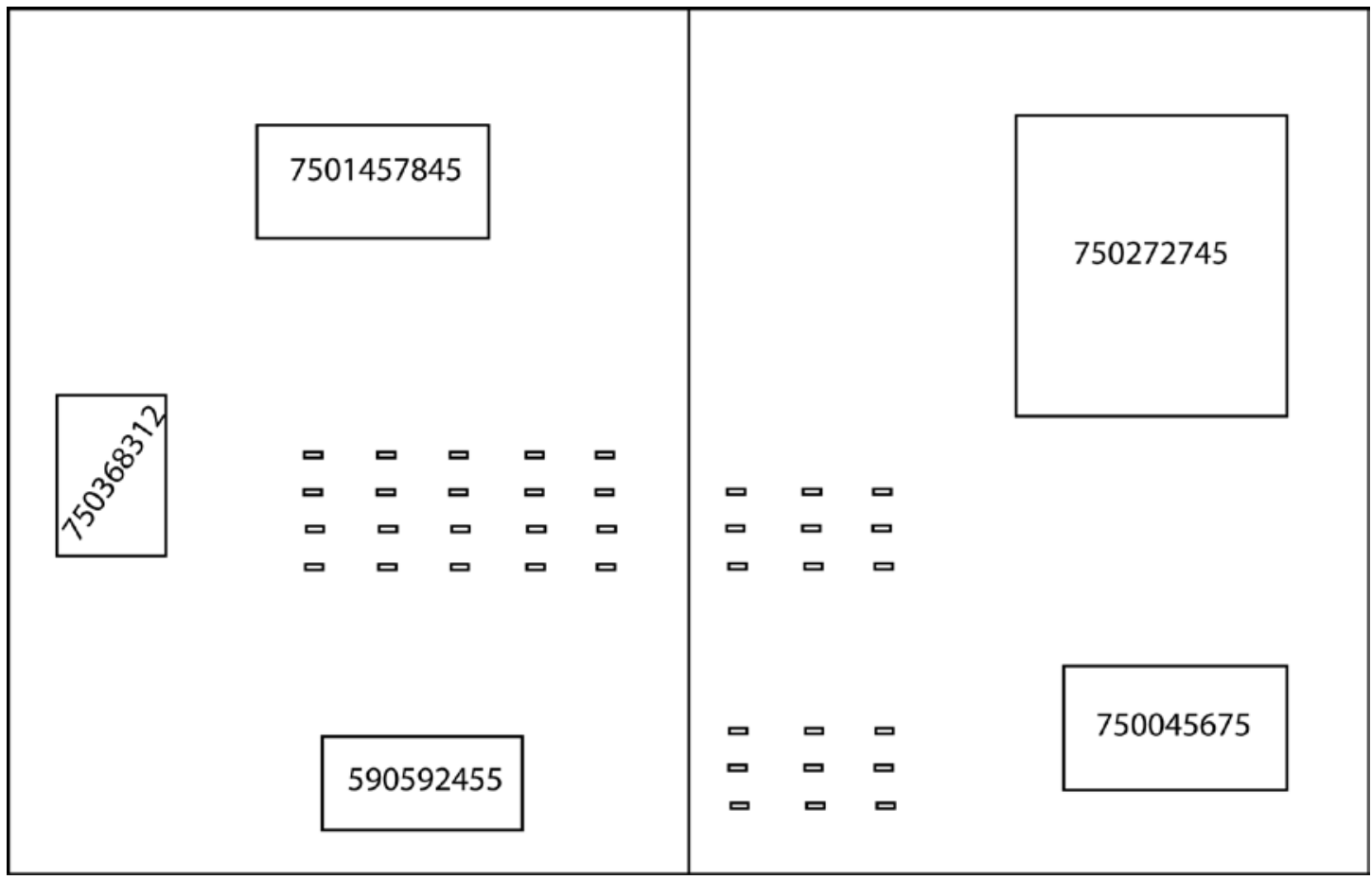

Checklist:

\begin{tabular}{|l|c|}
\hline Component & Correct? \\
\hline Spring Accelerometer Measurement Unit (\#7501457845) & $\square$ \\
\hline Imaging Control System (\#750368312) & $\square$ \\
\hline Deep Space Transponder (\#590592455) & $\square$ \\
\hline Laser Altimeter Electronics Unit (\#750272745) & $\square$ \\
\hline RAM JDB87-R35 (\#750045675) & $\square$ \\
\hline
\end{tabular}




\section{Panel 2:}

\section{Bepi Colombo Subsystem 2}

Now move again to panel 2, the Bepi Colombo Subsystem 2. Please check against the blueprint, whether all cables are connected correctly. Use the checklist to indicate, which socket is connected to which other socket.

If you spot an error, please indicate where each wrongly connected end needs to be connected to instead in the according 'Change to' column. For example, if A10 should be connected to A15, but is in fact connected to A16, then you would write down the following:

\begin{tabular}{|c|l|l|c|c|c|}
\hline Cable & End 1 & End 2 & Correct? & (Change end 1 to) & (Change end 2 to) \\
\hline 8 & A10 & A16 & $\square$ & & A15 \\
\hline
\end{tabular}

\section{Blueprint:}

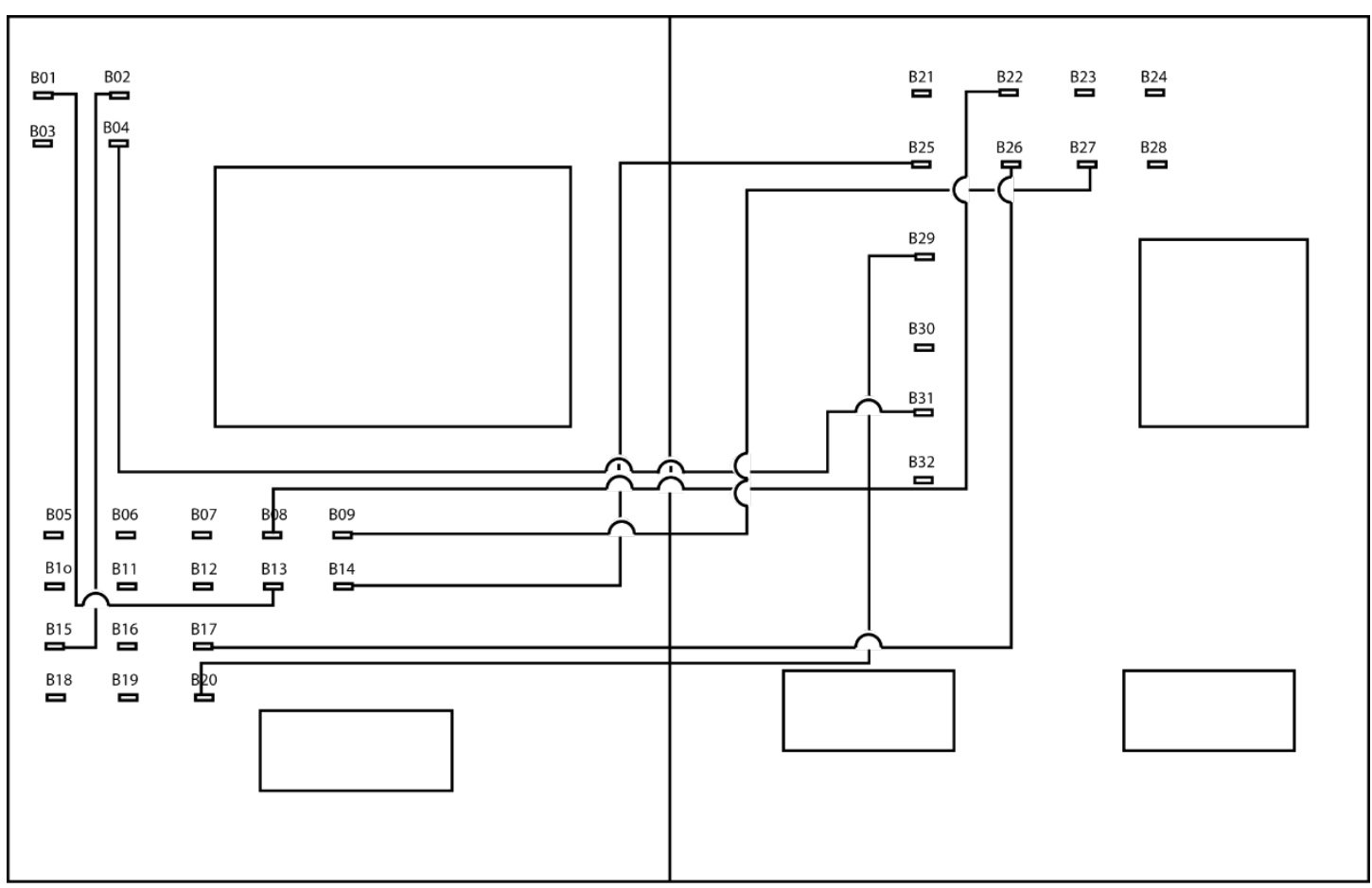

Checklist:

\begin{tabular}{|c|l|l|l|l|l|}
\hline Cable & End 1 & End 2 & Correct? & (Change end 1 to) & (Change end 2 to) \\
\hline 1 & & & $\square$ & & \\
\hline
\end{tabular}


UNIVERSITAT ROVIRA I VIRGILI

AUGMENTED REALITY FOR THE ENHANCEMENT OF SPACE PRODUCT ASSURANCE AND SAFETY

Raul Alarcon Ruiz

\begin{tabular}{|c|l|c|c|l|l|}
\hline 2 & & & $\square$ & & \\
\hline 3 & & & $\square$ & & \\
\hline 4 & & & $\square$ & & \\
\hline 5 & & & $\square$ & & \\
\hline 6 & & & $\square$ & & \\
\hline 7 & & & $\square$ & & \\
\hline
\end{tabular}




\section{Panel 3:}

\section{Bepi Colombo Test Configuration 3}

Now move again to panel 3, the Bepi Colombo Test Configuration 3. Please checkagainst the blueprint, whether all cables are connected correctly also on this panel. Use the checklist to indicate, which socket is connected to which other socket. Ifyou spot an error, please indicate where each wrongly connected end needs to be connected to instead in the according 'Change to' column.

Blueprint:

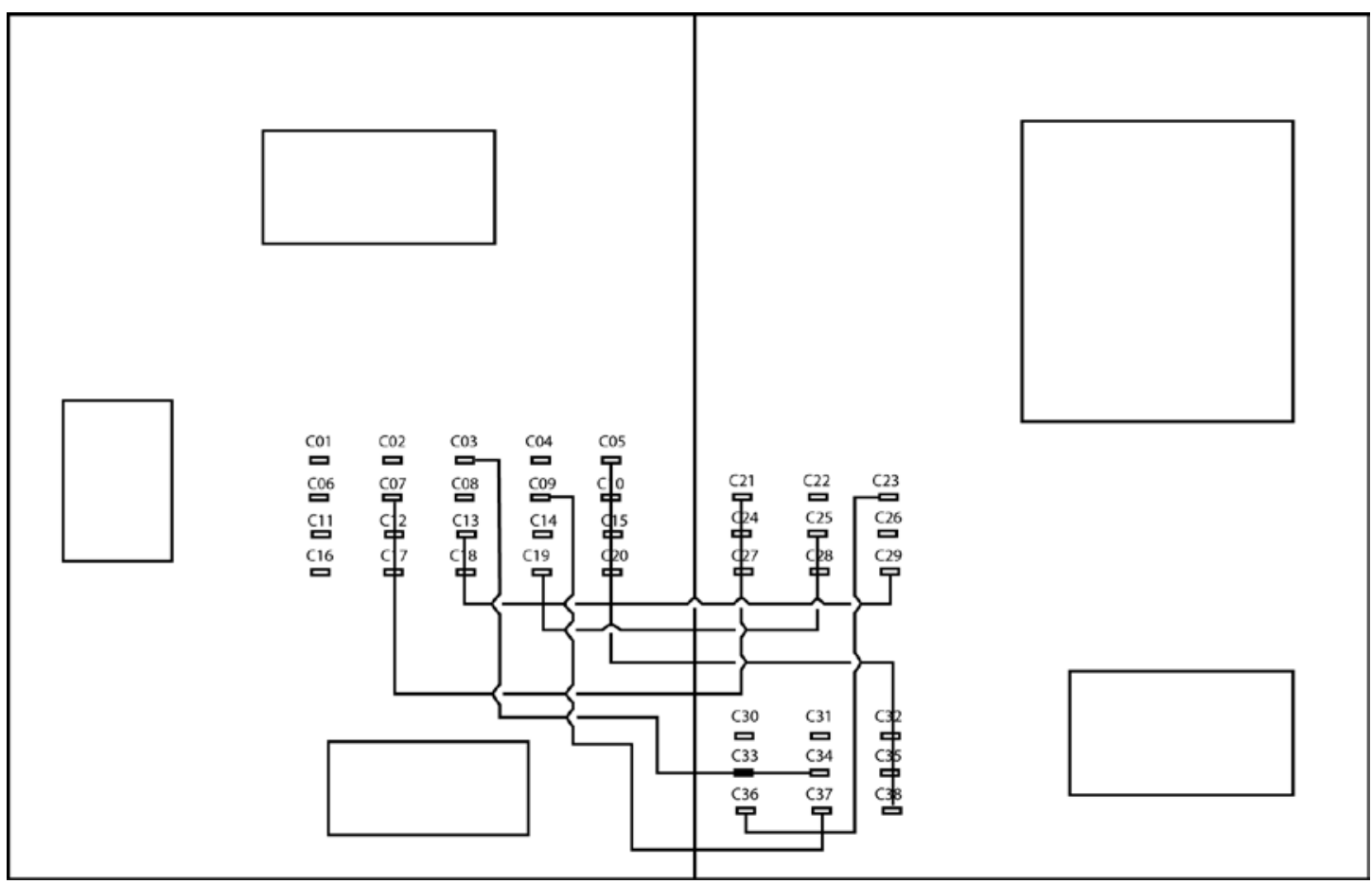

Checklist:

\begin{tabular}{|c|l|l|c|l|l|}
\hline Cable & End 1 & End 2 & Correct? & (Change end 1 to) & (Change end 2 to) \\
\hline 1 & & & $\square$ & & \\
\hline 2 & & & $\square$ & & \\
\hline 3 & & & $\square$ & & \\
\hline
\end{tabular}


UNIVERSITAT ROVIRA I VIRGILI

AUGMENTED REALITY FOR THE ENHANCEMENT OF SPACE PRODUCT ASSURANCE AND SAFETY

Raul Alarcon Ruiz

\begin{tabular}{|l|l|l|c|l|l|}
\hline 4 & & & $\square$ & & \\
\hline 5 & & & $\square$ & & \\
\hline 6 & & & $\square$ & & \\
\hline 7 & & & $\square$ & & \\
\hline
\end{tabular}




\section{Panel 1:}

\section{Bepi Colombo Processing Panel}

Now move again to panel 1, the Bepi Colombo Processing Panel. Please check against the blueprint, whether all cables are connected correctly also on this panel. Use the checklist to indicate, which socket is connected to which other socket. Ifyou spot an error, please indicate where each wrongly connected end needs to be connected to instead in the according 'Change to' column.

Blueprint:

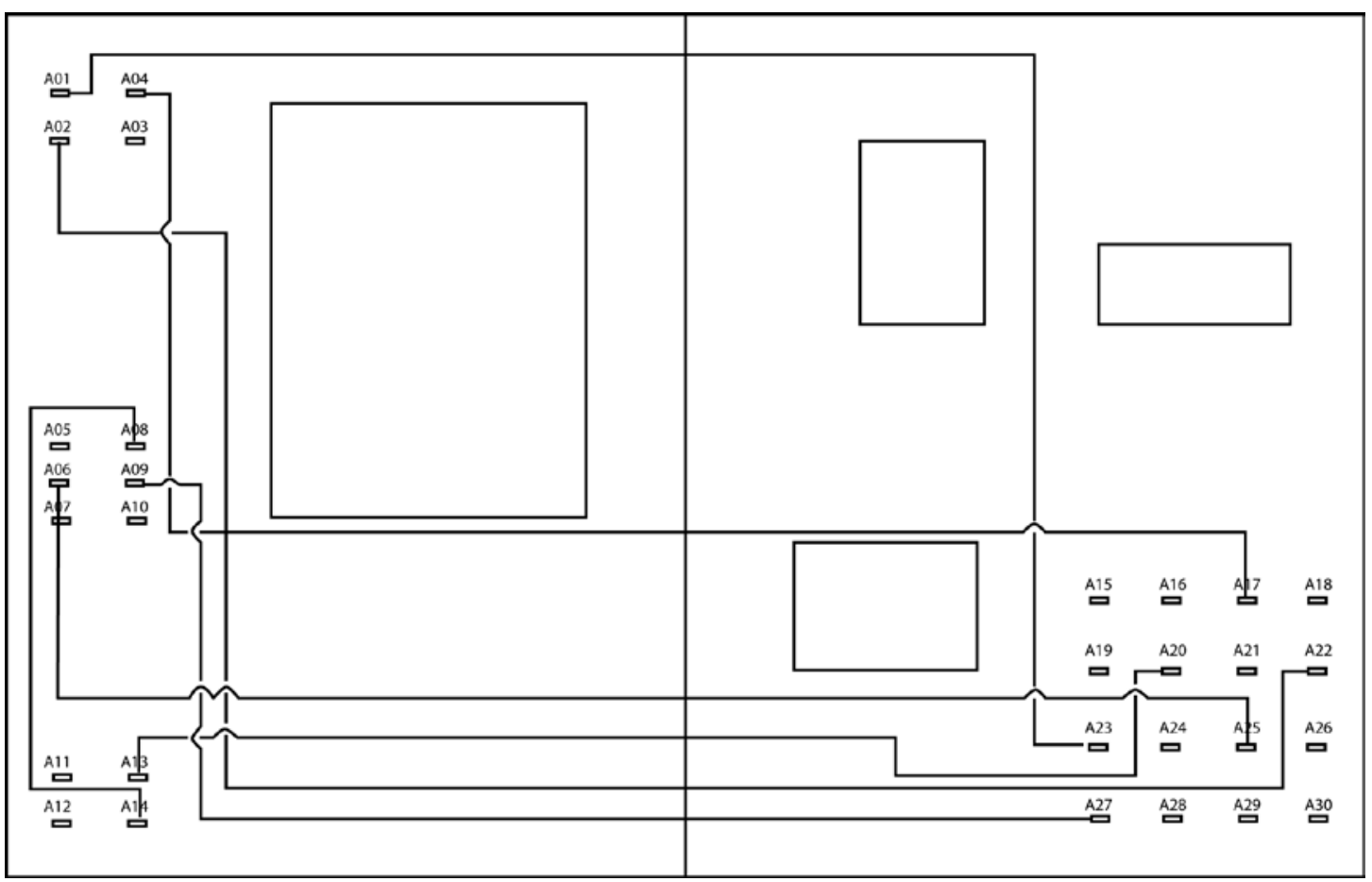

Checklist:

\begin{tabular}{|c|l|l|c|l|l|}
\hline Cable & End 1 & End 2 & Correct? & (Change end 1 to) & (Change end 2 to) \\
\hline 1 & & & $\square$ & & \\
\hline 2 & & & $\square$ & & \\
\hline 3 & & & $\square$ & & \\
\hline
\end{tabular}


UNIVERSITAT ROVIRA I VIRGILI

AUGMENTED REALITY FOR THE ENHANCEMENT OF SPACE PRODUCT ASSURANCE AND SAFETY

Raul Alarcon Ruiz

\begin{tabular}{|l|l|l|c|l|l|}
\hline 4 & & & $\square$ & & \\
\hline 5 & & & $\square$ & & \\
\hline 6 & & & $\square$ & & \\
\hline 7 & & & $\square$ & & \\
\hline
\end{tabular}




\section{Experiment 2 : Procedural guidance (repair)}

Thank you for participating in this experiment. Please note that this experiment is not aboutyou (e.g. how quick or smartyou are), butrather about the usability and usefulness of Augmented Reality supported training in comparison to traditional paper \& pencil. Your participation will help improve such software systems.

You will be given a number of tasks. Please try to solve them by yourself. Do not ask for help.

Imagine that the hardware demonstrator you see in front of you would be a real satellite, Bepi Colombo. The names and part numbers of the components are made up. This experiment is not about whether these make sense (or are real), but about repair instructions.

For each of the panels, you will find a blueprint of how the components should be installed on the panel. You will also be given a list of repair jobs to be executed, namely changing wrongly installed components. Your task is find the wrongfully installed component and change it to the correct one. Then use the checklist to report, whether you performed the repair job.

The number and name of the panel is written on label on the side. 


\section{Panel 1:}

\section{Bepi Colombo Processing Panel}

Move to panel 1, the Bepi Colombo Processing Panel. Please remove the wrong components first. Then find the correct component on the workbench and install it. Use the checklist to indicate whether you performed the exchange.

Blueprint:

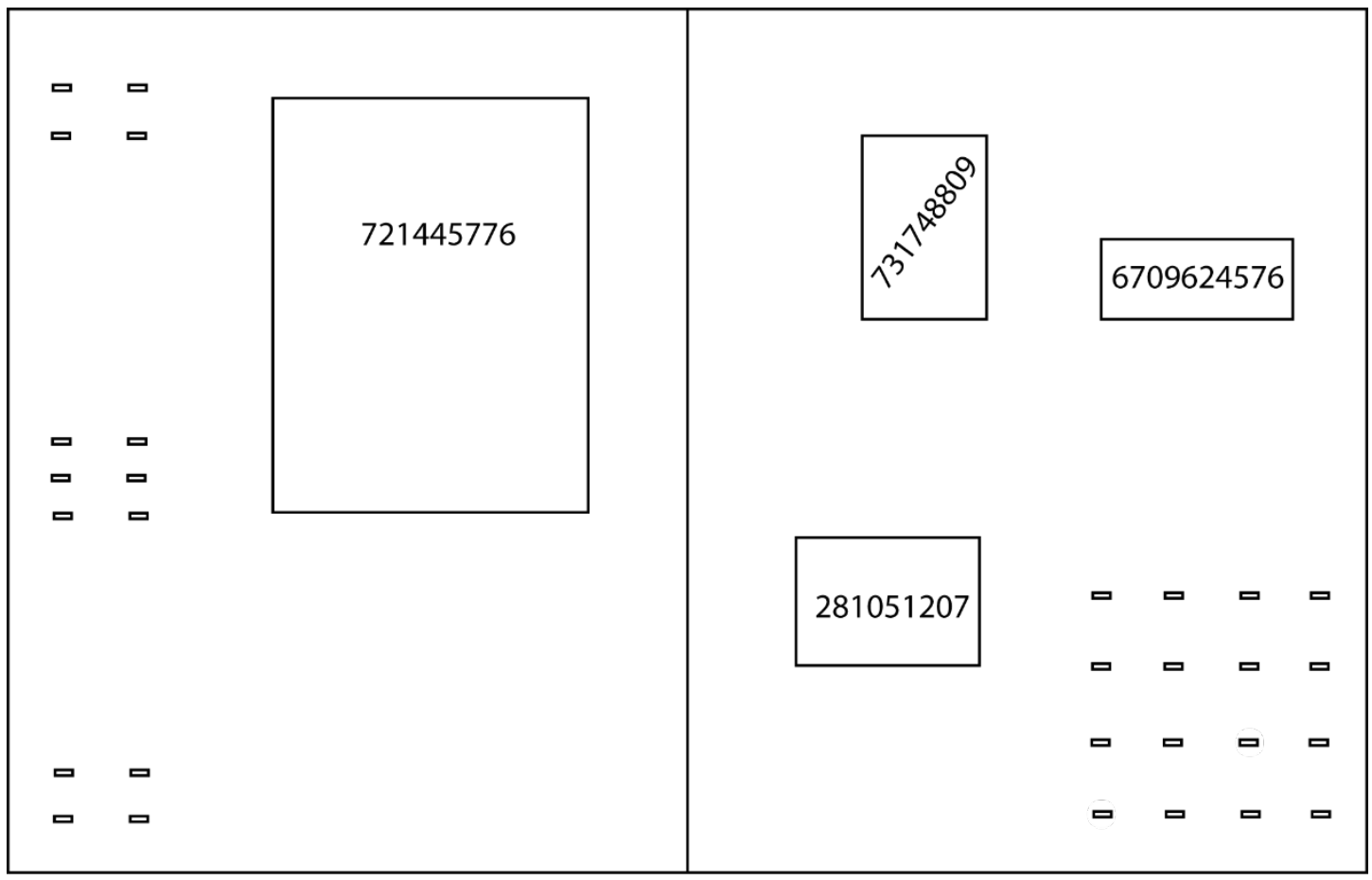

Checklist:

\begin{tabular}{|l|l|c|}
\hline Wrong component & Change to & Fixed? \\
\hline $\begin{array}{l}\text { Differential Magnetometer Data } \\
\text { Storage Unit (\#721545566) }\end{array}$ & A/D converter unit (\#721445776) & $\square$ \\
\hline $\begin{array}{l}\text { Magic Teleportation Device } \\
(\# 670782845)\end{array}$ & RAM JDB87-R35 (\#6709624576) & $\square$ \\
\hline
\end{tabular}




\section{Panel 3:}

\section{Bepi Colombo Test Configuration 3}

Now move to panel 3, the Bepi Colombo Test Configuration 3. Please remove the wrong components first. Then find the correct component on the workbench and install it. Use the checklist to indicate whether you performed the exchange.

Blueprint:

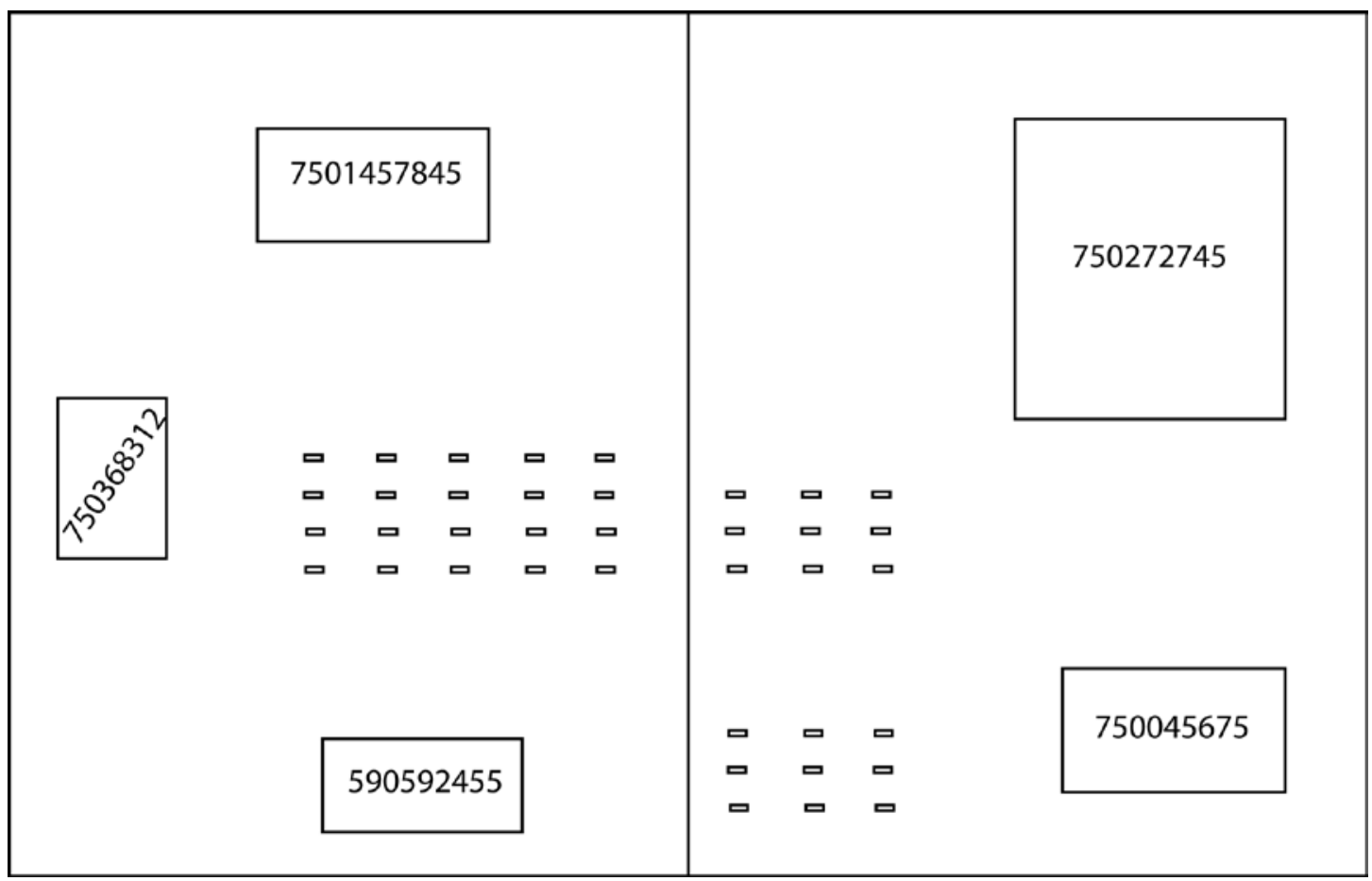

Checklist:

\begin{tabular}{|l|l|c|}
\hline Wrong component & Change to & Fixed? \\
\hline $\begin{array}{l}\text { Radiometer Control Unit } \\
(\# 59040467)\end{array}$ & $\begin{array}{l}\text { Spring Accelerometer Measurement } \\
\text { Unit (\#7501457845) }\end{array}$ & $\square$ \\
\hline
\end{tabular}




\section{Panel 1:}

\section{Bepi Colombo Processing Panel}

Now move again to panel 1, the Bepi Colombo Processing Panel. Testing found an incorrectly connected cable. Please reconnect it correctly as specified.

Blueprint:

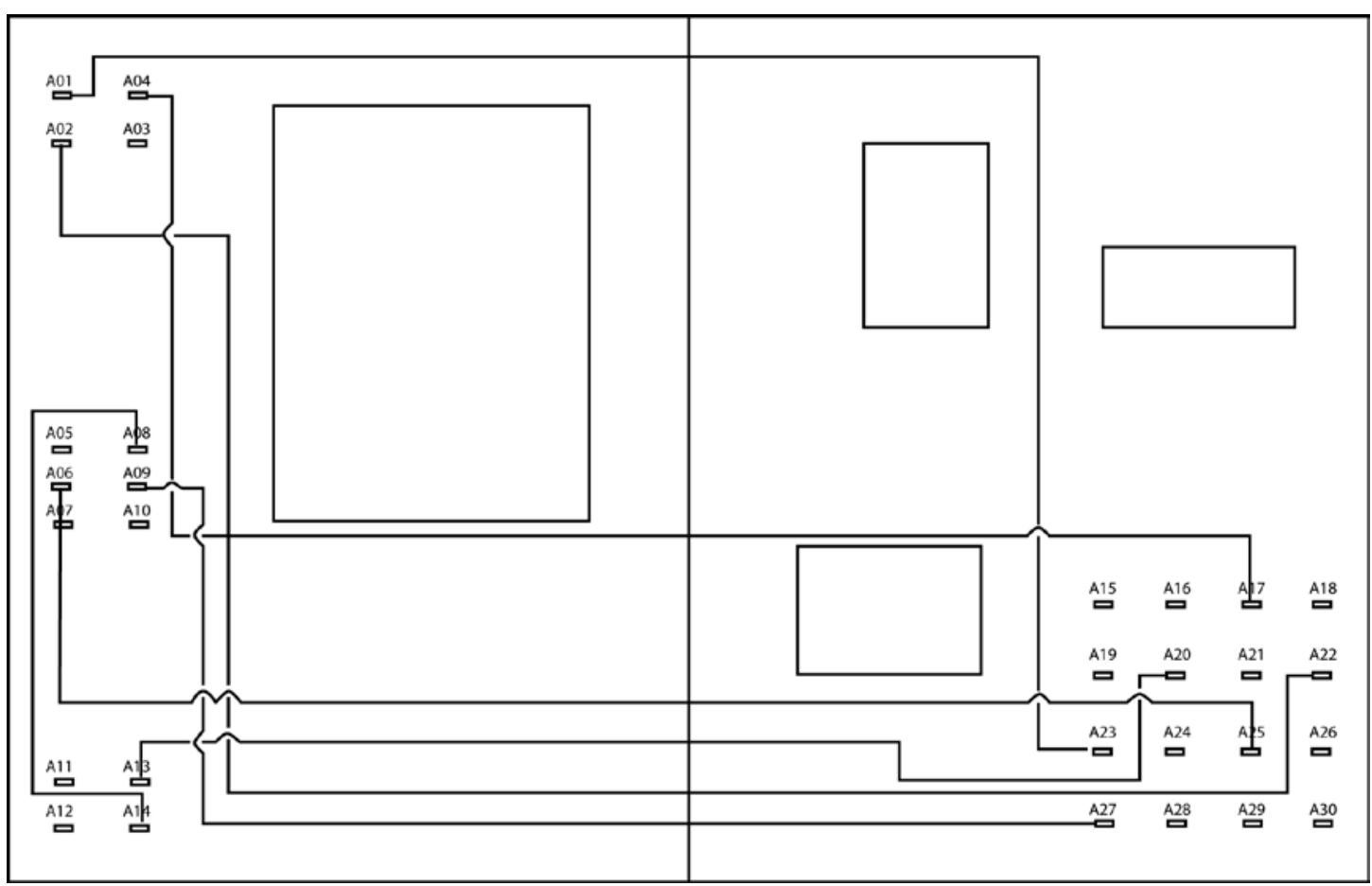

Checklist:

\begin{tabular}{|c|c|c|c|c|c|}
\hline Cable & Is: End 1 & Is: End 2 & Change to: End 1 & Change to: End 2 & Fixed? \\
\hline 1 & A6 & A19 &. & A25 & $\square$ \\
\hline
\end{tabular}




\section{Panel 2:}

\section{Bepi Colombo Subsystem 2}

Now move again to panel 2, the Bepi Colombo Subsystem 2. Testing found an incorrectly connected cable. Please reconnect it correctly as specified.

Blueprint:

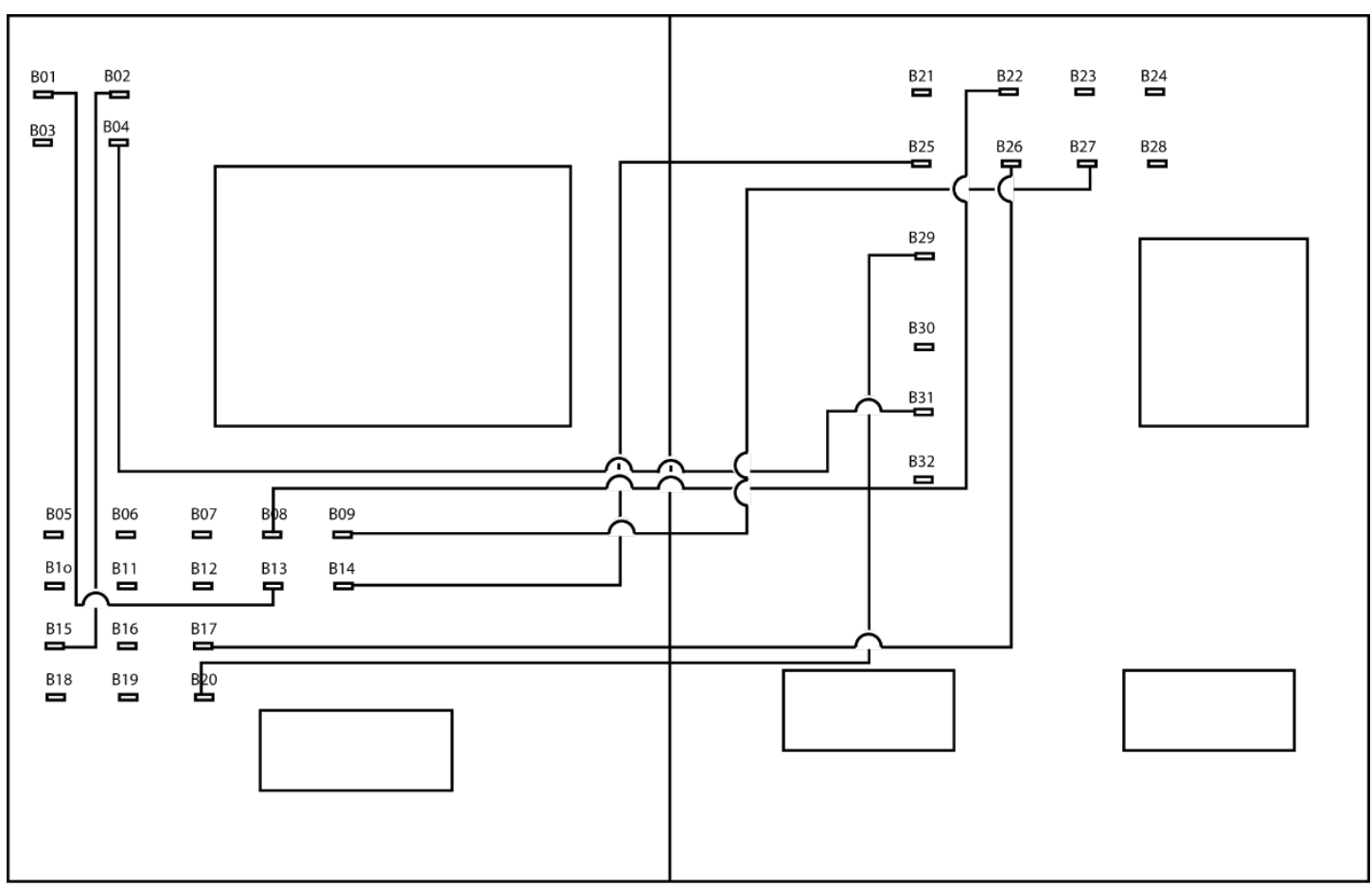

Checklist:

\begin{tabular}{|c|c|c|c|c|c|}
\hline Cable & Is: End 1 & Is: End 2 & Change to: End 1 & Change to: End 2 & Fixed? \\
\hline 1 & B16 & B27 & B09 &.$/$ & $\square$ \\
\hline
\end{tabular}




\section{Panel 3:}

\section{Bepi Colombo Test Configuration 3}

Now move to panel 3, the Bepi Colombo Test Configuration 3. Testing found an incorrectly connected cable. Please reconnect it correctly, as specified.

Blueprint:

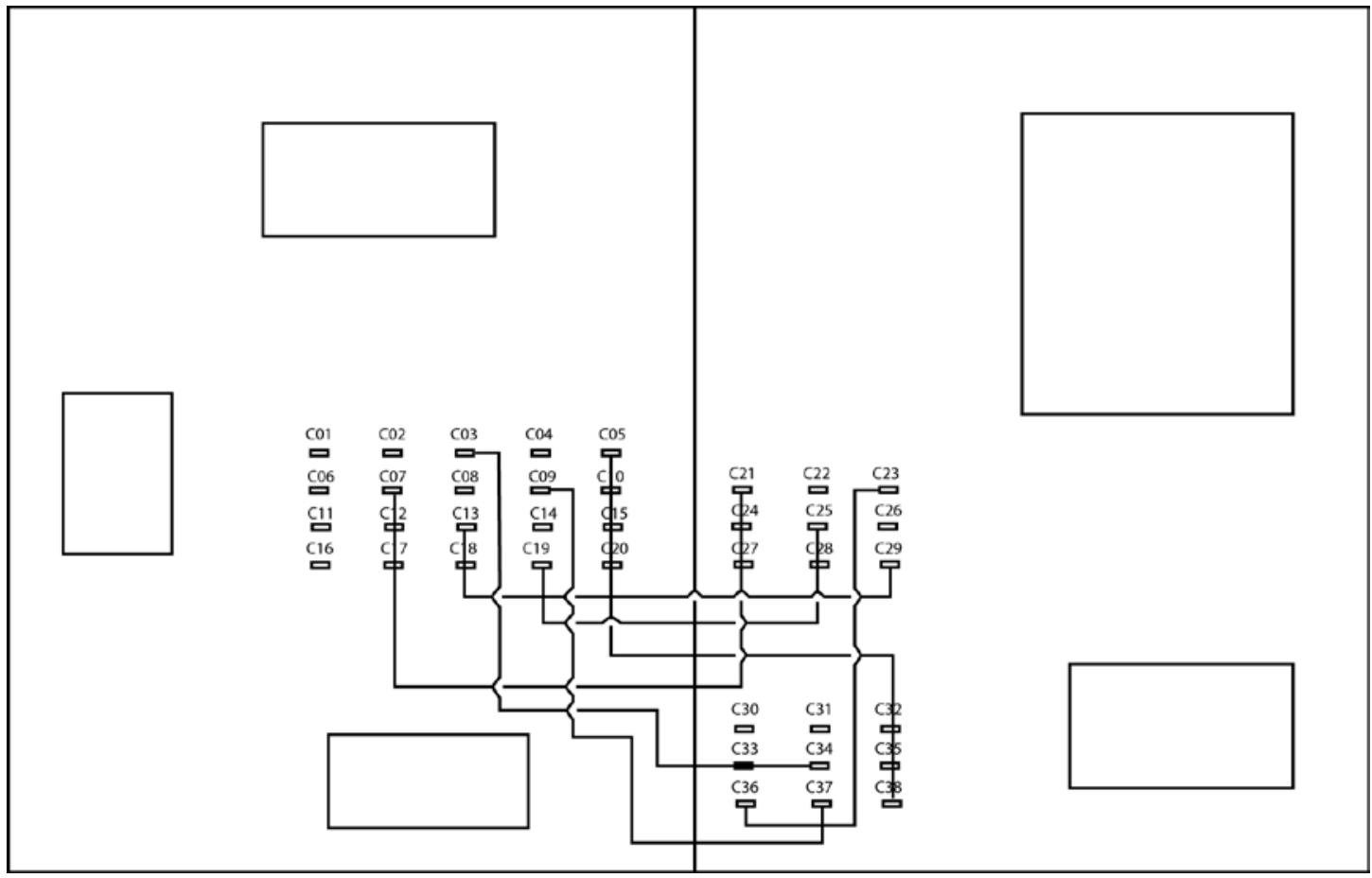

Checklist:

\begin{tabular}{|c|c|c|c|c|c|}
\hline Cable & Is: End 1 & Is: End 2 & Change to: End 1 & Change to: End 2 & Fixed? \\
\hline 1 & C11 & C38 & C05 &.$/$ & $\square$ \\
\hline
\end{tabular}




\section{Appendix F Prototype Demonstration}

\section{Description}

A video of the prototype demonstrator presented in Chapter 5 is supplemental to this thesis. It displays the use of the AR-assistant for the performance of procedural guidance tasks and as an aid for configuration control (i.e. recognition of hardware errors). The aim is to demonstrate the AR technology applied to space product assurance in a laboratory environment.

\section{Filename:}

Prototype demonstration.mp4

\section{Link:}

https://www.dropbox.com/sh/4yv5f5f61kpe1et/AAAw_dIRgXgQkb0LborbGHtga?dl=0 
UNIVERSITAT ROVIRA I VIRGILI

AUGMENTED REALITY FOR THE ENHANCEMENT OF SPACE PRODUCT ASSURANCE AND SAFETY

Raul Alarcon Ruiz

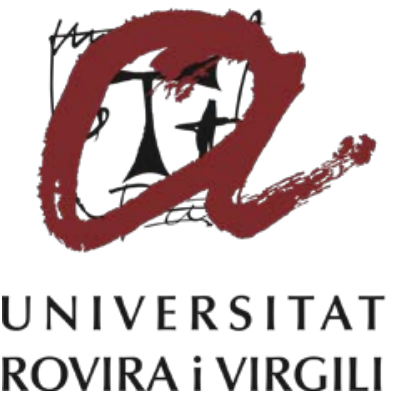

